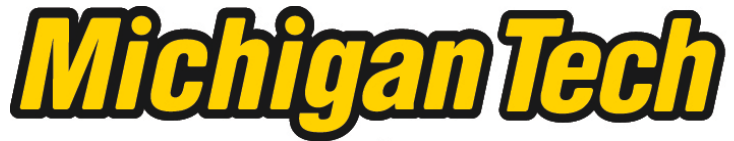 \\ Michigan Technological University Create the Future Digital Commons @ Michigan Tech
}

Dissertations, Master's Theses and Master's Reports - Open

Dissertations, Master's Theses and Master's

Reports

2015

Optical Access Engine Setup and Validation

Jiongxun (Justin) Zhang

Michigan Technological University

Follow this and additional works at: https://digitalcommons.mtu.edu/etds

Part of the Mechanical Engineering Commons

Copyright 2015 Jiongxun (Justin) Zhang

\section{Recommended Citation}

Zhang, Jiongxun (Justin), "Optical Access Engine Setup and Validation", Master's report, Michigan Technological University, 2015.

https://doi.org/10.37099/mtu.dc.etds/924

Follow this and additional works at: https://digitalcommons.mtu.edu/etds

Part of the Mechanical Engineering Commons 


\title{
Optical Access Engine Setup and Validation
}

\author{
By \\ Jiongxun(Justin) Zhang \\ A REPORT \\ Submitted in partial fulfillment of the requirements for the degree of \\ MASTER OF SCIENCE \\ In Mechanical Engineering \\ MICHIGAN TECHNOLOGICAL UNIVERSITY \\ 2015 \\ (C) 2015 Jiongxun(Justin) Zhang
}


This report has been approved in partial fulfillment of the requirements for the Degree of MASTER OF SCIENCE in Mechanical Engineering

\title{
Department Of Mechanical Engineering - Enginering Mechanics
}

\author{
Report Advisor: Jeffrey D. Naber \\ Committee Member: Mahdi Shahbakhti \\ Committee Member: $\quad$ Brett Hamlin \\ Department Chair: William W. Predebon
}




\section{Table of Contents}

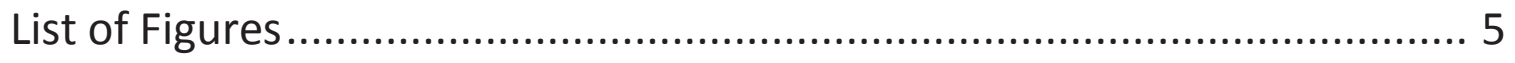

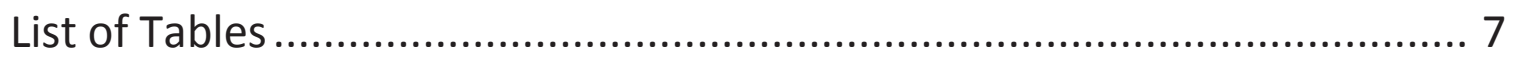

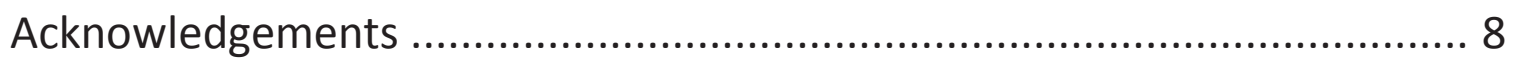

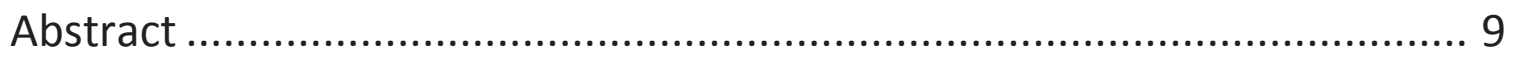

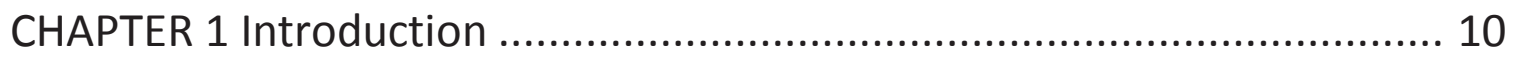

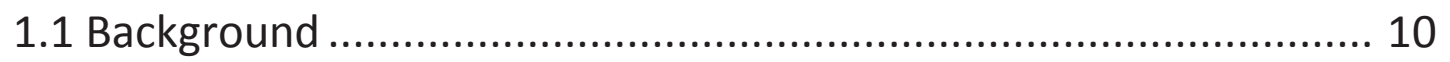

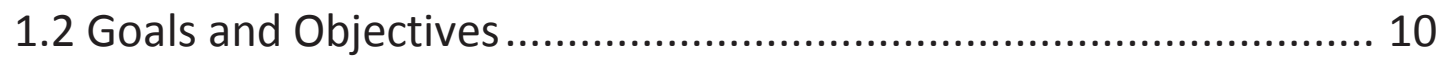

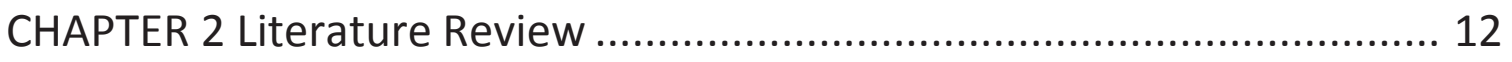

CHAPTER 3 Engine Test Cell Setup ...................................................... 18

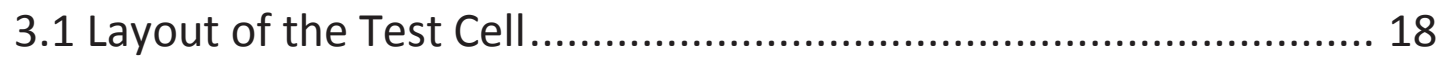

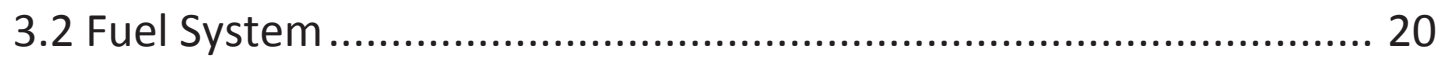

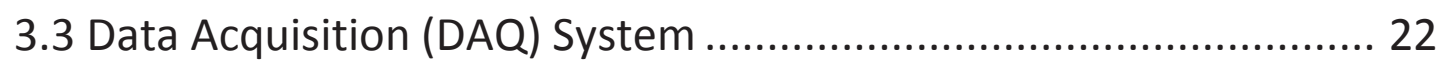

3.3.1 DSP-ACAP Combustion Analysis System .............................. 22

3.3.2 National Instrument (NI) Data Acquisition System ................ 27

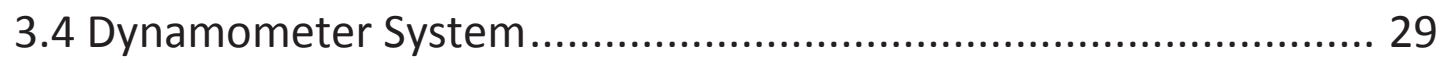

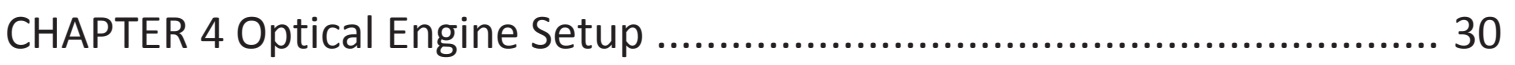

4.1 Optical Engine Specification ....................................................... 30

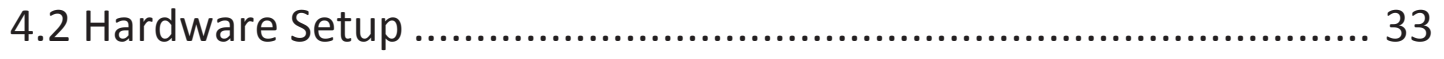

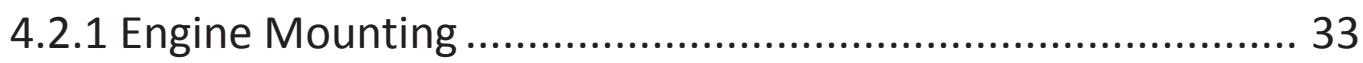

4.2.2 Cart Interface Panel Design ................................................. 36

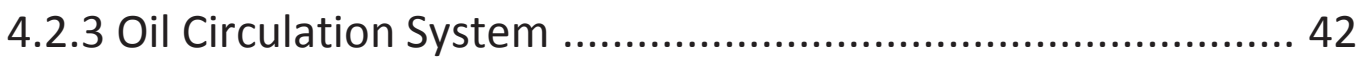

4.3 Engine Control Unit (ECU) and Wiring ....................................... 43 


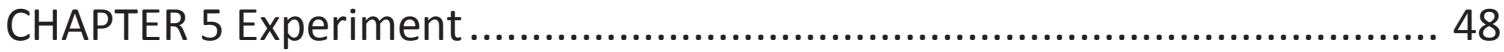

5.1 Experiment: Motoring and Firing Cycle ....................................... 48

5.2 Optical Instrumentation ........................................................... 51

CHAPTER 6 Conclusion and Future Work ................................................. 54

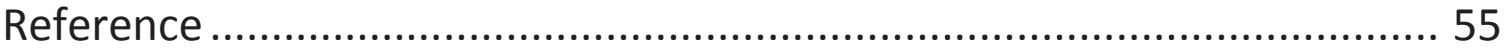

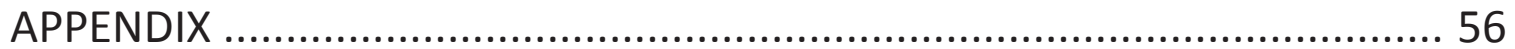




\section{List of Figures}

Figure 2-1: Exploded View and Photo of the Optical Accessible Engine on the Test Bench. ${ }^{1} 13$

Figure 2-2: Sketch of the experimental setup for optical investigation and detail of combustion chamber and ICCD for UV-Visible ${ }^{1}$ 14

Figure 2-3: (a); computed fuel-air equivalence ratio distribution at spark-timing, range 0 (blue) - 2 (red); (b) combustion chemiluminescent image; (c) computed liquid film distribution on the piston at spark-timing; (d) computed distribution of the relative airfuel ratio inside the cylinder at spark-timing. Injection pressure: 100 bar; SOI: 110 CAD BTDC $^{1}$ 14

Figure 2-4: Engine Test Bed Schematic ${ }^{2}$ .15

Figure 2-5: Base Diesel Image Sequence ${ }^{2}$ 16

Figure 3-1: APSRC Test Cell Optical Engine Setup 18

Figure 3-2: Block Diagram of Test Cell Layout. 19

Figure 3-3: Low Pressure Fuel Cart (Left); High Presure Fuel Cart (Rigt) 20

Figure 3-4: Fuel System Connection Block Diagram......................................................... 21

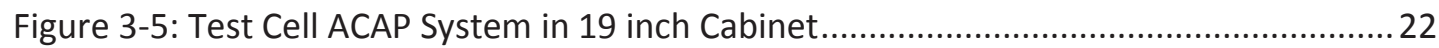

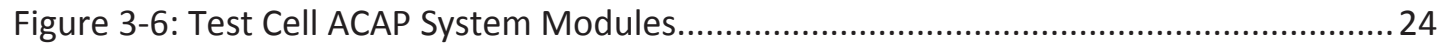

Figure 3-7: Test Cell National Instruments Data Acquisition System...................................2

Figure 3-8: GE Motors Adjustable Speed AC Dynamometer................................................29

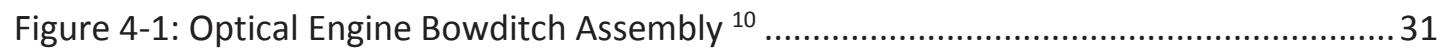

Figure 4-2: Optical Engine Pent-Roof Shape Optical Grade Quartz Liner Upper Window..... 31

Figure 4-3: MAHLE Powertrain 3D CAD Design Concept Overview of Optical Engine ${ }^{6}$............32

Figure 4-4: Optical Engine (Left) and Optical Engine Mounting on Engine Cart (Right) .........33

Figure 4-5: Engine Mounting Components Connection Block Diagram.................................. 34

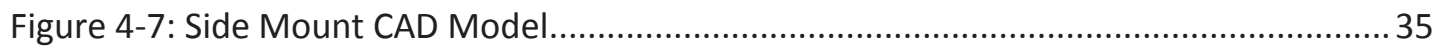

Figure 4-6: Bell Housing Mounted with Front Mount Frame................................................ 35

Figure 4-8: Interface Panel: Coolant and Fuel Line Panel (left); Connector Panel (Right) ..... 36

Figure 4-9: Machined Interface Panels: (1) Coolant and Fuel Line Panel (left);..................... 37

Figure 4-10 : Omega MTC-55-FF Series 55-Pin Thermocouple Connectors ........................... 38 
Figure 4-11: 63 pin AMP Series 2 STD Flange Receptacle

Figure 4-12: Omega PX209-030A5V Manifold Absolute Pressure (MAP) Sensor Position .... 40

Figure 4-13: Circular Plastic Connectors Series 3 7-Pin ........................................................ 41

Figure 4-14: Oil Heater and Pump Mounted on Universal Cart ............................................ 42

Figure 4-15: Block Diagram of Engine Oil System ............................................................ 42

Figure 4-16: MotoHawk ECM 0554 (Left) and Bosch ES-HDEV-1 Fuel Injector Driver (Right)43

Figure 4-17: Enclosure Mount on One Side of Universal Cart ............................................. 44

Figure 4-18: ECU Enclosure inside Components Block Diagram .......................................... 45

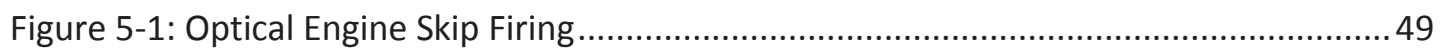

Figure 5-2: Optical Engine Pressure Trace for Motoring Cycle ........................................... 49

Figure 5-3: Optical Engine Log P-log V at Firing Cycle ..................................................... 50

Figure 5-4: Optical Engine Pressure Trace for Firing Cycle................................................... 50

Figure 5-5: Optical Engine and Camera Setup................................................................. 51

Figure 5-6: Optical Engine USS 16 Imaging Result with Nikon 200 Lens, 6 CA (1000 us) per

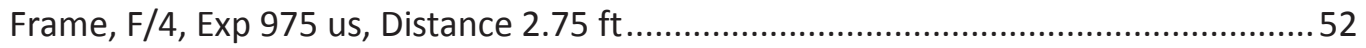

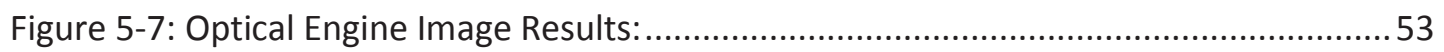




\section{List of Tables}

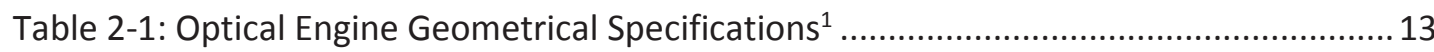

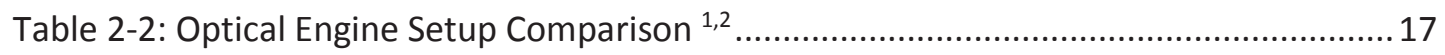

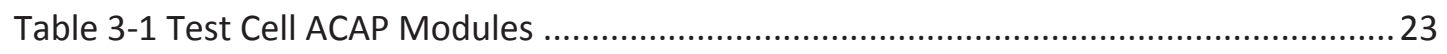

Table 3-2: Test Cell ACAP Modules Channel Connections ….................................................. 25

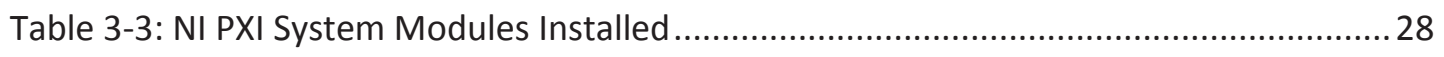

Table 4-1: Ford Ecoboost Engine and Optical Engine Geometry Parameters ..........................30

Table 4-2: MTC 55-Pin Thermocouple Wire Connections ..................................................... 38

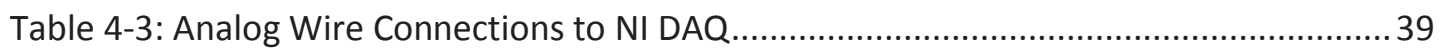

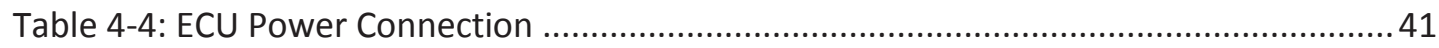

Table 4-5: Harness Connections between MotoHawk ECU and Optical Engine.................. 46

Table 4-6: Terminal Block Connections between MotoHawk ECU and Optical Engine ..........47

Table 5-1: Test Condition for the Optical Engine ................................................................ 48

Table 5-2: Test Condition for the Optical Engine .............................................................. 52 


\section{Acknowledgements}

I like to take this opportunity to thank my advisor Dr. Jeffrey Naber and my committee member Dr. Mahdi Shahbakhti and Dr. Brett Hamlin for all of the support and guidance. I started the optical access engine research in September 2012. It has been a long journey to achieve the current status with the experiment well performed on the optical engine. I want to thank people in the research group, Jeremy Worm, Paul Dice, Yanyu (Simon) Wang, Owen Marttila and all my lab mates including Dr. Wei Chen, Meng Tang and Zhuyong Yang. Without their kindly help and technical support, I would not be able to accomplish the optical access engine setup and validation. In addition, I appreciate my writing coach Katelynne Bauer for reviewing my report and improving my writing skills.

Last but not the least, I want to make a grateful acknowledgement for my family and friends supporting me throughout the completion of my Master of Science degree in Mechanical Engineering. I am proud of graduating from Michigan Technological University as a mechanical engineer. 


\section{Abstract}

The optical access engine integrated with the diagnostic and optical measurement techniques is a great platform for engine research because it provides clear visual access to the combustion chamber inside the engines. An optical access engine customized based on a 4-cylinder spark ignited direct injection (SIDI) production engine is located in the Advanced Power Systems Laboratories (APS LABS) at Michigan Technological University. This optical access engine inside the test cell has been set up for different engine research.

In this report, two SAE papers in engine research utilizing the optical access engine are reviewed to gain basic understanding of the methodology. Though the optical engine in APS LABS is a little bit different from the engines used in the literature, the methodology in the papers provides guidelines for engine research through optical access engines. In addition, the optical access engine instrumentation including the test cell setup and the optical engine setup is described in detail in the report providing a solid record for later

troubleshooting and reference. Finally, the motoring tests, firing tests and optical imaging experiment on the optical engine has been performed to validate the instrumentation.

This report only describes so far the instrumentation of the optical engine in the APS LABS by April 2015. 


\section{CHAPTER 1 Introduction}

\subsection{Background}

An optical engine customized based on a 2013 Ford Escape 2.0L EcoBoost 4 cylinder spark ignited direct injection (SIDI) production engine is located in the Advanced Power Systems Laboratories (APS LABS) at Michigan Technological University. The optical engine, as the name suggests, allows visual access to the combustion chamber helping understand the different aspects of combustion and its diagnostics. Optical engines provide a realistic engine environment to study in-cylinder flow, mixing, combustion and emissions phenomena by a qualitative and quantitative non-intrusive, imaging diagnostic technique.

\subsection{Goals and Objectives}

The long-term goal of the optical access engine is to perform ignition research sponsored by Ford Motor Company utilized laser diagnostics and optical measurement techniques. The research team will continue working toward the goal and cooperated with engineers at Ford Motor Company for ignition research. The short-term goal of the project is to set up the optical access engine to run basic experiments without integrated the diagnostic and optical measurement techniques. The following list outlines the objectives of the optical engine research.

- Optical access engine instrumentation including data acquisition system and engine control system.

- Integration the optical access engine with the diagnostic and optical measurement techniques such as high speed camera setup and particle image velocimetry (PIV).

- Ford Motor Company ignition research through optical access engine including spark plasma stretching and spark energy study.

The objective of this report is to record the current status of the optical access engine instrumentation, which includes the test cell setup and the optical engine setup. The test cell setup covers the layout of the test cell, the fuel system, the data acquisition (DAQ) 
system and the dynamometer system. The optical engine setup consists of engine specification, hardware setup and engine control unit (ECU) setup. Moreover, basic experiment on the optical engine has been performed to validate the setup. The motoring tests, firing tests and optical imaging results captured by high-speed camera are discussed. 


\section{CHAPTER 2 Literature Review}

A lot of researchers use the optical access engine for different engine parameters study such as fuel injection system and ignition. Two technical papers are reviewed to study how researchers use the optical engine for research. Although not all of the papers study SIDI engine, their research apparatus, conclusions provide a reasonable support and theory guide for later experimental research utilizing the optical engine.

Lucchini et al. developed computational fluid dynamics (CFD) models for the air/fuel mixing process in stratified charge, spark-ignited engines. They validate the CFD model with experimental results from a constant volume vessel as well as a 4-stroke, 4-cylinder optically accessible gasoline direct injection (GDI) Engine ${ }^{1}$.

Grill et al. studied in-cylinder fuel injection and combustion process through a narrow cone fuel injector of a high-speed direct injection (HSDI) single cylinder optical diesel engine. They found out that "the indicated mean effective pressure (IMEP) values were fairly low with multiple injections strategy because of limited performance of an optical engine and the difficulty in achieving good mixture formation and combustion with multiple injections"2.

\footnotetext{
1.Lucchini, T., Fiocco, M., Onorati, A., Montanaro, A. et al., "Full-Cycle CFD Modeling of Air/Fuel Mixing Process in an Optically Accessible GDI Engine," SAE Int. J. Engines 6(3):1610-1625, 2013, doi:10.4271/2013-24-0024.

2 Gill, K. and Zhao, H., "In-cylinder Studies of Fuel Injection and Combustion from a Narrow Cone Fuel Injector in a High Speed Single Cylinder Optical Engine," SAE Technical Paper 2008-01-1789, 2008, doi:10.4271/2008-01-1789.
} 
For the first paper, several engine simulations point results were validated through the optical access engine. The geometry exploded view and the real engine on test bench are shown in Figure 2-1. Four optical access elongated pistons were installed. The optical engine piston similar to commercial piston was transparent through a sapphire window place in the bowl region ${ }^{1}$. Unlubricated Teflon-bronze composite piston rings were used for the optical engine. The detail parameters of the optical engine are listed in Table 2-1.
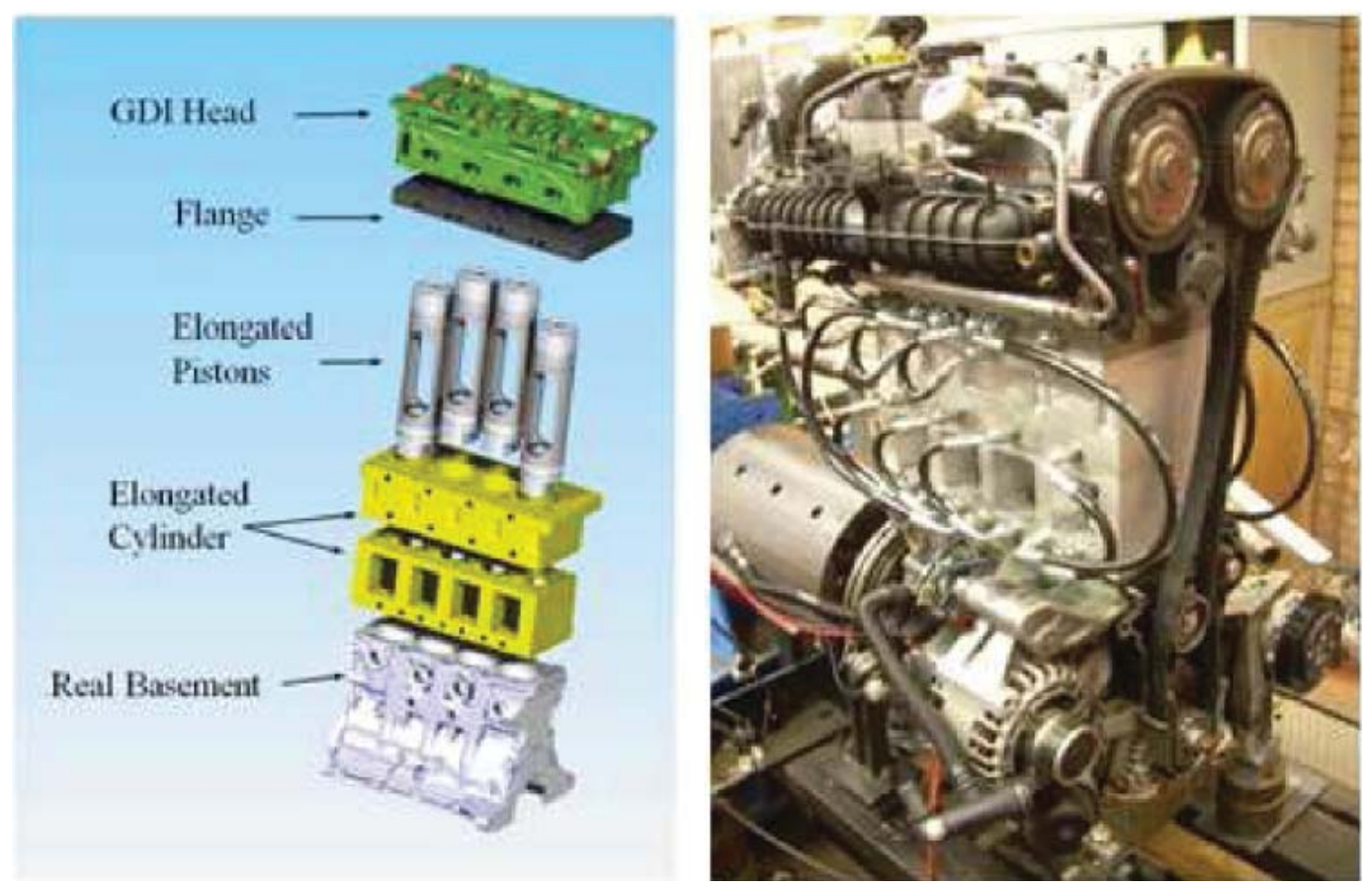

Figure 2-1: Exploded View and Photo of the Optical Accessible Engine on the Test Bench. ${ }^{1}$

Table 2-1: Optical Engine Geometrical Specifications ${ }^{1}$

\begin{tabular}{|l|c|}
\hline \multicolumn{1}{|c|}{ Engine Specification } & 4 stroke 4 cylinder SIDI Optical Engine \\
\hline Bore $(\mathrm{mm})$ & 83 \\
\hline Stroke $(\mathrm{mm})$ & 80.5 \\
\hline Compression Ratio & $9.5: 1$ \\
\hline Swept Volume $\left(\mathrm{cm}^{3}\right)$ & 1742 \\
\hline Swept Volume per cylinder $\left(\mathrm{cm}^{3}\right)$ & 435.5 \\
\hline Max Torque $(\mathrm{Nm})$ & 320.4 at $1400 \mathrm{rpm}$ \\
\hline Max Power $(\mathrm{kW})$ & 147.1 at $5000 \mathrm{rpm}$ \\
\hline Max Boost Pressure $(\mathrm{bar})$ & 2.5 \\
\hline
\end{tabular}




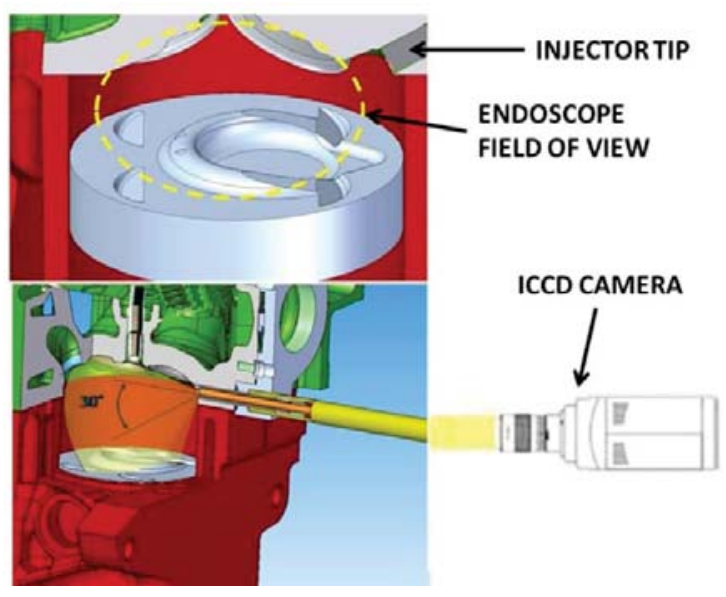

Figure 2-2: Sketch of the experimental setup for optical investigation and detail of combustion chamber and ICCD for UV- Visible ${ }^{1}$

The sapphire window was placed in the fourth cylinder head providing optical access for an endoscope, whose field of view was centered in the combustion chamber and perpendicular to the axis of the cylinder. The endoscope had a 30-degree viewing angle to capture the area of the spark and the injection of fuel and coupled with an intensified charge coupled device (ICCD) camera as shown in Figure 2-2. With the optical access engine setup, the authors were able to compare their CFD results with synchronized chemiluminescent images as shown in Figure 2-3.

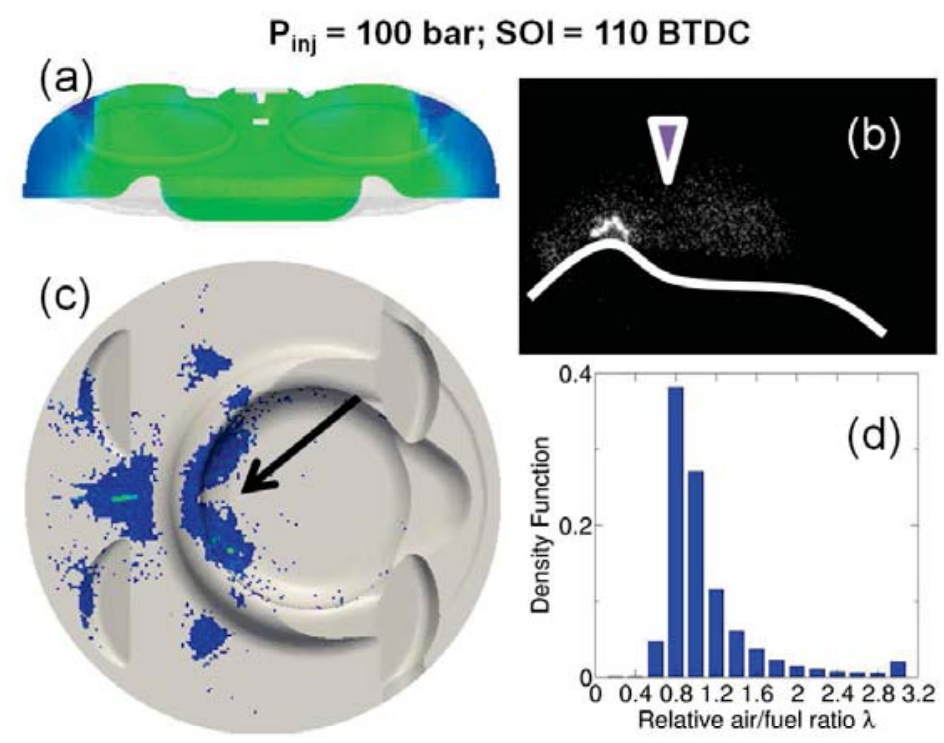

Figure 2-3: (a); computed fuel-air equivalence ratio distribution at spark-timing, range 0 (blue) - 2 (red); (b) combustion chemiluminescent image; (c) computed liquid film distribution on the piston at spark-timing; (d) computed distribution of the relative air-fuel ratio inside the cylinder at sparktiming. Injection pressure: 100 bar; SOI: 110 CAD BTDC ${ }^{1}$ 
In Grill et al.'s paper, the authors used a single cylinder Ricardo Hydra HSDI optical access engine to investigate a narrow cone fuel injector with multiple injection strategy and various alternated fuels ${ }^{2}$. The author analyzed the $\mathrm{CHO}$ and $\mathrm{OH}$ radical chemiluminescence images with an intensified camera to study the auto ignition and combustion characteristics. The test setup schematic was shown in Figure 2-4. The optical engine had a flat quartz window in the piston crown, and the piston was a Bowditch piston which is an extension piston with space for a 45 degree mirror in the middle to observe the combustion chamber.

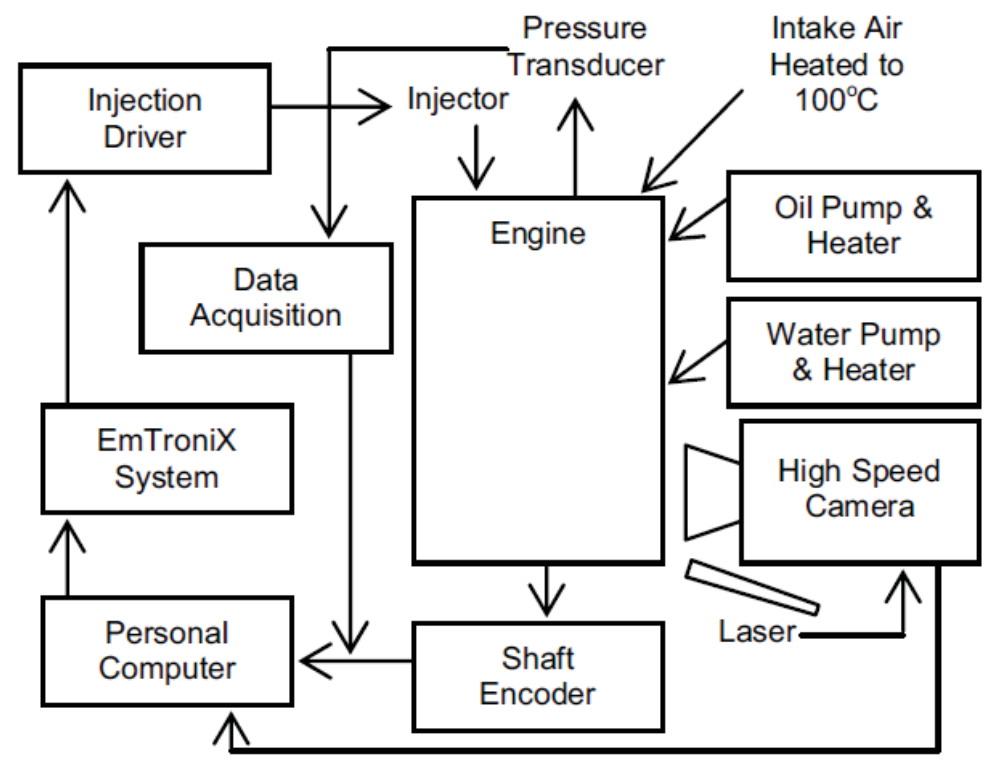

Figure 2-4: Engine Test Bed Schematic ${ }^{2}$

Two cameras were used in authors' test. One is NAC Memrecam fx6000 video camera for recording images of spray and flame. "The camera has a frame rate of up to 10,000 fps at a resolution of 512 X 248 obtained through a high-resolution high-speed CMOS sensor. To record images of the spray and flame, the combustion chamber is illuminated by a copper vapor laser operating at a repetition rate of $10 \mathrm{KHz}$. The output from the laser is coupled to an optical fiber, the end of which is mounted in front of the mirror providing light into the combustion chamber"2. Several footages of the video captured by the camera is shown in Figure 2-5 first row. The spray and the flame development are easily observed through the optical engine. The other camera was an intensified CCD camera for CHO and $\mathrm{OH}$ radical imaging and two-color method imaging ${ }^{2}$. The camera was triggered based on 
the heat release rate data. The results are shown in Figure 2-5. Based on the images, the authors analyzed the injector spray and in-cylinder combustion.

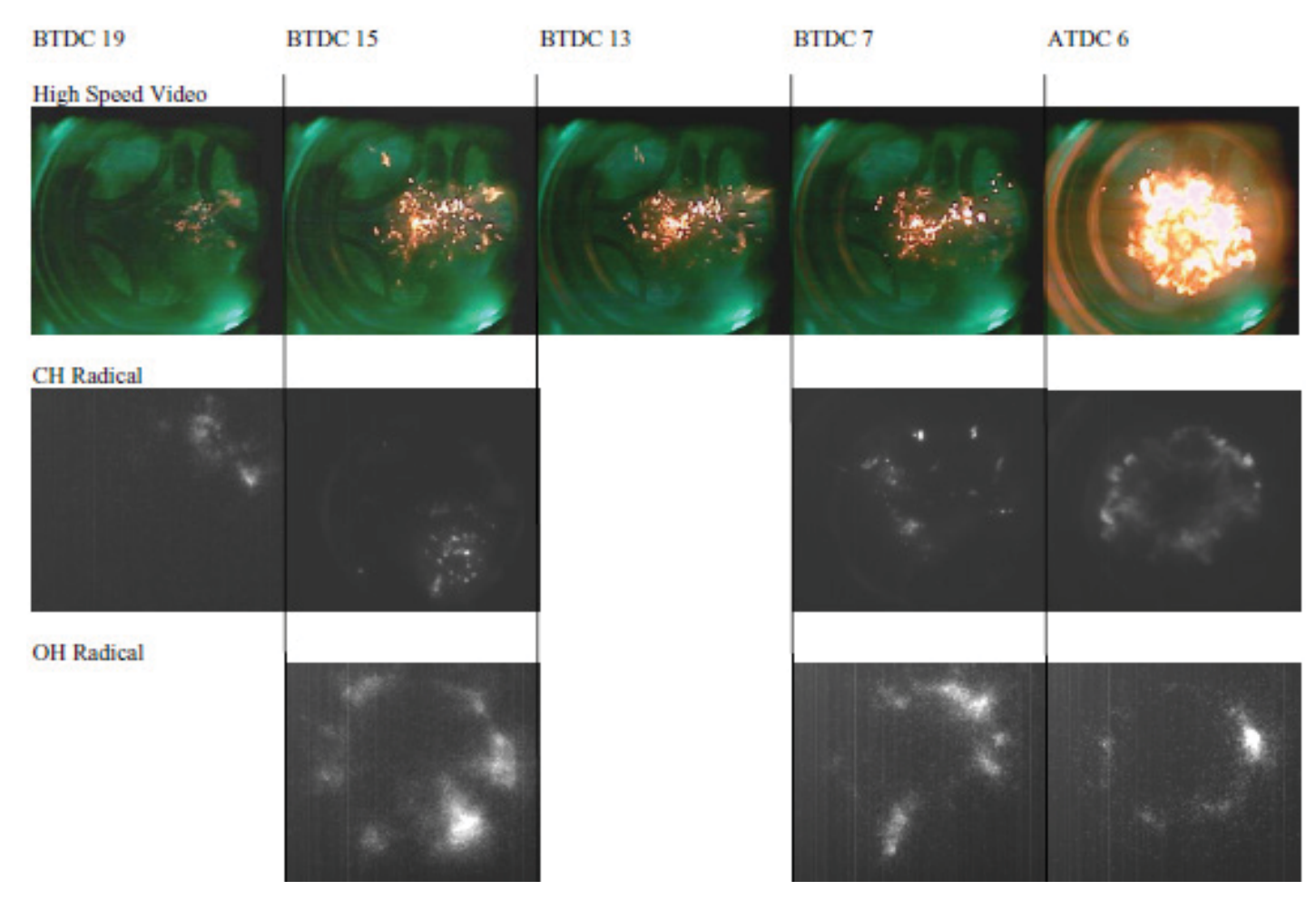

Figure 2-5: Base Diesel Image Sequence ${ }^{2}$

Through the two papers above, the optical access engines are used for fuel injection research either in SIDI gasoline engines or in HSDI diesel engine. Both of these researches had specified injectors to study the fuel injection system or alternative fuel system, which was a main factor of spray characteristics. In the first paper, various spray models were investigated through the penetration difference and fuel injection rate. The second paper studied the fuel spray through the analysis of image obtained from the optically accessible engine.

The differences between the optical engines' setup are listed in Table 2-2. For the way of observation, the first research group chose an endoscope probe inserting inside the cylinder to obtain the in-cylinder combustion images, and the second research group used a 45 degree mirror to reflect in cylinder view and recorded video or images through two different cameras. Both of these two papers studied fuel injection system including fuel 
spray characteristics, injection pressure, fuel flow rate and fluid dispersion. The images captured by the cameras through the optical access engines provides clear visualization match to the injection phenomena.

From Table 2-2, the optical engine in the Advanced Power Systems Laboratories (APS LABS) is a little bit different from these engines. Compared with the engine in the first paper, the optical engine in the APS LABS does not utilize endoscopic probe to capture images. In the second paper, the engine used in the research was a single cylinder diesel engine. Though the engines were not the same with the one in APS LABS, the methodology of utilizing optical access engines in fuel injection research from these papers provides a detailed guide and reference for future research with the optical engine in APS LABS.

Table 2-2: Optical Engine Setup Comparison ${ }^{1,2}$

\begin{tabular}{|l|l|l|}
\hline Optical Engine Setup & $\begin{array}{l}\text { Full-Cycle CFD Modeling of } \\
\text { Air/Fuel Mixing Process }\end{array}$ & $\begin{array}{l}\text { Fuel Injection and Combustion } \\
\text { from a Narrow Cone Fuel } \\
\text { Injector }\end{array}$ \\
\hline Piston Setup & $\begin{array}{l}\text { Four optically accessible } \\
\text { elongated piston }\end{array}$ & One Extended piston \\
\hline Visual Window & $\begin{array}{l}\text { Sapphire window (diameter of 5 } \\
\text { mm) }\end{array}$ & A flat quartz window \\
\hline Way of Observation & Endoscopic probe & 45 degree silver coated mirror \\
\hline Camera Setup & $\begin{array}{l}\text { Intensified Charge Couples } \\
\text { Device(ICCD) Camera }\end{array}$ & $\begin{array}{l}\text { Two Camera: NAC Memrecam } \\
\text { fx6000 Video Camera ) } \\
\text { Intensified CCD Camera }\end{array}$ \\
\hline Illumination & $\begin{array}{l}\text { Intense strobe lamp (enlighten the } \\
\text { combustion chamber) }\end{array}$ & Cooper vapor laser at $10 \mathrm{kHz}$ \\
\hline Lens & $\begin{array}{l}78 \mathrm{~mm} \text { focal length, f/3.8 UV } \\
\text { Nikon objective }\end{array}$ & - \\
\hline Features & $\begin{array}{l}512 * 512 \text { pixels and 16-bit } \\
\text { dynamic range digitization at } 10 \\
\mathrm{kHz}\end{array}$ & $512 * 248$ pixel CMOS Sensor \\
\hline
\end{tabular}




\section{CHAPTER 3 Engine Test Cell Setup}

\subsection{Layout of the Test Cell}

The engine test cell is located at Michigan Tech's Advanced Power System Research Center (APSRC). In the test cell, hardware setup is shown in Figure 3-1, which includes an exhaust system, a fuel system and an engine mounted on the universal cart which connects an electric dynamometer and a data acquisition (DAQ) system on the wall. On the cart, there is an interface panel connecting the engine harness and engine control module (ECM) harness with the DAQ system.

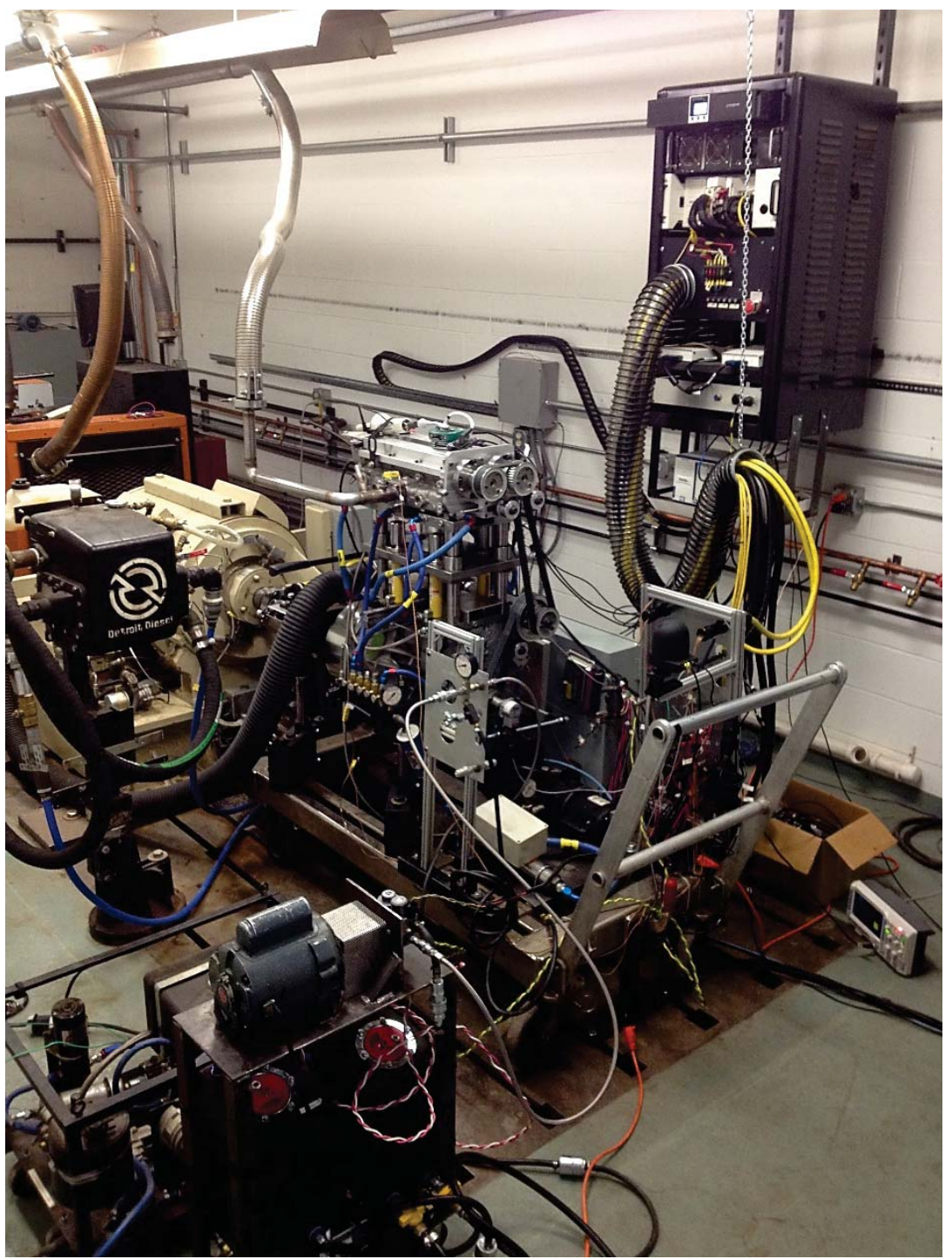

Figure 3-1: APSRC Test Cell Optical Engine Setup 
A simplified block diagram in Figure 3-2 explains the layout of the engine test cell. The ambient air from outside of the test cell goes through a laminar flow element (LFE), then enters into the engine intake manifold through a black flexible plastic hose. The fuel system includes a low-pressure fuel pump and a high-pressure fuel pump system. The DAQ system consists of a DSP-ACAP combustion analysis system and a National Instrument (NI) system. The optical engine is mounted on a universal cart with interface panels installed. The exhaust system is stationary and has quick connections between the pipes mounted on the ceiling of the test cell and engine exhaust manifold pipe through a 3-inch V-Band clamp flange. The dynamometer in the test cell is an AC type dynamometer for motoring the engine and absorbing energy while the engine is running.

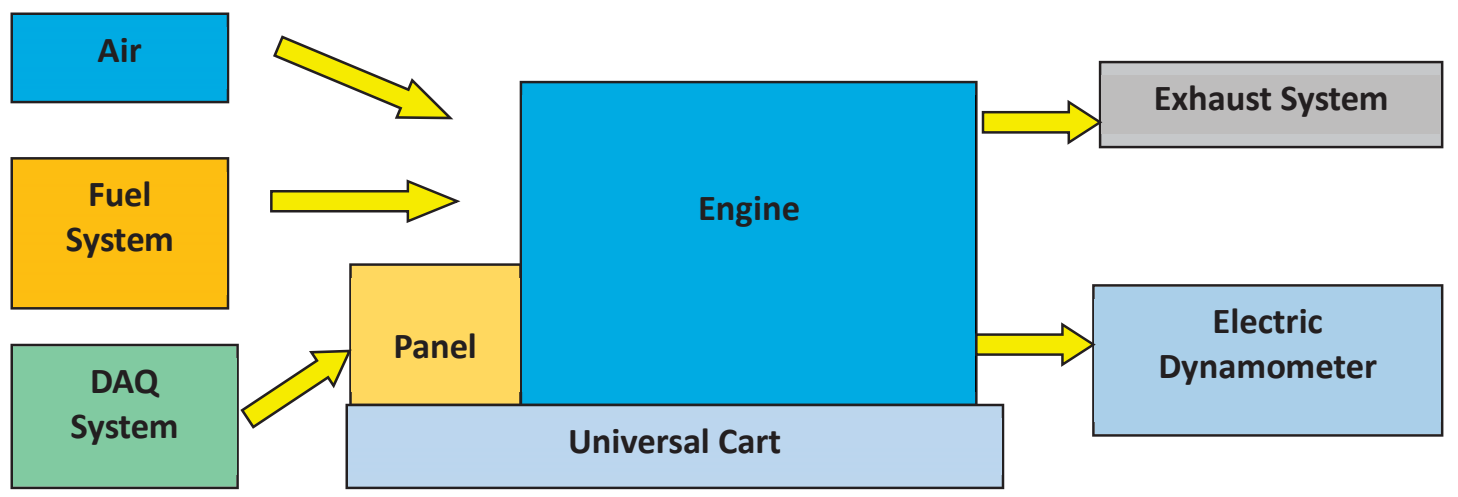

Figure 3-2: Block Diagram of Test Cell Layout 


\subsection{Fuel System}

A low-pressure fuel pump system and a high-pressure fuel pump system are used in the test cell for the optical engine as shown in Figure 3-3. The optical engine is not equipped with a high-pressure pump same as the production Ecoboost engine. The fuel system for a regular engine has a low-pressure fuel pump inside the fuel tank to pump the fuel to the high-pressure fuel pump located near the common fuel rail in the engine. Therefore, the low-pressure and high-pressure fuel carts serve as the fuel system in the regular engine.

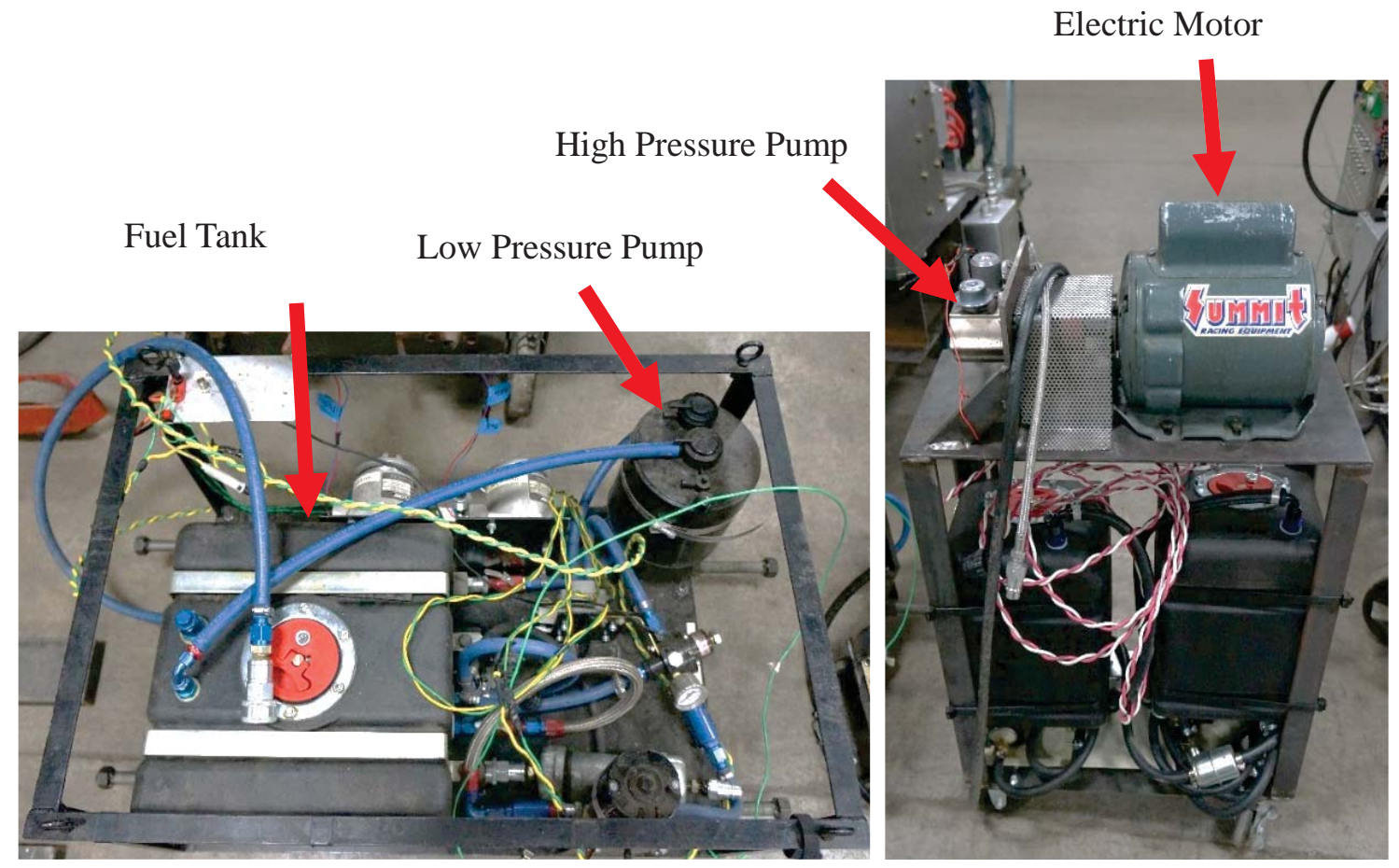

Figure 3-3: Low Pressure Fuel Cart (Left); High Presure Fuel Cart (Rigt)

As the low-pressure fuel cart shown in Figure 2-3, the thin green and yellow wire connects to the DAQ system in the test cell to obtain power. The blue fuel tube connects to the highpressure fuel pump. For the high-pressure fuel cart, the useful components for the optical engine are the electric motor, the high-pressure fuel pump on the top of the cart and a switch on the bottom of the cart. The a 1 Horsepower electric motor is powered by regular $110 \mathrm{~V}$ outlet and used to drive the high-pressure fuel pump. 
The fuel flow across the high-pressure pump is controlled by a signal from the engine control unit. Then a fuel line connects the high-pressure fuel pump and the common fuel rail on the optical engine through a valve mounted on the interface panel. The connections of the fuel system are simplified as shown in Figure 2-4. This block diagram shows the basic connections between the fuel system and the optical engine. The switch of the lowpressure fuel pump is embedded in the NI LabVIEW program, but the switch of the highpressure fuel pump is on the cart, which is turned on or off manually.

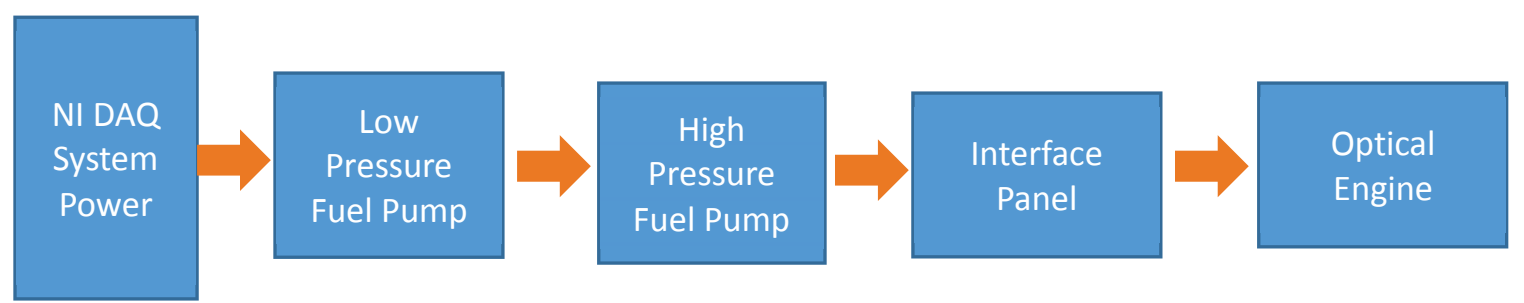

Figure 3-4: Fuel System Connection Block Diagram 


\subsection{Data Acquisition (DAQ) System}

\subsubsection{DSP-ACAP Combustion Analysis System}

The data acquisition system for the test cell includes a DSP-ACAP combustion analysis system and a National Instrument system. The combustion analysis system is a PC-based program for real-time internal combustion engine analysis and general data acquisition from DSP Technology ${ }^{3}$. In the test cell, the DSP-ACAP system are installed in a standard 19-inch instrumentation cabinet. The cabinet acts as a Faraday Cage preventing instrumentation from Electro-Magnetic Interference. The actual setup is shown in Figure 3-5. The top parts are the quick connection panels connected on the back of the ACAP system, which are used for BNC connections. The bottom part of Figure 3-5 is the ACAP combustion analysis system. Different modules are mounted on a power frame to power up the system. The modules used in the system are listed in Table 3-1.

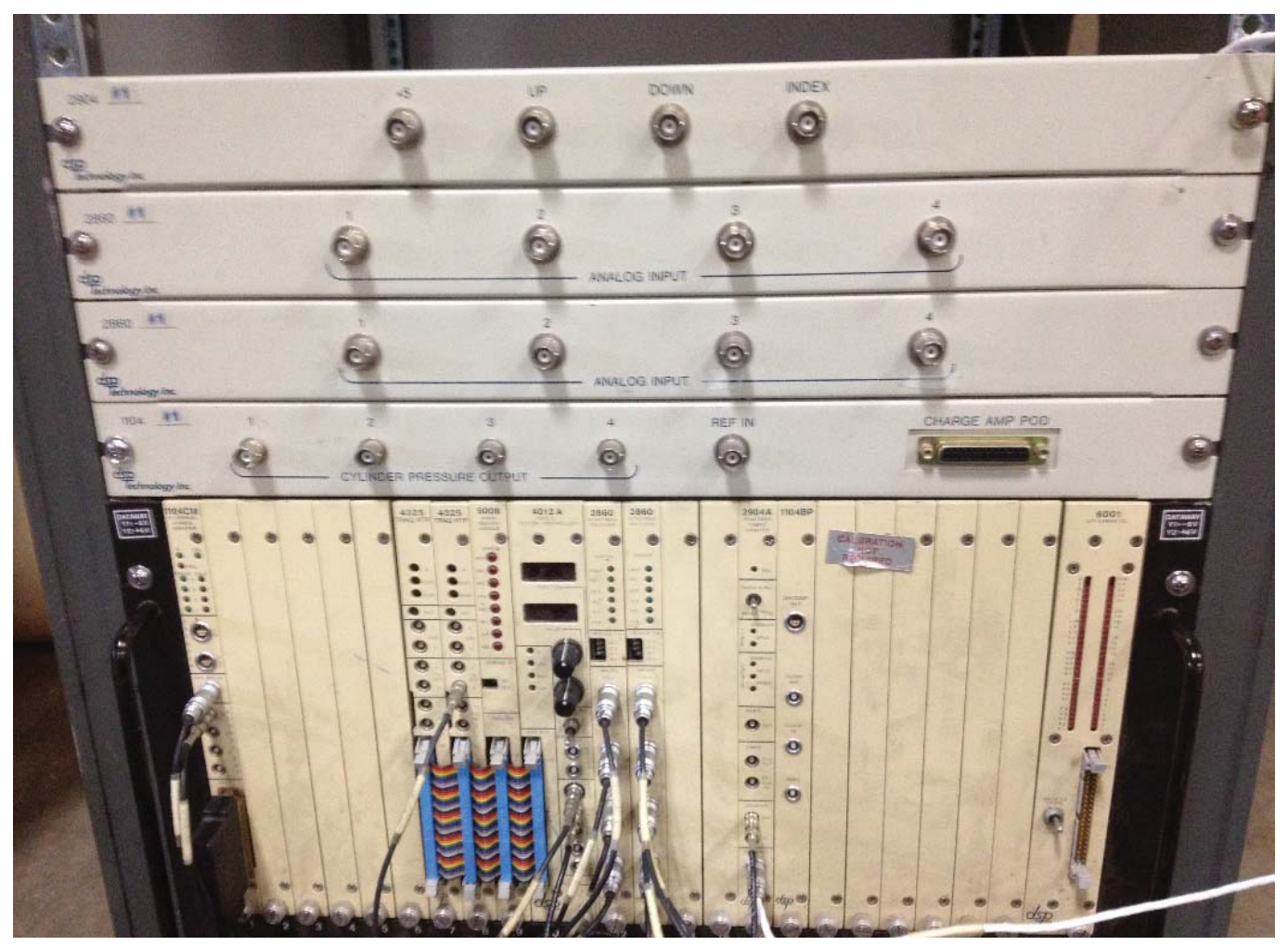

Figure 3-5: Test Cell ACAP System in 19 inch Cabinet

3 REDLINE ACAP, User Manual Version 4.0, DSP Technology Inc. 
To run a minimum real combustion analysis package in ACAP, several modules are required in the power frame, including module 4325 Real Time Processor (RTP), 4012 TRAQ Controller, TRAQ ADC modules, 2904 SPINCODER and either model 6001 or 6002 crate controller ${ }^{3}$. TRAQ stands for transient and signal acquisition. The modules used are listed in Table 3-1, with information collected through the manual. The modules chosen are based on the module inventory and the requirements for running the ACAP system. The model number in Table 3-1 is ordered through the actual setup.

Table 3-1 Test Cell ACAP Modules ${ }^{3}$

\begin{tabular}{|l|l|c|l|}
\hline $\begin{array}{c}\text { Model } \\
\text { NO. }\end{array}$ & \multicolumn{1}{|c|}{ Name } & QTY & \multicolumn{1}{|c|}{ Description } \\
\hline $1104 \mathrm{CM}$ & $\begin{array}{l}\text { Signal Conditioning } \\
\text { Modules }\end{array}$ & 1 & $\begin{array}{l}\text { Four channel charge amplifier for conditioning and } \\
\text { scaling cylinder pressure transducers (piezo- } \\
\text { electric type) }\end{array}$ \\
\hline 4325 & Real Time Processor & 2 & $\begin{array}{l}\text { Model4325 Real Time Processor is a high speed } \\
\text { processing unit using the Texas Instrument } \\
\text { TMS320C25 digital signal processing chip capable } \\
\text { of 10 million instructions per second. }\end{array}$ \\
\hline 5008 & Memory Module & 2 & Memory Module, 8 Mega-sample memory module. \\
\hline $4012 \mathrm{~A}$ & TRAQ Controller & 1 & $\begin{array}{l}\text { TRAQ Controller, the "brains" for the control of the } \\
\text { acquired data flow and for the communications } \\
\text { between the host computer and the TRAQ system. }\end{array}$ \\
\hline 2860 & ADC Modules & 3 & $\begin{array}{l}\text { ADC Module, 4 channels, 12 bit resolution, } \\
\text { maximum 1 Mega sample per second per channel } \\
\text { conversion rate. } \pm 5 \text { Volt input range. }\end{array}$ \\
\hline $2904 \mathrm{~A}$ & SPINCODER & 1 & $\begin{array}{l}\text { SPIN CODER encoder counter/timer used to } \\
\text { condition encoder signals, time stamp the encoder } \\
\text { pulses, and provide position information from a } \\
\text { pulse counter. }\end{array}$ \\
\hline 1642 & Knock Module & 1 & $\begin{array}{l}\text { Four-input knock filter/amplifier with knock peak } \\
\text { detection and knock intensity integration. }\end{array}$ \\
\hline 6001 & Crate Controller & 1 & $\begin{array}{l}\text { Communicate link between the TRAQ crate and } \\
\text { the host computer. }\end{array}$ \\
\hline
\end{tabular}


According to the manual, " 4325 RTP is installed to the left of the 500x memory module. 500x memory modules are installed to the immediate left of the 4012. Model 4012 is installed at a location in which all the signal input modules (2812, 2814, 2860, 2904, etc.) may be placed to its right and all memory modules and RTPs may be placed to its left. The CRATE Controller $(6001,6002$, or CC488) is always installed in slots 24 and 25"3. These rule must be followed to avoid connection damage to the ACAP system. The actual modules are installed as shown in Figure 3-6. For further information about each module, please refer to the REDLINE ACAP User Manual.

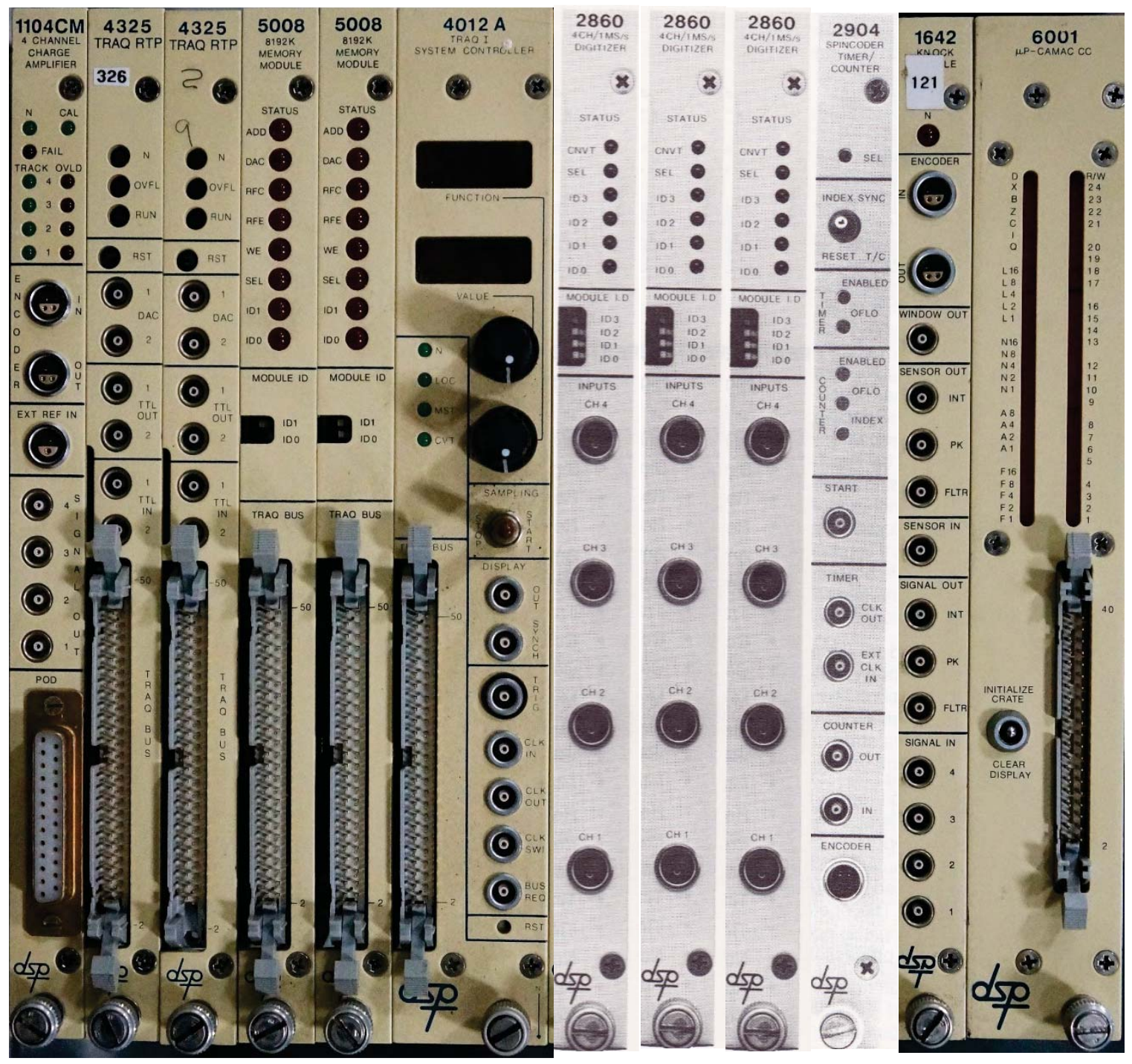

Figure 3-6: Test Cell ACAP System Modules 
Table 3-2: Test Cell ACAP Modules Channel Connections

\begin{tabular}{|c|c|c|c|}
\hline Model No. & Channel & Connection & Cable \\
\hline \multirow{8}{*}{$\begin{array}{l}\text { 1104CM Signal } \\
\text { Conditioning } \\
\text { Modules }\end{array}$} & Encoder In & 1642 Encoder Out & LEMO FFA-0S 4 Pin Cable \\
\hline & Encoder Out & 2904 Encoder & LEMO FFA-0S 4 Pin Cable \\
\hline & EXT Ref In & 1104 Front Panel Ref & LEMO FFA-0S 2 Pin Cable \\
\hline & Signal 4 & $\begin{array}{l}1104 \text { Front Panel Cylinder } \\
\text { Pressure } 4\end{array}$ & $\begin{array}{l}\text { CD International Inc. L00LO0F- } \\
174 \mathrm{LN}-1\end{array}$ \\
\hline & Signal 3 & $\begin{array}{l}1104 \text { Front Panel Cylinder } \\
\text { Pressure } 3\end{array}$ & $\begin{array}{l}\text { CD International Inc. L00L00F- } \\
174 \mathrm{LN}-1\end{array}$ \\
\hline & Signal 2 & $\begin{array}{l}1104 \text { Front Panel Cylinder } \\
\text { Pressure } 2\end{array}$ & $\begin{array}{l}\text { CD International Inc. L00L00F- } \\
\text { 174LN-1 }\end{array}$ \\
\hline & Signal 1 & $\begin{array}{l}\text { 1104 Front Panel Cylinder } \\
\text { Pressure } 1\end{array}$ & $\begin{array}{l}\text { CD International Inc. L00L00F- } \\
174 \mathrm{LN}-1\end{array}$ \\
\hline & POD & 1104 Front Panel POD & POD Connector \\
\hline $\begin{array}{l}4325 \text { Real Time } \\
\text { Processor }\end{array}$ & TTL Out 2 & 4012A TRIG & $\begin{array}{l}\text { CD International Inc. L00L00F- } \\
174 \mathrm{LN}-1\end{array}$ \\
\hline \multirow{3}{*}{$\begin{array}{l}\text { 4012A TRAQ } \\
\text { Controller }\end{array}$} & & & \\
\hline & TRIG & 4325 TTL Out 2 & $\begin{array}{l}\text { CD International Inc. L00L00F- } \\
\text { 174LN-1 }\end{array}$ \\
\hline & CLK In & 2904 Counter Out & $\begin{array}{l}\text { CD International Inc. L00L00F- } \\
174 \mathrm{LN}-1\end{array}$ \\
\hline \multirow{4}{*}{$\begin{array}{l}2860 \text { ADC } \\
\text { Modules }\end{array}$} & $\mathrm{CH} 4$ & 2860 Front Panel & LEMO FFA-0S 2 Pin Cable \\
\hline & $\mathrm{CH} 3$ & 2860 Front Panel & LEMO FFA-0S 2 Pin Cable \\
\hline & $\mathrm{CH} 2$ & 2860 Front Panel & LEMO FFA-0S 2 Pin Cable \\
\hline & $\mathrm{CH} 1$ & 2860 Front Panel & LEMO FFA-0S 2 Pin Cable \\
\hline \multirow{2}{*}{$\begin{array}{l}\text { 2904A } \\
\text { SPINCODER }\end{array}$} & Counter Out & 4012 CLK In & $\begin{array}{l}\text { CD International Inc. L00L00F- } \\
174 \mathrm{LN}-1\end{array}$ \\
\hline & Encoder & 1104CM Encoder Out & LEMO FFA-0S 4 Pin Cable \\
\hline \multirow{8}{*}{$\begin{array}{l}1642 \text { Knock } \\
\text { Module }\end{array}$} & Encoder In & $\begin{array}{l}\text { Encoder Front Panel with } \\
\text { A, Z Output Chanel }\end{array}$ & LEMO FFA-0S 4 Pin Cable \\
\hline & Encoder Out & 1104CM Encoder Out & LEMO FFA-0S 4 Pin Cable \\
\hline & $\begin{array}{l}\text { SINGAL Out } \\
\text { INT }\end{array}$ & 1104 Front Panel & $\begin{array}{l}\text { CD International Inc. L00L00F- } \\
\text { 174LN-1 }\end{array}$ \\
\hline & $\begin{array}{l}\text { SINGAL Out } \\
\text { PK }\end{array}$ & 1104 Front Panel & $\begin{array}{l}\text { CD International Inc. L00L00F- } \\
\text { 174LN-1 }\end{array}$ \\
\hline & SINGAL In 4 & $\begin{array}{l}\text { 1104 Front Panel Cylinder } \\
\text { Pressure } 4\end{array}$ & $\begin{array}{l}\text { CD International Inc. L00L00F- } \\
174 \mathrm{LN}-1\end{array}$ \\
\hline & SINGAL In 3 & $\begin{array}{l}\text { 1104 Front Panel Cylinder } \\
\text { Pressure } 3\end{array}$ & $\begin{array}{l}\text { CD International Inc. L00L00F- } \\
174 \mathrm{LN}-1\end{array}$ \\
\hline & SINGAL In 2 & $\begin{array}{l}\text { 1104 Front Panel Cylinder } \\
\text { Pressure } 2\end{array}$ & $\begin{array}{l}\text { CD International Inc. L00L00F- } \\
174 \mathrm{LN}-1\end{array}$ \\
\hline & SINGAL In 1 & $\begin{array}{l}1104 \text { Front Panel Cylinder } \\
\text { Pressure } 1\end{array}$ & $\begin{array}{l}\text { CD International Inc. L00L00F- } \\
174 \mathrm{LN}-1\end{array}$ \\
\hline $\begin{array}{l}\text { 6001 Crate } \\
\text { Controller }\end{array}$ & BUS & Host Computer & 40 Pin Flat Ribbon Bus \\
\hline
\end{tabular}


The module 1104CM is a four-channel charge amplifier module for piezoelectric type pressure transducer signal. Most of the channels on 1104CM are connected to the 1104 quick connection front panel, which is connected to the engine cart panel with BNC cables. The Encoder In and the Encoder Out channel are wired to the 1604 module and the 2904 module as shown in Table 3-2.

The RTP module 4325 is connected to the memory module 5008 and the control module 4012A through the 50 pin Flat Ribbon Bus with several connectors on it. For the current setup, the two RTP 4325 modules, two memory 5008 and one 4012A in Figure 3-6 are connected through the 50-pin bus with 5 connectors. Data acquired from the signal input modules by $4012 \mathrm{~A}$ is transferred through a private bus to the local memory storage 5008 which is an 8 mega sample memory module and to the RTP 4325. A jumper cable is used to connect one of the two 4325 modules TTL Out 2 channel with the TRIG channel on 4012A. In addition, the CLK In channel is wired to the Counter Out channel of the 2904 SPINCODER module as shown in Table 3-2. The encoder signals from the engine are connected to the system through a multiple-pin connector on the 2904A. The encoder pulse signal is used to "clock" the system. Three 2860 ADC modules are used according to Figure 3-6, which have four channels with 12-bit resolution each. This module is used for input and acquisition of analog data. LEMO FFA-0S 2-pin cables are used to connect module 2860 to the amplifier and later to the engine for data acquisition. All the channels on these three 2860 modules are connected to the quick connection front panels.

For 1642 Knock Module, the Encoder In is connected to the quick connection encoder panel, which has two channels including encoder $\mathrm{A}$ and $\mathrm{Z}$ signals. These will be connected to the engine cart interface panel. The Encoder Out is wired to the 1104CM Encoder Out channel. The rest of the channels connect to the 1104 quick connection front panel.

The crate controller 6001 communicates with the TRAQ crate and host computer through a 40-pin Flat Ribbon Bus. Since this ACAP system is an old combustion system, it requires a special module Industry Standard Architecture (ISA) slot on the host computer motherboard. The motherboard purchased is an ADEK MS-98A9 Ivy Bridge Industrial ATX motherboard; the quote for the motherboard is attached in the APPENDIX 1. 


\subsubsection{National Instrument (NI) Data Acquisition System}

Besides the ACAP combustion analysis system, the National Instrument (NI) system serves as the main control system supporting the dynamometer control and electronic sensors power. In the test cell, the NI data acquisition system is mounted on one side of the test cell wall and could easily slide backward and forward. The whole system is shown in Figure 3-7, which includes an Uninterrupted Power Supply (UPS) unit, NI PXI system, harness, power fuse and an emergency stop button on the panel. The NI PXI system uses PXIe-1078 chassis and several modules for data acquisition. The PXIe-1078 supports a maximum of 9 slots and has up to $1.75 \mathrm{~GB} / \mathrm{s}$ data transfer rate. The modules installed on the chassis are listed in Table 3-3. For further information about each module, please refer to NI website.

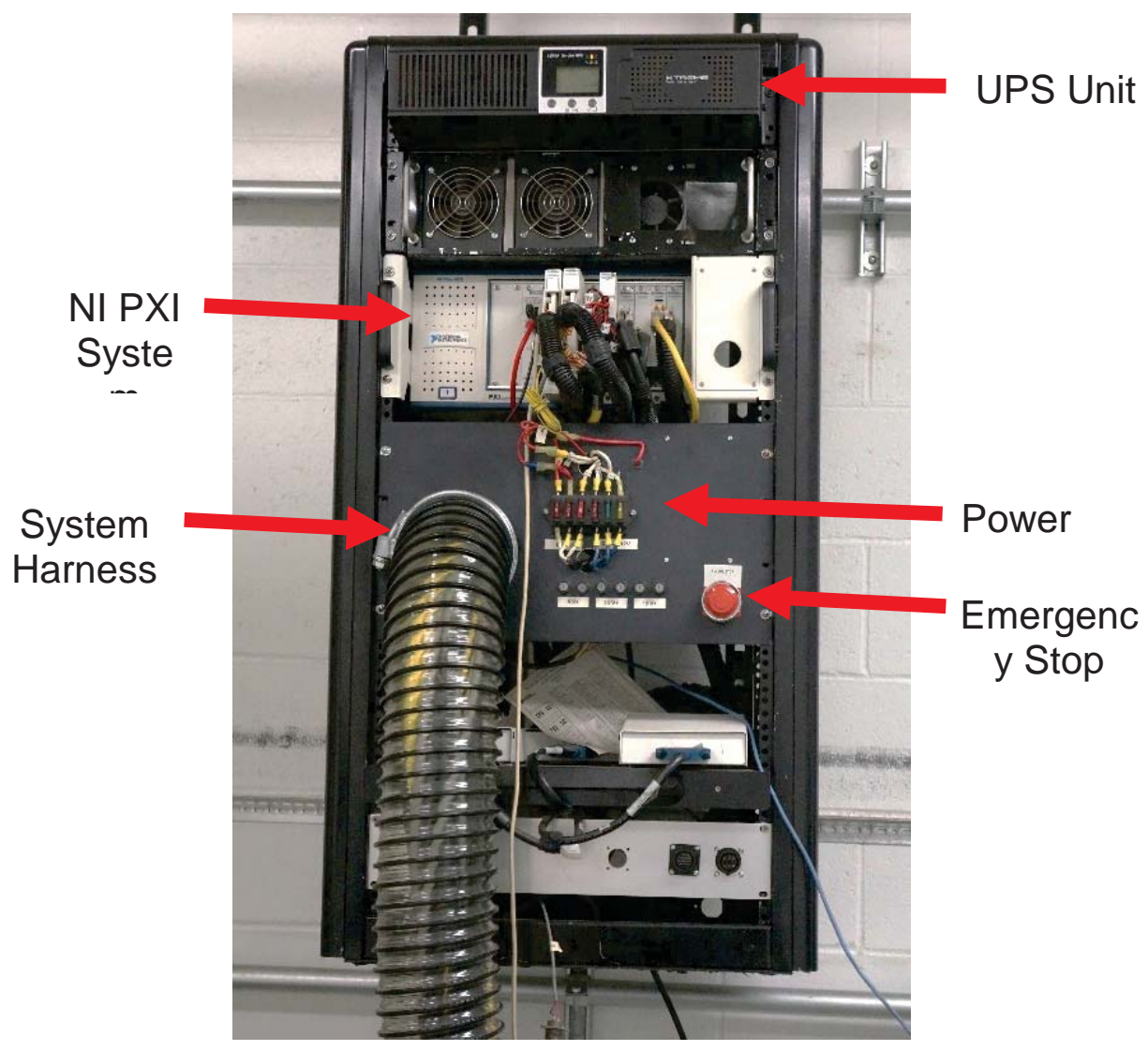

Figure 3-7: Test Cell National Instruments Data Acquisition System 
Table 3-3: NI PXI System Modules Installed ${ }^{4}$

\begin{tabular}{|c|c|c|}
\hline Chasis & QTY & Description \\
\hline NI PXIe-1078 & 1 & $\begin{array}{l}\text { 9-Slot 3U PXI Express Chassis With } \\
\text { AC - Up to } 1.75 \mathrm{~GB} / \mathrm{s}\end{array}$ \\
\hline Module & QTY & Description \\
\hline NI PXIe-8100 & 1 & $\begin{array}{l}\text { Deployment platform for LabVIEW } \\
\text { Real-Time and LabWindows } \\
\text { Real-Time applications }\end{array}$ \\
\hline NI TB-4353 & 2 & $\begin{array}{l}\text { thermocouple input module, a front } \\
\text { mounting isothermal terminal } \\
\text { block, } 12 \mathrm{CH} \text { Thermocouple }\end{array}$ \\
\hline NI TB-2706 & 1 & $\begin{array}{l}\text { Direct Connectivity Terminal Block, } \\
70 \text { screw terminals, and } \\
\text { a metal enclosure with strain relief } \\
\text { hardware }\end{array}$ \\
\hline NI PXI6225 & 1 & $\begin{array}{l}\text { 16-Bit, } 250 \mathrm{kS} / \mathrm{s}, 80 \text { Analog Input } \\
\text { Multifunction DAQ }\end{array}$ \\
\hline NI PXI6722 & 1 & $\begin{array}{l}\text { Static and Waveform Analog Output } \\
--13-B i t, 8 \text { Channels }\end{array}$ \\
\hline NI PXI-8513 & 1 & $\begin{array}{l}\text { 1-Port Software-Selectable/FD NI- } \\
\text { XNET CAN Interface }\end{array}$ \\
\hline NI PXIe-8430/8 & 1 & $\begin{array}{l}\text { High Performance, 8-Port Serial } \\
\text { Interface }\end{array}$ \\
\hline
\end{tabular}

${ }^{4}$ www. Ni. com 


\subsection{Dynamometer System}

A GE Motors Adjustable Speed AC Dynamometer 5TKF445DC03A004 shown in Figure 3-8 is used to measure the power output of the engine. The absorbing capacity of the dynamometer is $460 \mathrm{Hp}$ and motoring capacity is $400 \mathrm{Hp}$. Also, the maximum speed for the dynamometer is 8000 RPM.

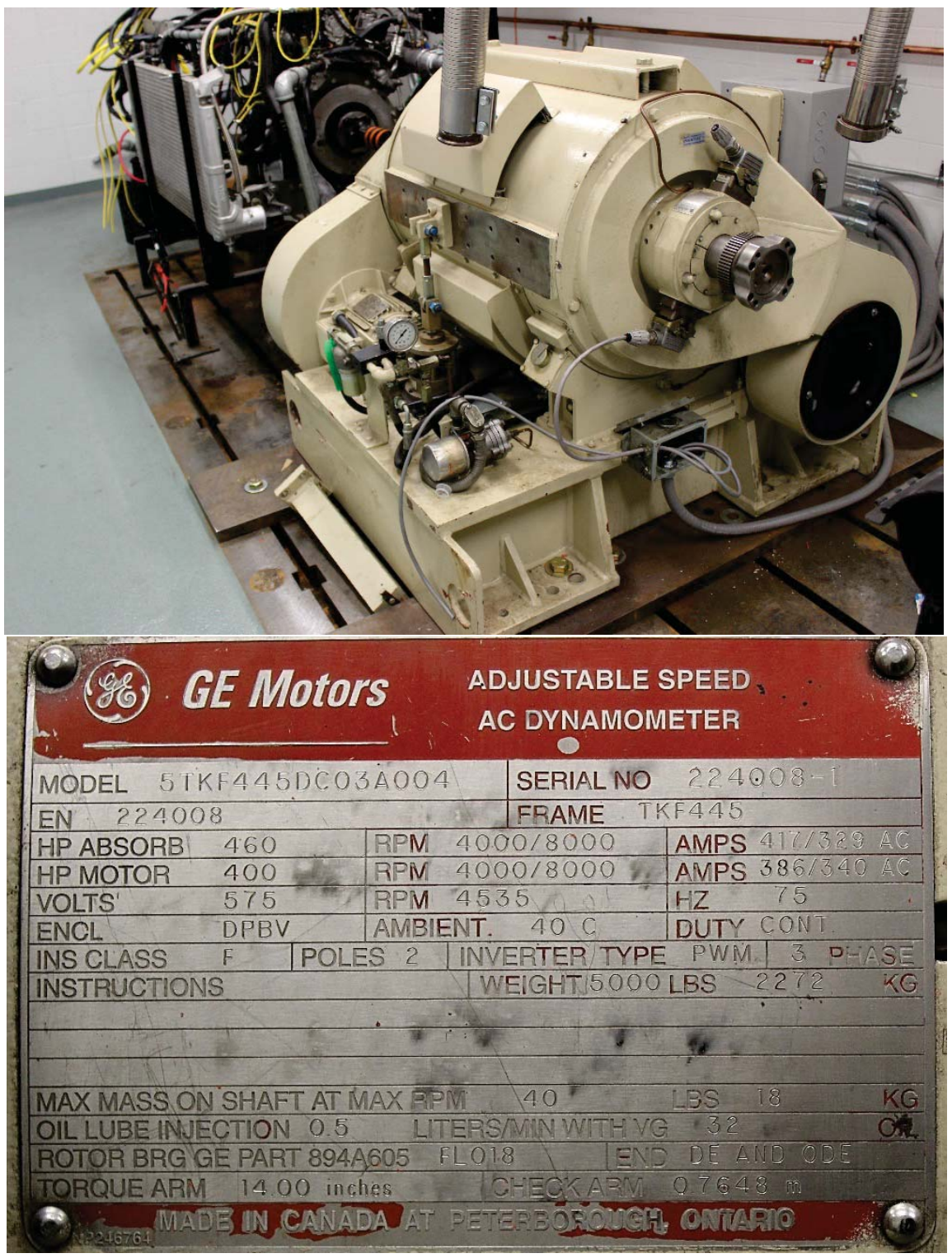

Figure 3-8: GE Motors Adjustable Speed AC Dynamometer 


\section{CHAPTER 4 Optical Engine Setup}

\subsection{Optical Engine Specification}

The optical engine provided by MAHLE Powertrain is an engine based on a 2013 Ford Escape 2.0L EcoBoost 4 cylinder spark ignited direct injection (SIDI) production engine. For the Ford Ecoboost engine, the detail geometry parameters are listed in Table 4-1 from the service manual. These parameters could be used to set up the engine control unit, DSPACAP combustion analysis system.

Table 4-1: Ford Ecoboost Engine and Optical Engine Geometry Parameters ${ }^{56}$

\begin{tabular}{|c|c|c|c|}
\hline Engine Type & EcoBoost 2.0L & Optical Engine & Unit \\
\hline No. of Active cylinders & 4 & 1 & - \\
\hline Bore & 87.5 & 87.5 & $\mathrm{~mm}$ \\
\hline Stroke & 83.1 & 100 & $\mathrm{~mm}$ \\
\hline Displacement & 2 & 0.6 & $\mathrm{~L}$ \\
\hline Firing Order & $1-3-4-2$ & NA & - \\
\hline Connecting Rod Length & 155.87 & 155.87 & $\mathrm{~mm}$ \\
\hline Compression Ratio & $9.3: 1$ & $10.24: 1$ & - \\
\hline Spark Plug & NGK T4025R & NGK T4025R & - \\
\hline Spark Plug Gap & 0.8 & 0.8 & $\mathrm{~mm}$ \\
\hline
\end{tabular}

According to the information from MAHLE Powertrain, though the optical engine is modified based on the Ecoboost engine, there are some differences between these two engines. Compared with the Ecoboost engine, the optical engine's stroke is $100 \mathrm{~mm}$, engine displacement is $0.6 \mathrm{~L}$ for the single cylinder and compression is $10.24: 1$ instead of $9.3: 1$. In addition, the optical engine utilizes customized connecting rod and pistons, whose piston

\footnotetext{
52013 Escape Workshop Manual Section 303-01B Engine-2.0L GTDI Specifications

6 MAHLE Powertrain 01735 DOE Optical Engine
} 
has a flat top and four threaded holes. These four threaded holes are used to mount the Bowditch elongated piston, showing in Figure 4-1 ${ }^{6}$.

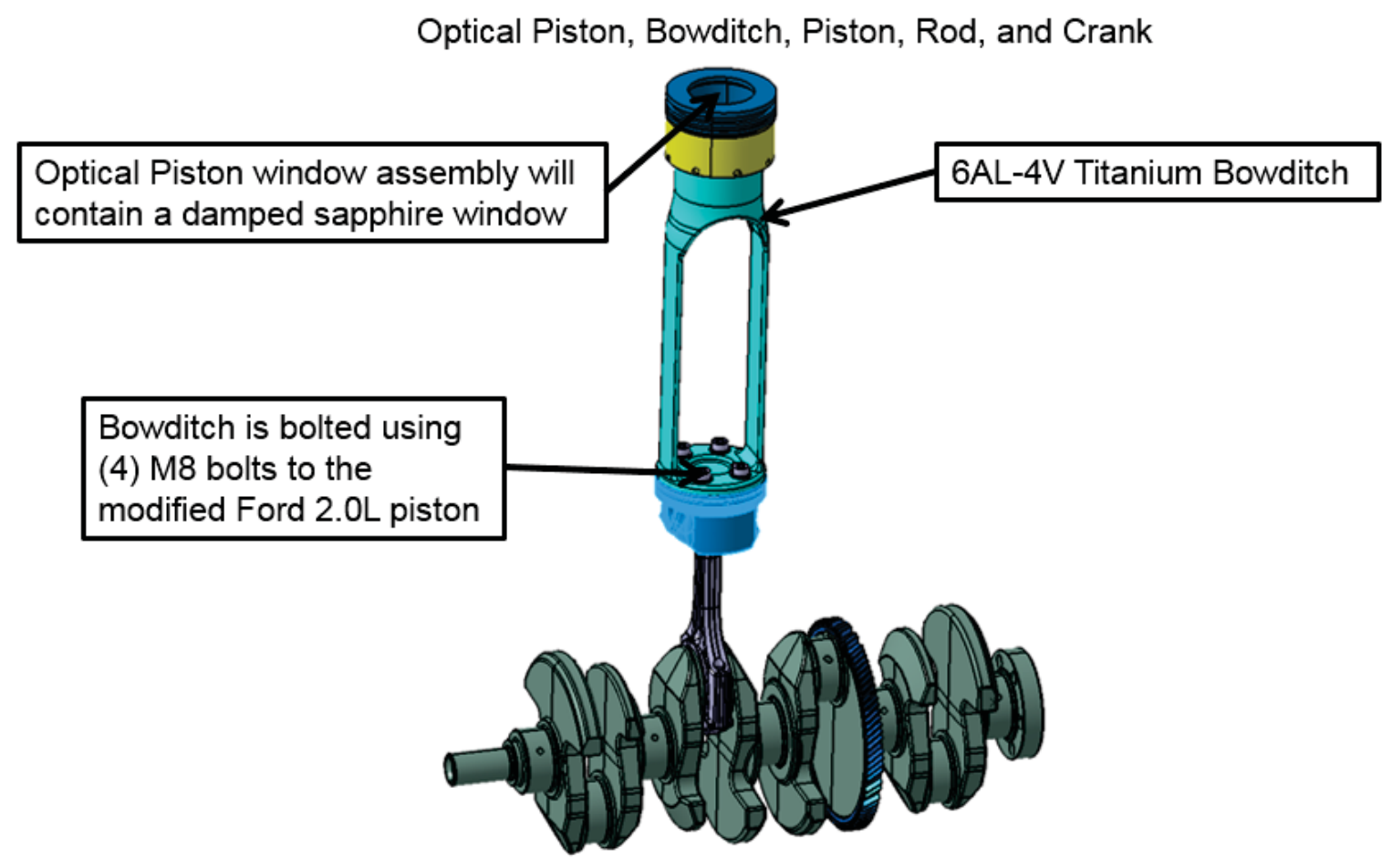

Figure 4-1: Optical Engine Bowditch Assembly ${ }^{10}$

In Figure 4-1, the optical piston window is now equipped with a transparent pent-roof top shape optical grade quartz liner upper window, which is clamped between the cylinder head and hydraulic deck through hydraulic pressure. The window is shown in Figure 4-2. The gray layer is the gasket to seal the combustion chamber and the quartz ring.

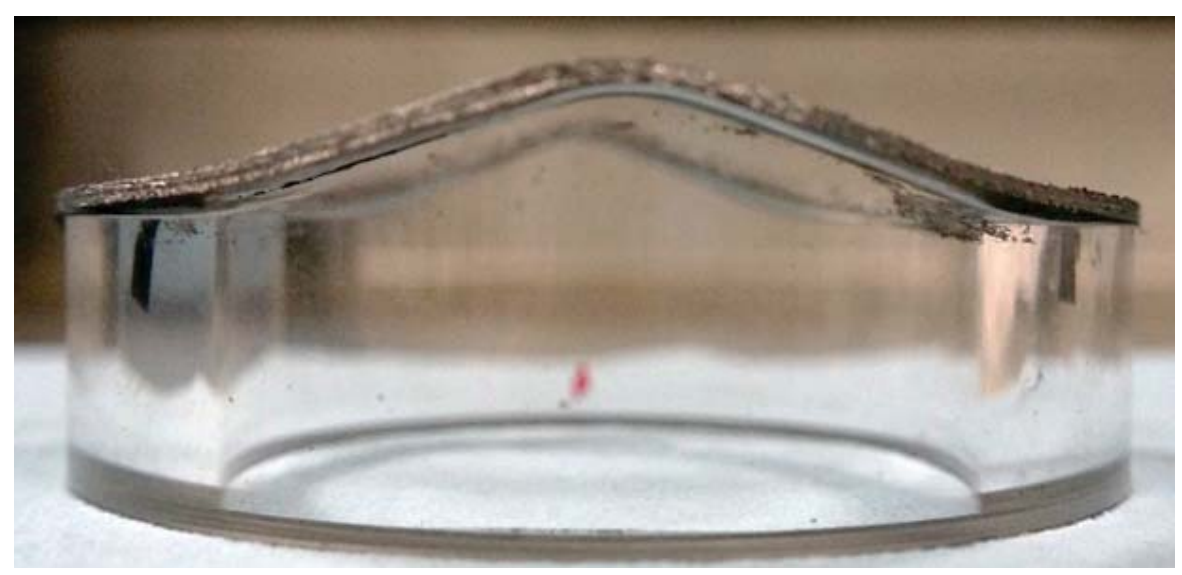

Figure 4-2: Optical Engine Pent-Roof Shape Optical Grade Quartz Liner Upper Window 


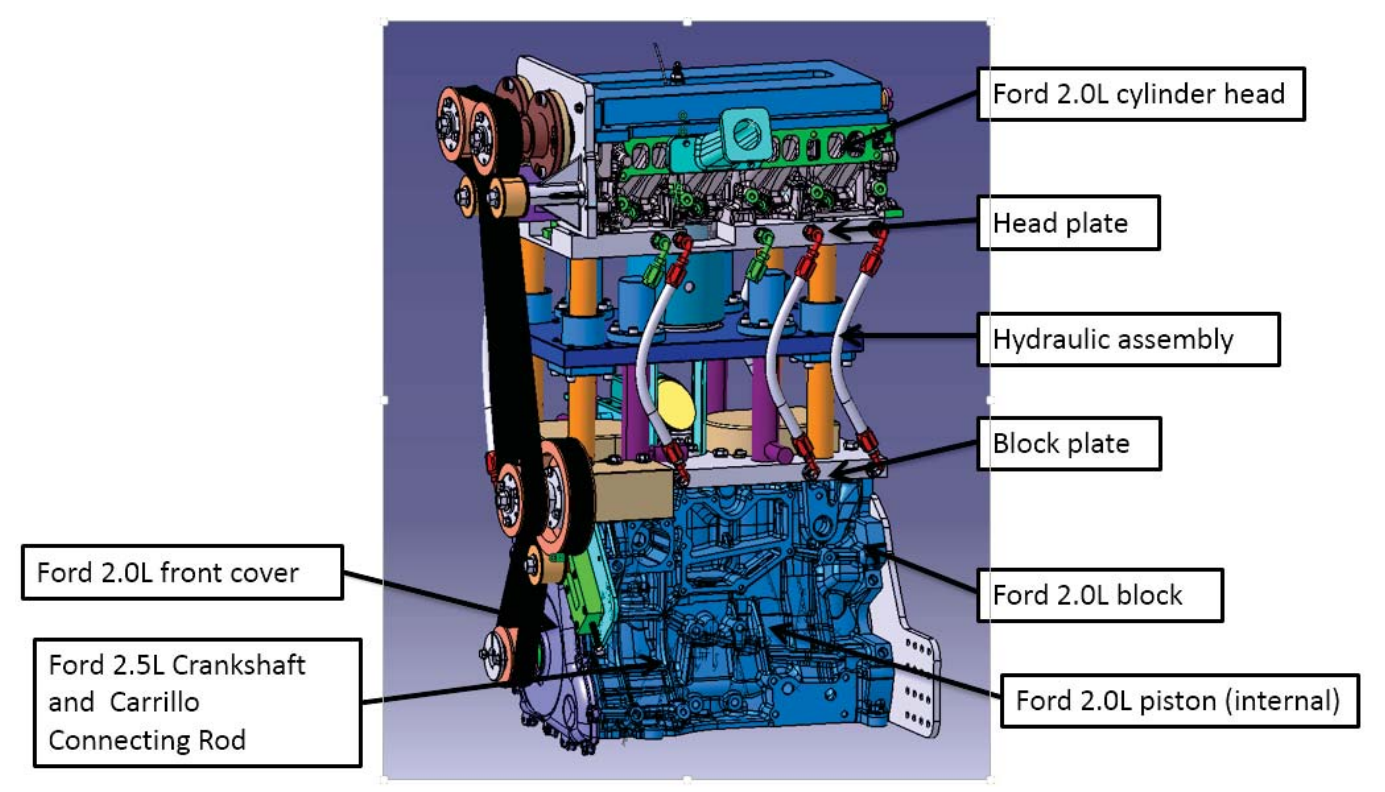

Figure 4-3: MAHLE Powertrain 3D CAD Design Concept Overview of Optical Engine ${ }^{6}$

The full assembly of the optical engine in Figure 4- $3^{6}$ from MAHLE Powertrain shows the design overview. For the optical engine at Michigan Technological University, the cylinder head is the 2.0L Ecoboost production cylinder head machined for the pent-roof optical access accommodating a standard production spark plug. 


\subsection{Hardware Setup}

\subsubsection{Engine Mounting}

The engine is mounted on a universal cart shown in Figure 4-4. The left side shows the original optical engine without any instrumentation. On the right side, the optical engine is mounted on a universal cart, which provides mobility to move the engine to the test cell. Because there are different engine platforms in the test cell, it is easy to move the engine out of the test cell after the experiment. Moreover, from the right side of Figure 4-4, the engine is jacked to a specified height of $78.9 \mathrm{~cm}(31.0625$ inch) to mate with the dynamometer shaft.
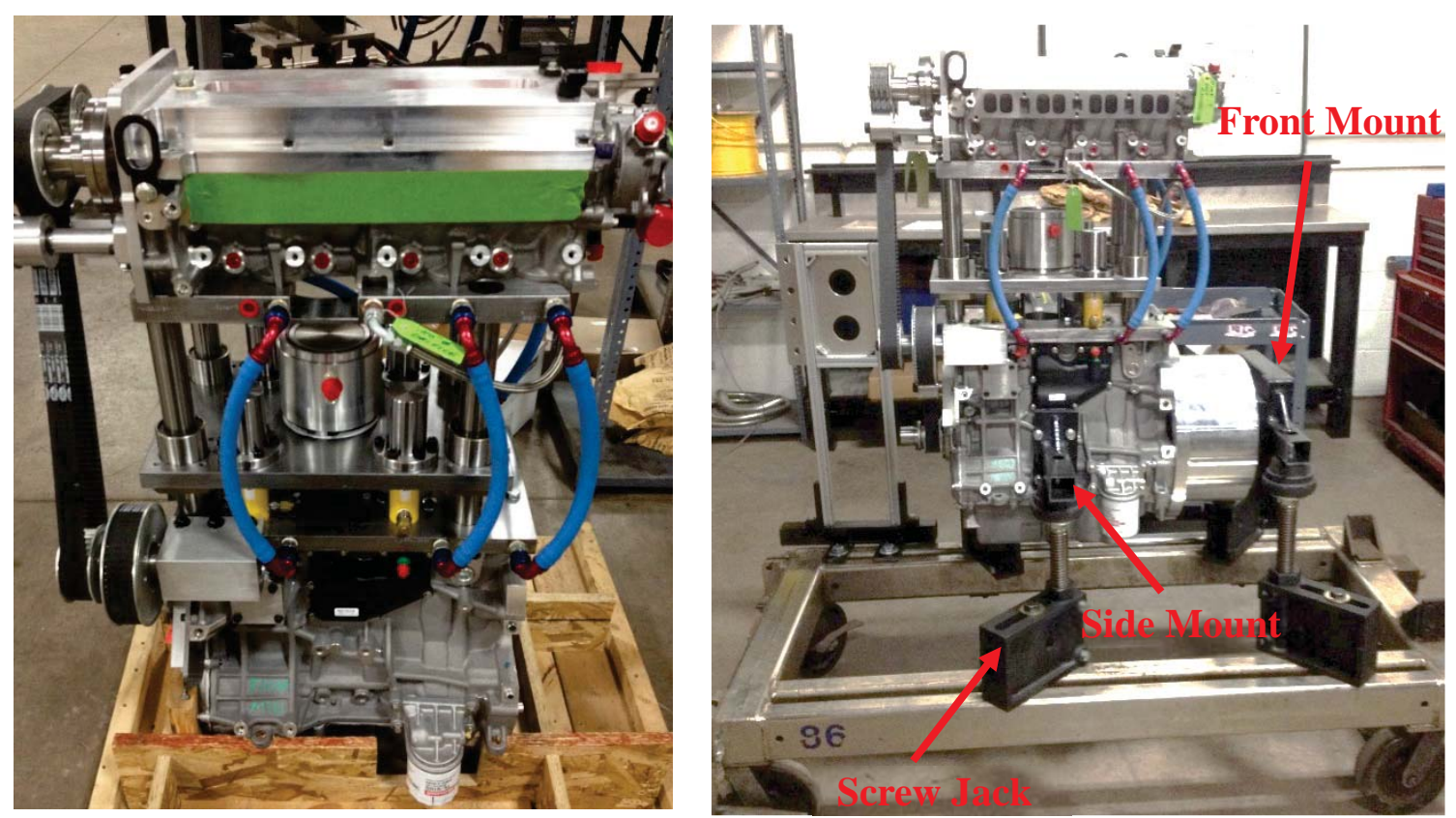

Figure 4-4: Optical Engine (Left) and Optical Engine Mounting on Engine Cart (Right)

To mount the engine on the cart, several accessories are required and some of them are designed and fabricated. The mounting process of each component is presented in the block diagram in Figure 4-5. These components include front mount frame, side mount welded by two inches square tube, four screw jacks for engine support, bell housing, screw jack adapters and ranger mount to reduce vibration. 


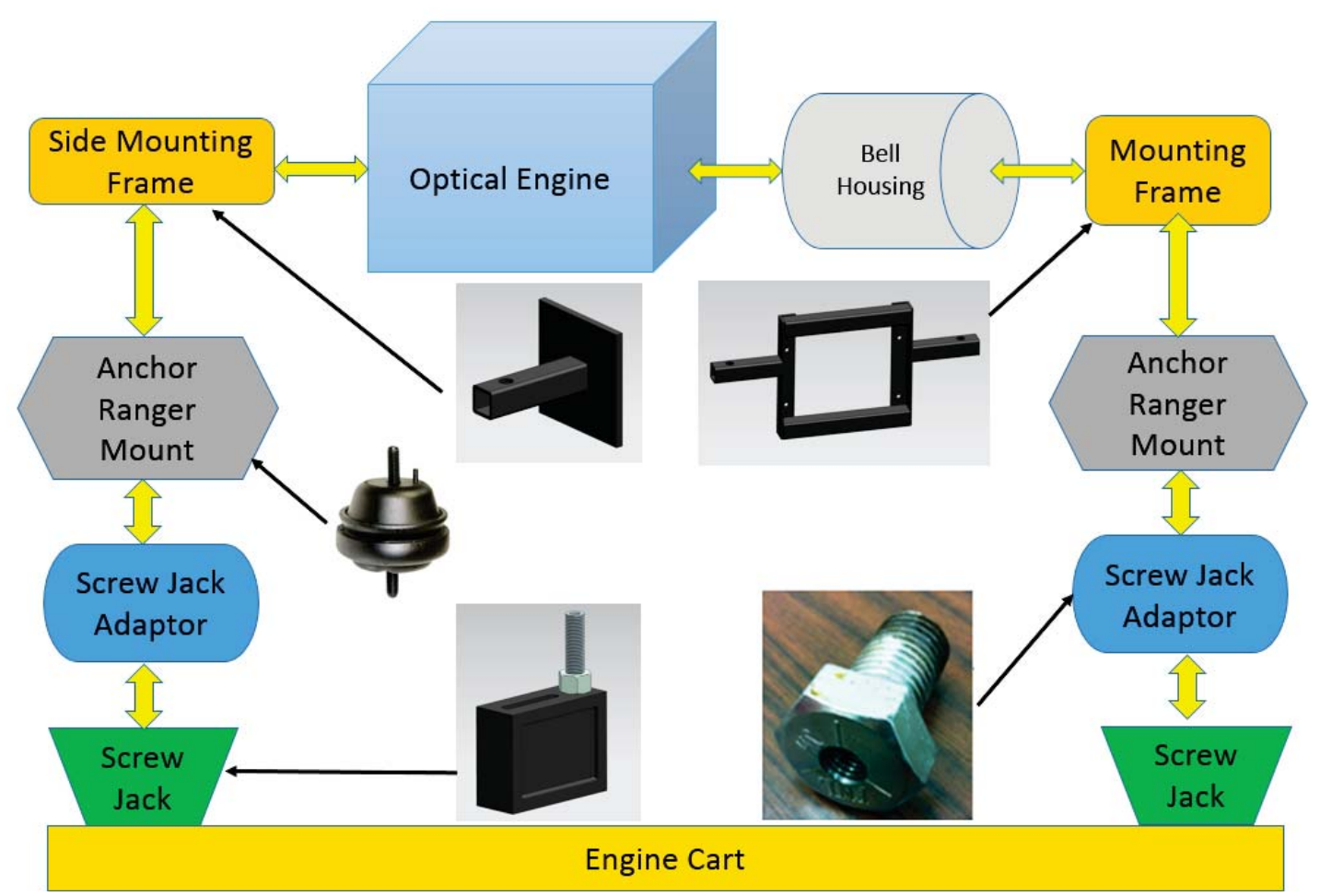

Figure 4-5: Engine Mounting Components Connection Block Diagram

Basically, the engine on the cart is supported by the four heavy duty screw jacks, which makes it adjustable and easy for positioning the height of the optical engine. Then four ranger mounts are connected to the screw jacks through screw jack adapters, which are machined from 7/8-9 hex bolts with $12 \mathrm{~mm}$ diameter, $1.75 \mathrm{pitch}, 35 \mathrm{~mm}$ depth threaded holes at the center to fit the ranger mount threaded stud. The detailed CAD drawings are attached in APPENDIX 2.

On the end of the ranger mount, front mount frame and side mount frames are supported. The ranger mounts act as dampers to balance the vibration while the engine is running. For the front side of the engine, the bell housing connects the engine flywheel with the dynamometer shaft. Then the housing is mounted on the front mount frame through four bolts as shown in Figure 4-6. The front frame is made of 2-inch carbon steel square tubing with 0.25 inch thickness. By cutting and welding the tube, the front frame is built. The holes on the tube are used to connect to the ranger mount. The bell housing has a four screw holes square pattern to fit with the engine rear end. 


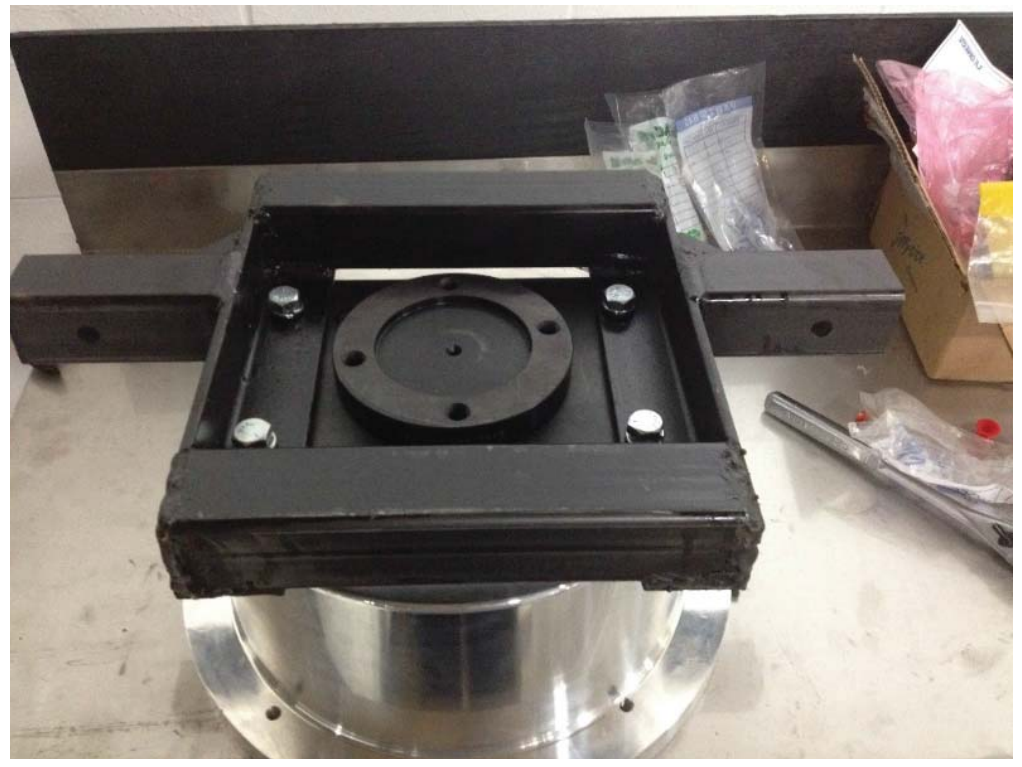

Figure 4-7: Bell Housing Mounted with Front Mount Frame

There are two side mounting frames on the left and right sides of the optical engine. Their setup is similar to the front mounting frame, except that the 2 inch square tube is welded on a metal plate as shown in Figure 4-7. Then, several holes are drilled according to the optical engine side screw pattern. Above all, the engine is supported and mounted on the universal cart.

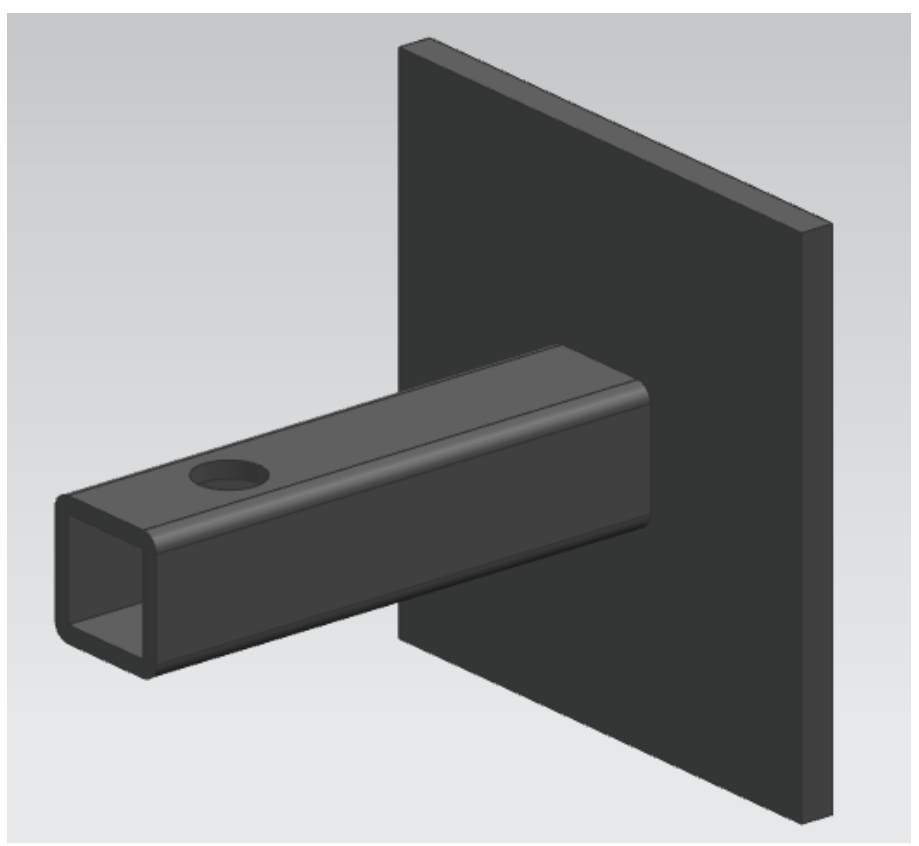

Figure 4-6: Side Mount CAD Model 


\subsubsection{Cart Interface Panel Design}

Interface panel mounting on the universal cart provides easy and fast connections between the engine harness and data acquisition system. The interface panel includes mounting holes for different flange receptacles, BNC, USB and Ethernet connectors. Two panels are designed as shown in Figure 4-8. Both of them are machined from ASTM B209 aluminum sheets. One is the coolant and fuel line panel and the other one is the connector panel. The design of the panels is standardized for all APS LABS research engines, and some features are not used by the optical engine, for example, the AUX WATER ports on the coolant and fuel line panel.
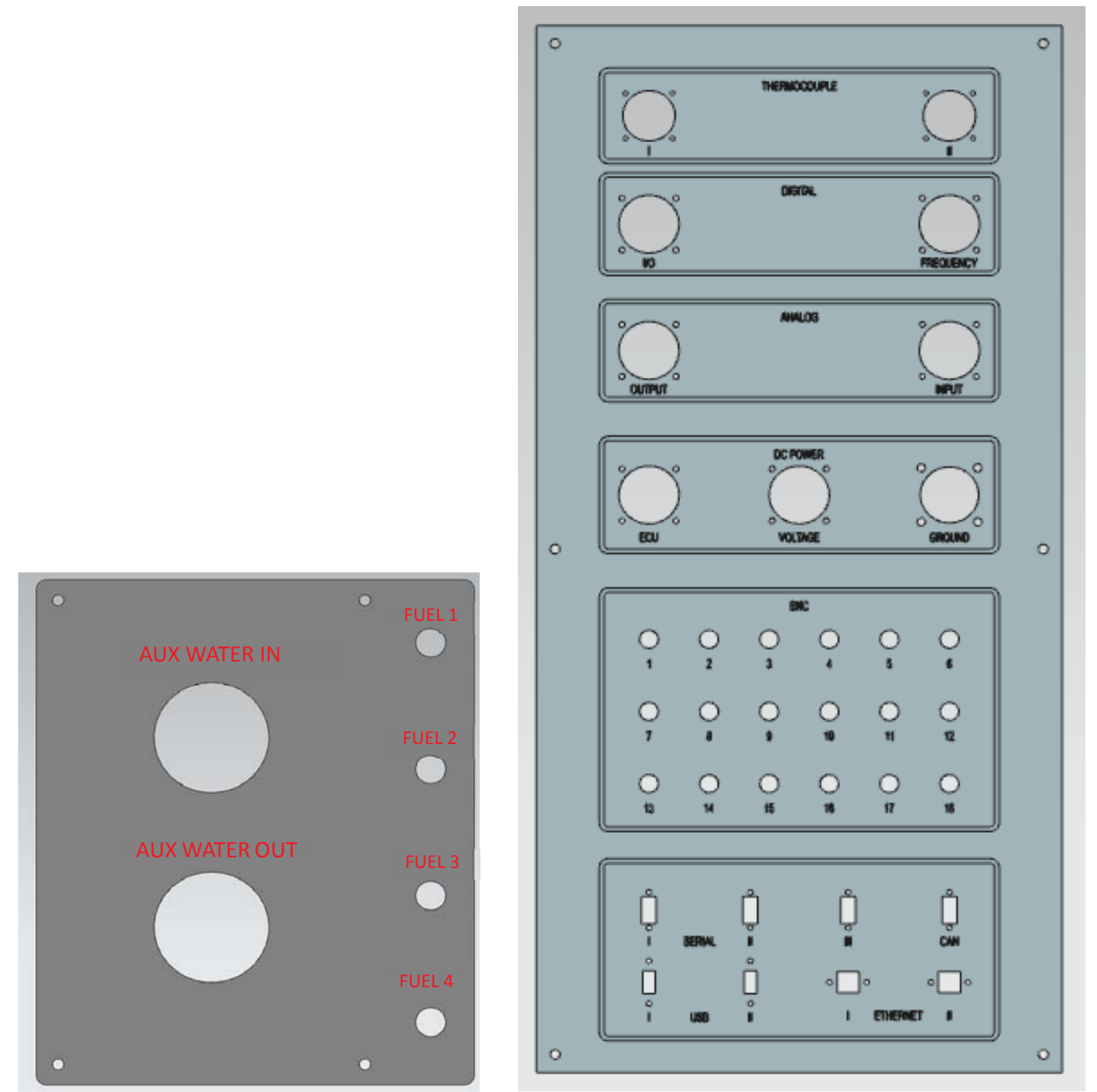

Figure 4-8: Interface Panel: Coolant and Fuel Line Panel (left); Connector Panel (Right) 
The coolant and fuel panel includes coolant inlet, outlet and four fuel line connectors. The connector panel is designed to have spare holes for additional connectors. The connector panel is separated into six sections including two thermocouple connectors, two digital input or output connectors, two analog connectors, three DC power connectors, 18 BNC connectors and one section for USB and Ethernet connectors. These two panels are mounted separately on different sides of the universal cart through 80/20 frame. Figure 4-9 shows the machined panels with connectors on it, which shows the connectors being used for current setup. The connectors could be easily changed based on the test requirement for future research. The detailed dimensions CAD drawings of these two panels are attached in APPENDIX 3 and 4. Moreover, the detail connections are listed as follows including thermocouple connection, analog connection and ECU power supply.
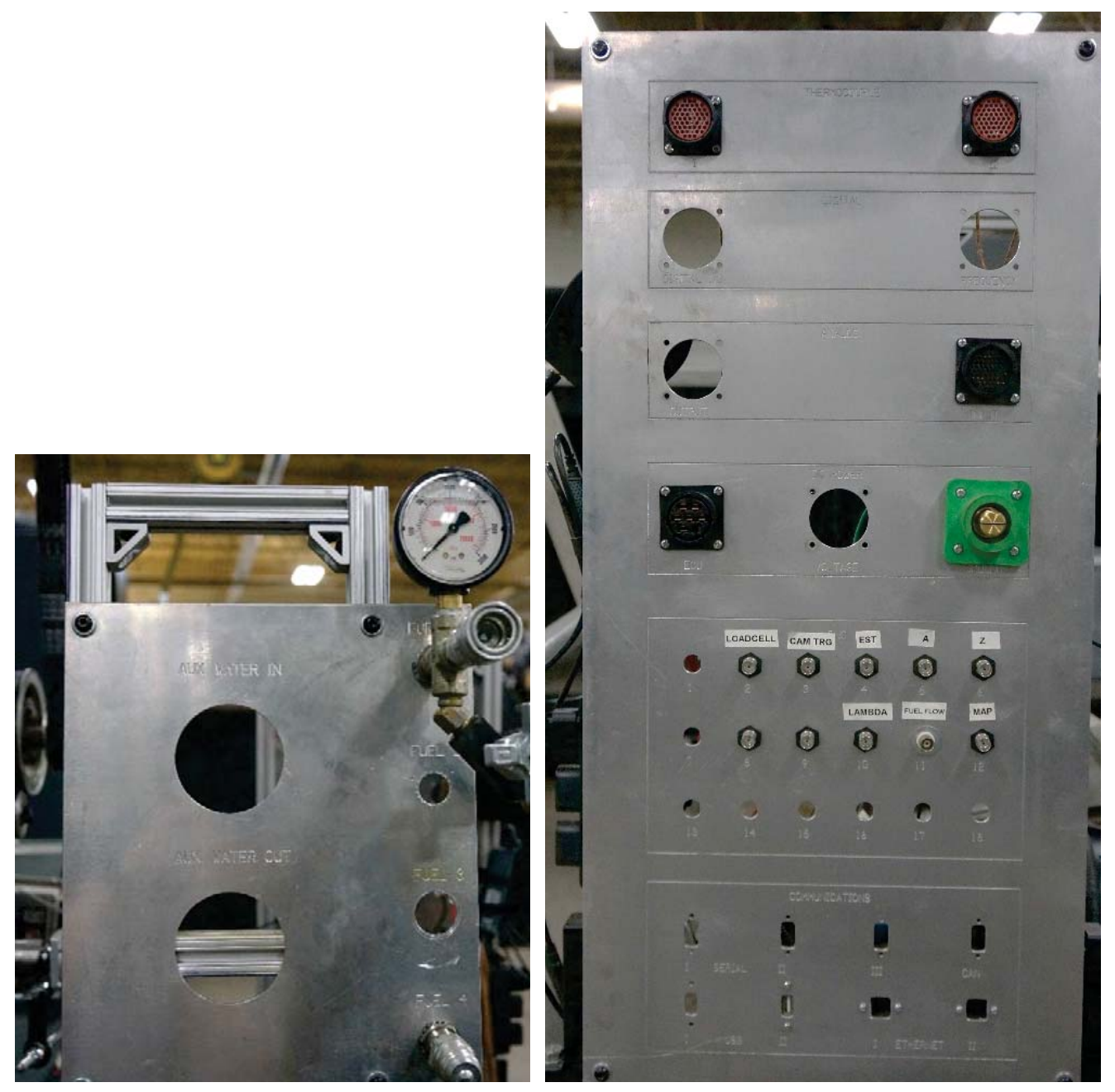

Figure 4-9: Machined Interface Panels: (1) Coolant and Fuel Line Panel (left);

(2) Connector Panel (Right) 


\subsubsection{Thermocouple Connection}

There are two thermocouple connectors mounted on the interface panel, which are the 55pin female flange thermocouple connectors. These connectors are shown in Figure 4-10. Pin socket number one is located in the center of the connector, and the last pin socket is located on the outside boundary of the connectors, counting counterclockwise.

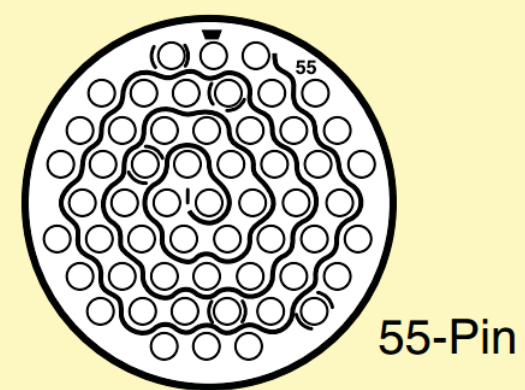

Figure 4-10 : Omega MTC-55-FF Series 55-Pin Thermocouple Connectors

For optical engine setup, not all the pins in the connectors are used. The pin connections are chosen based on the optical engine research requirements. The thermocouples' connections are listed in

Table 4-2, taking the left side connector mounting on the panel as the connector No.1, the other as No.2. K type thermocouples are used for whole setup in the research. For normal K-type thermocouples, the red wire is made of nickel-aluminum, which is the negative terminal (-). The yellow wire is made of nickel-chromium, which is the positive terminal (+). The detail components for the connectors are listed in APPENDIX 5.

Table 4-2: MTC 55-Pin Thermocouple Wire Connections

\begin{tabular}{|c|c|c|}
\hline \multicolumn{3}{|c|}{ Connector No.1 } \\
\hline Socket No. & Thermocouple Wire & Description \\
\hline 5 & K Type Red (-) & \multirow{2}{*}{ Oil In Temperature } \\
\hline 6 & K Type Yellow (+) & \\
\hline 7 & K Type Red (-) & \multirow{2}{*}{ Oil Out Temperature } \\
\hline 8 & K Type Yellow (+) & \\
\hline 29 & K Type Red (-) & \multirow{2}{*}{ Intake Temperature } \\
\hline 30 & K Type Yellow (+) & \\
\hline 33 & K Type Red (-) & \multirow{2}{*}{ Exhaust Temperature } \\
\hline 34 & K Type Yellow (+) & \\
\hline \multicolumn{3}{|c|}{$\begin{array}{r}\text { Connector No.2 } \\
\end{array}$} \\
\hline 29 & K Type Red (-) & \multirow{2}{*}{ Cylinder Liner Temperature } \\
\hline 30 & K Type Yellow (+) & \\
\hline
\end{tabular}




\subsubsection{Analog Connection}

A 63 pin amp series 2 flange receptacle shown in Figure 4-11 is mounted on the interface panel connecting the engine sensors to the data acquisition system. The first socket starts from the left side of the first row as shown in Figure 4-11.

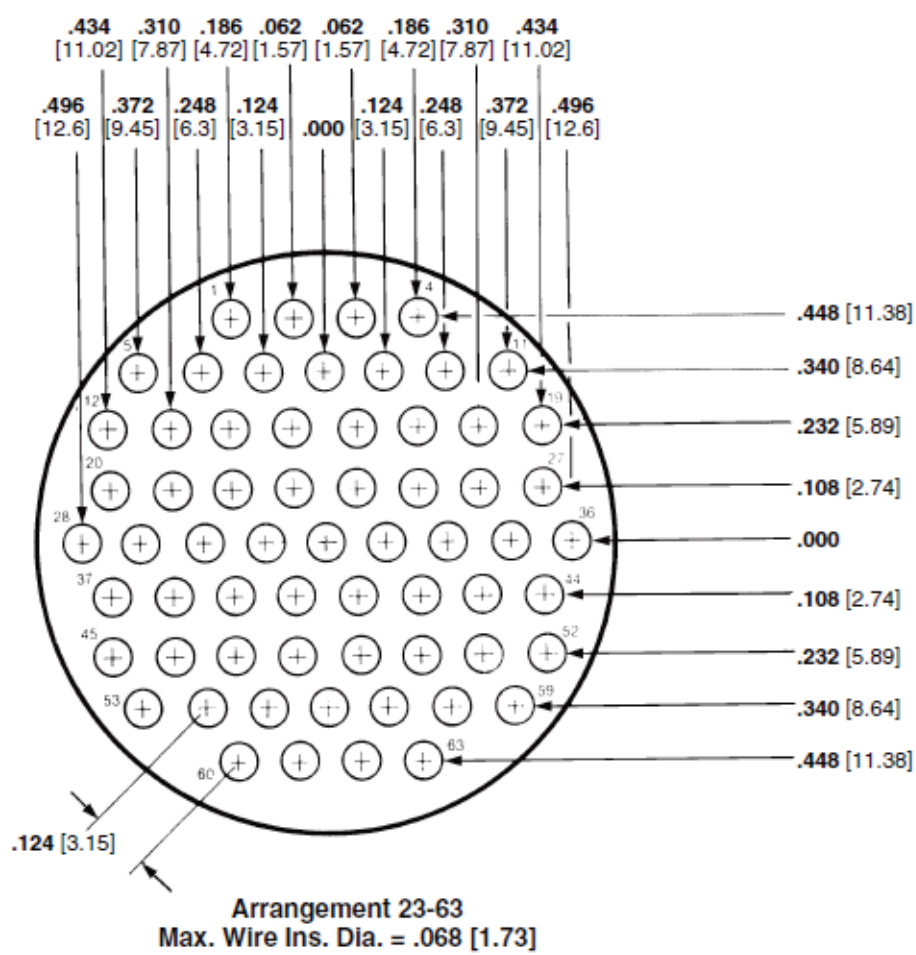

Figure 4-11: 63 pin AMP Series 2 STD Flange Receptacle

Table 4-3: Analog Wire Connections to NI DAQ

\begin{tabular}{|c|c|c|}
\hline Socket No. & Wire Color and Polarity & Description \\
\hline 7 & White Wire (+) & \multirow{2}{*}{ Omega PX209-030A MAP sensor } \\
\hline 8 & Black Wire (-) & \\
\hline 44 & Green Wire $(+)$ & \multirow{2}{*}{ Left Bank Lambda Sensor } \\
\hline 45 & Black Wire (-) & \\
\hline 46 & Red Wire (+) & \multirow{2}{*}{ Fuel Flow (g/s) Meter } \\
\hline 47 & White Wire (-) & \\
\hline 54 & Yellow Wire $(+)$ & \multirow{2}{*}{ GP50 211D Oil Pressure Sensor } \\
\hline 55 & Black Wire (-) & \\
\hline 58 & Orange Wire (+) & \multirow{2}{*}{ Optical Deck Hydraulic Pressure } \\
\hline 59 & Black Wire (-) & \\
\hline
\end{tabular}


For current setup, there are five sensors connected, including an Omega PX209-030A5V manifold absolute pressure (MAP) sensor, a lambda sensor, a fuel flow meter sensor, a GP50 211D oil pressure sensor and an optical deck hydraulic sensor. More sensors may be needed depending on future research. The pin connections are listed in Table 4-3. The MAP sensor installed on the engine here is the sensor in Figure 4-12.

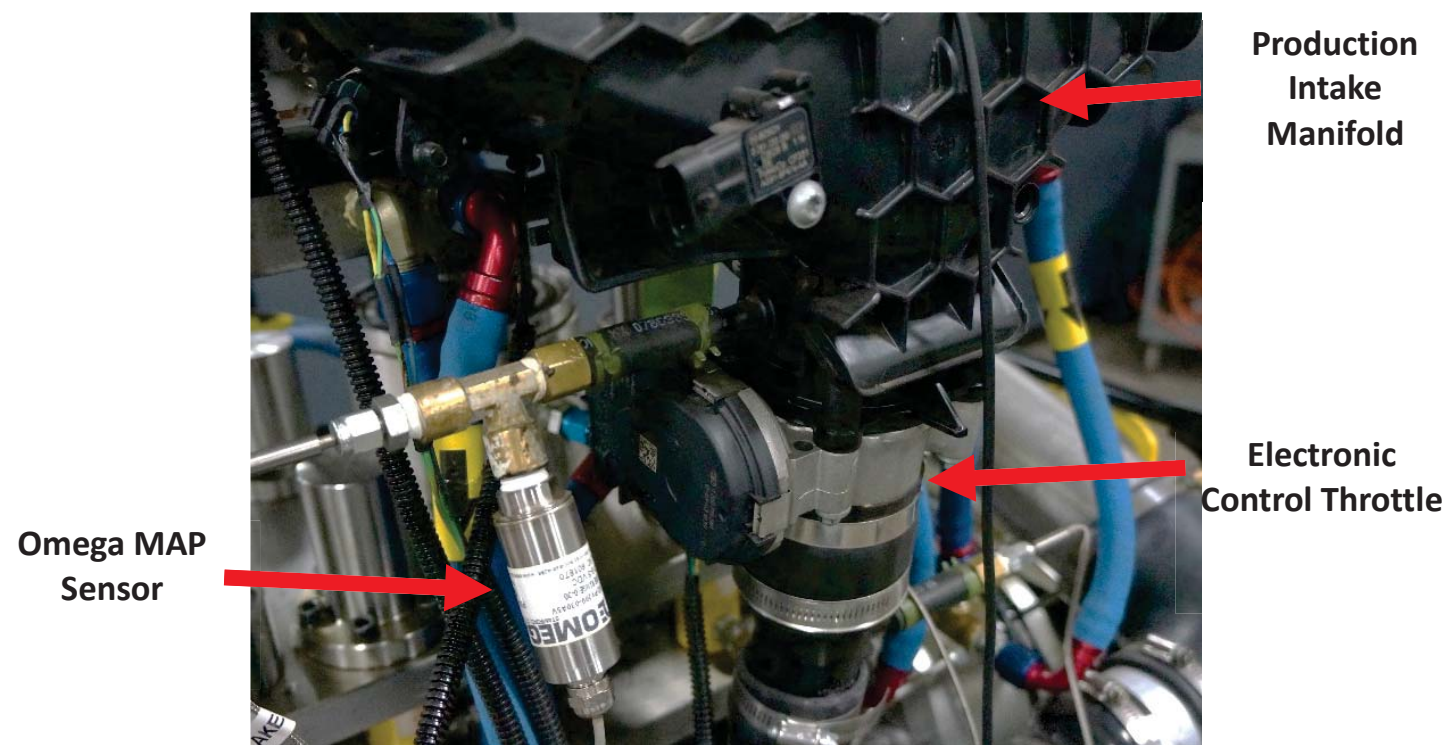

Figure 4-12: Omega PX209-030A5V Manifold Absolute Pressure (MAP) Sensor Position 


\subsubsection{Engine Control Unit (ECU) Power Supply}

The ECU is powered by a $14 \mathrm{~V}$ power supply from the data acquisition system. A sevenpin amp series 3 reverse flange receptacle on the interface panel is used to connect the ECU to the DAQ system shown in Figure 4-13. The specified socket connections of this connector are listed in Table 4-4.

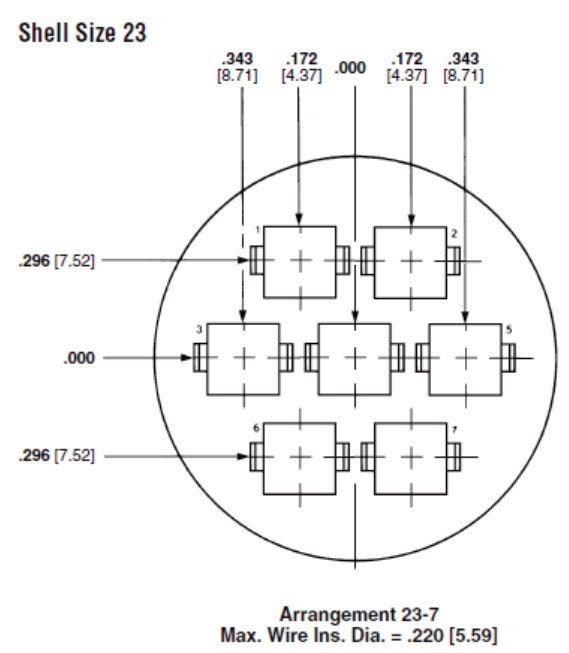

Figure 4-13: Circular Plastic Connectors Series 3 7-Pin

In Table 4-4, both clean 14V and dirty 14V are from the DAQ power supply system. The difference between them is that the clean $14 \mathrm{~V}$ is more noise resistive and used to power the sensors sensitive to the noise. The dirty $14 \mathrm{~V}$ connects to the components which are more noise tolerant such as the power for the GDI injector and ignition coils. "GND" represents the ground connections.

Table 4-4: ECU Power Connection

\begin{tabular}{|c|c|}
\hline Socket No. & Description \\
\hline 1 & ECU Battery \\
\hline 2 & ECU Key Switch \\
\hline 3 & Clean 14V \\
\hline 4 & Dirty 14V Power \\
\hline 5 & GND \\
\hline 6 & GND \\
\hline 7 & \\
\hline
\end{tabular}




\subsubsection{Oil Circulation System}

The engine oil system for the optical engine is similar to the production engine, which provides a thin film of oil lubricating and removing heat from the engine moving parts. Beside this purpose, the engine oil in the optical engine is also used to heat up the piston liner shown in Figure 4-3. The engine oil system consists of an electronic pump to pressurize the engine oil to circulate around the engine. In addition, an oil heater is also connected downstream to the oil pump to maintain the oil temperature around $45^{\circ} \mathrm{C}$. These two components are mounted on a metal plate which is secured on the universal cart as shown in Figure 4-14. The simplified block diagram is shown in Figure 4-15.

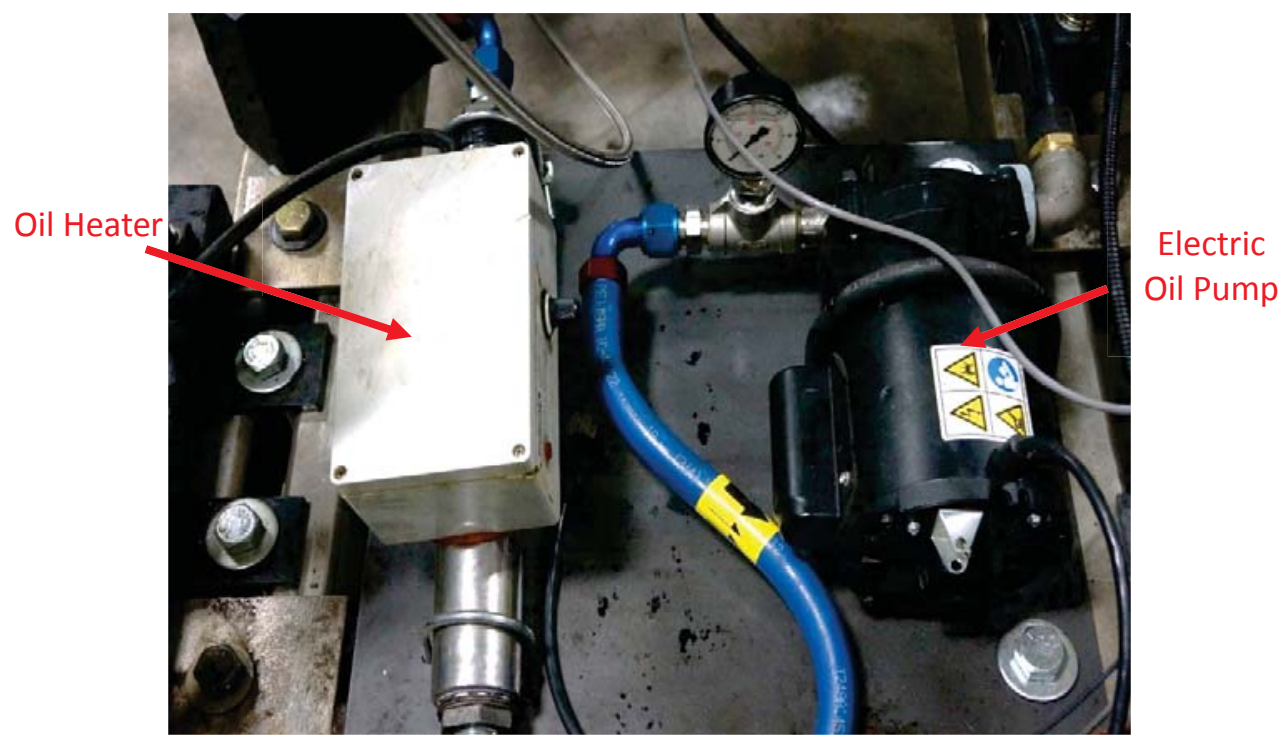

Figure 4-14: Oil Heater and Pump Mounted on Universal Cart

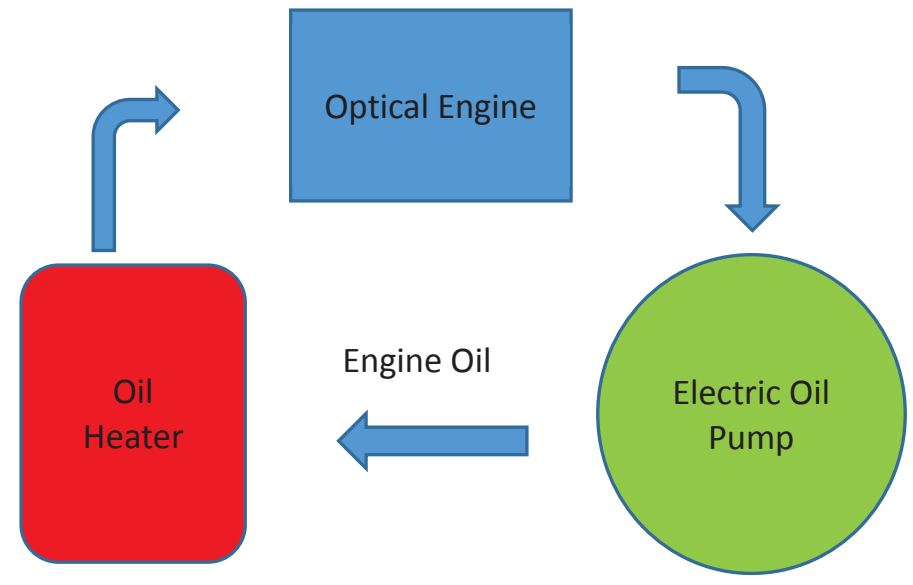

Figure 4-15: Block Diagram of Engine Oil System 


\subsection{Engine Control Unit (ECU) and Wiring}

Since the optical engine is customized based on the Ford Ecoboost 2.0L spark ignited direct injection engine, the production engine control unit from Ford could not satisfy the control requirement for the optical engine. Therefore, MotoHawk ECM-5554-112-0904-C/F 112pin engine control unit is chosen to meet control requirements for the optical engine. This module can support up to 33 analog input channels, 8 high impedance injector output signals and 8 Electric Spark Trigger (EST) output signals ${ }^{7}$.

For the optical engine, throttle control, ignition control, speed limiter control, skip fire control and trigger signal for optical synchronization are carried out through this MotoHawk engine control unit. For skip firing control strategy, the engine does not fire continually, and it has only specified cycle combusted during the testing operation. In addition, the fuel injection of the optical engine is controlled through an individual driver, which is a Bosch ES-HDEV-1 GDI driver. These two components are shown in Figure 4-16. The detail information of the MotoHawk ECM and Bosch fuel injector is attached in

\section{APPENDIX 6.}
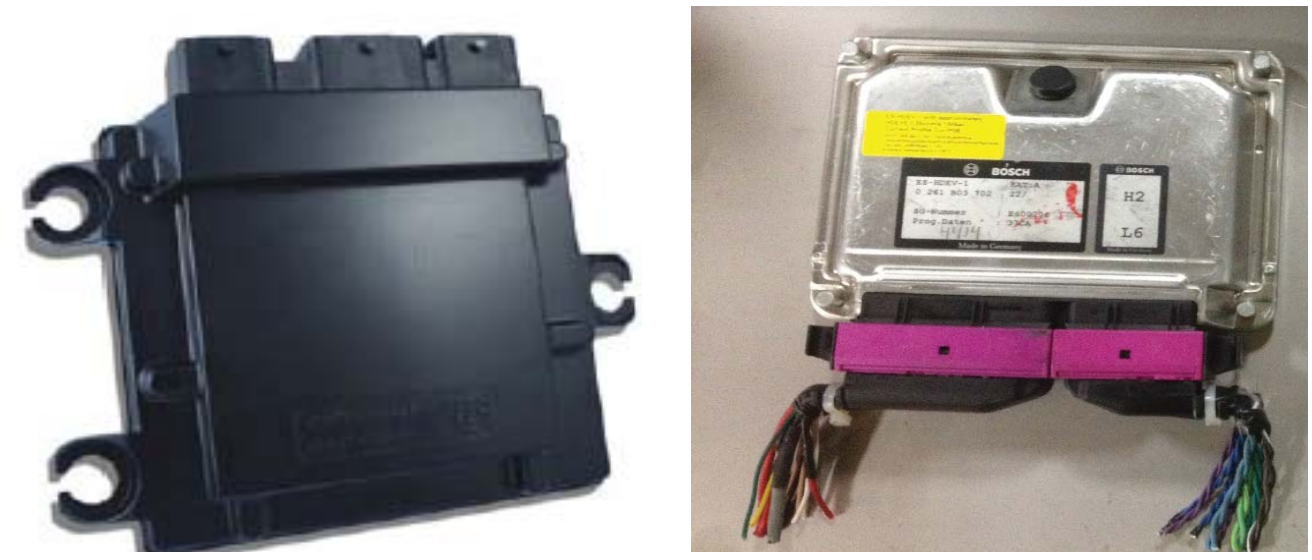

Figure 4-16: MotoHawk ECM 0554 (Left) and Bosch ES-HDEV-1 Fuel Injector Driver (Right)

Since the ECU harness is purchased with the MotoHawk ECU, which is independent of the optical engine harness. To connect both of them, a Hoffman A24N24ALP 24" x 24" x

\footnotetext{
7 Woodward Datasheet 36350, MotoHawk Control Solution ECM-5554-112-0904-C/F
} 
6.62" Medium Type NEMA 1 enclosure is installed on one side of the universal cart as shown in Figure 4-17.

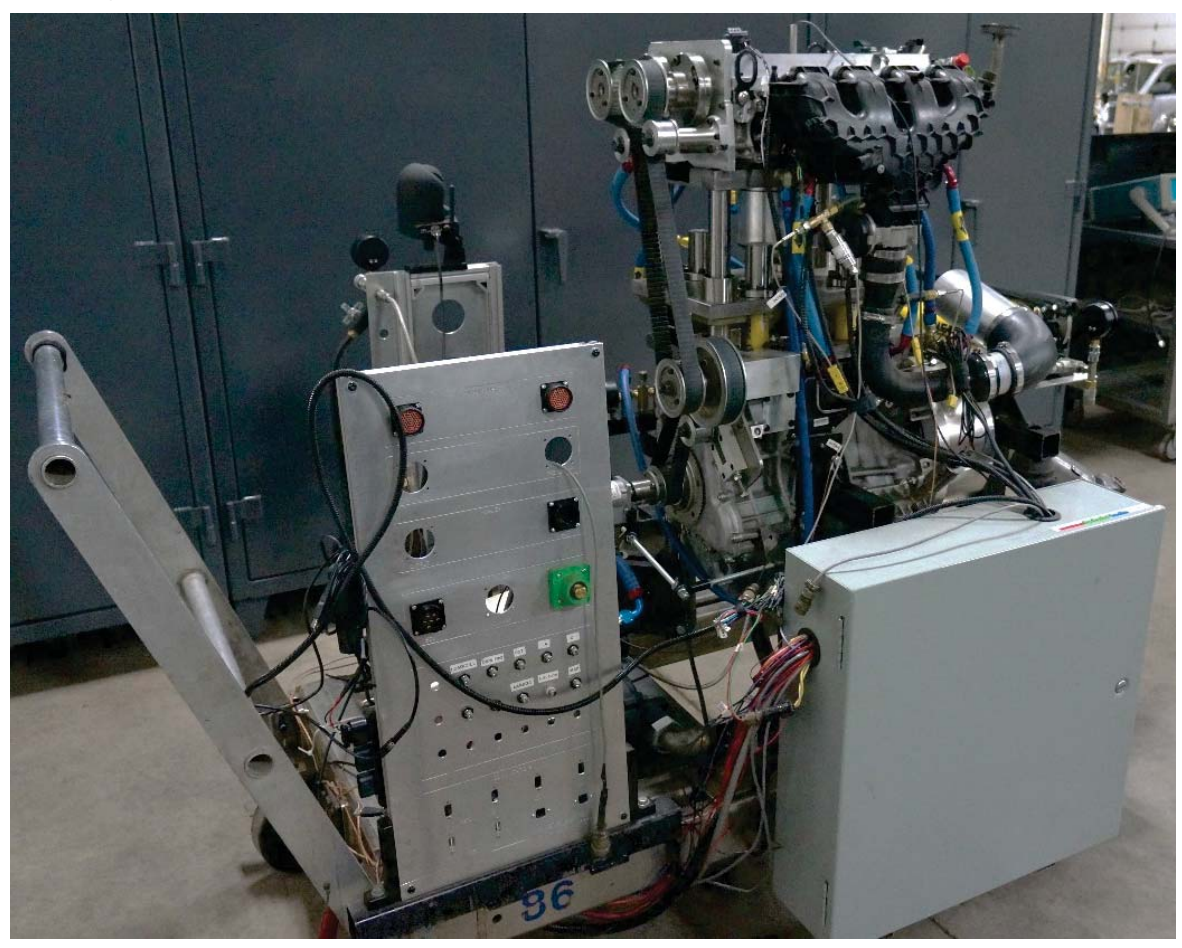

Figure 4-17: Enclosure Mount on One Side of Universal Cart

Inside the enclosure, ECU, din rails and terminal blocks are mounted on the panel. In Figure Figure 4-18, two din rails are mounted on the enclosure panel. On the left side of each din rail, the terminals are connected to the harness from the MotoHawk ECU. On the right side, the din rail terminals are connected to the optical engine harness. The ECU is connected with the optical engine. The detail of the ECU harness is on the harness manual from MotoHawk. For current setup, not all harnesses from ECU are useful and connected with the optical engine. The connected wires are listed in Table 4-5 which shows the current connection inside the enclosure. In Table 4-5, the optical engine harness connections are almost the same as the ECU harness except for some analog input signals such as an acceleration paddle, a MAP sensor, a fuel rail pressure, a Universal Exhaust Gas Oxygen (UEGO) sensor and an Electronic Control Throttle (ECT) components signals. Based on the research requirements, additional sensor wirings could be added to the ECU's default harness. The wire colors listed in Table 4-5 provide a reference for checking harness connections. 


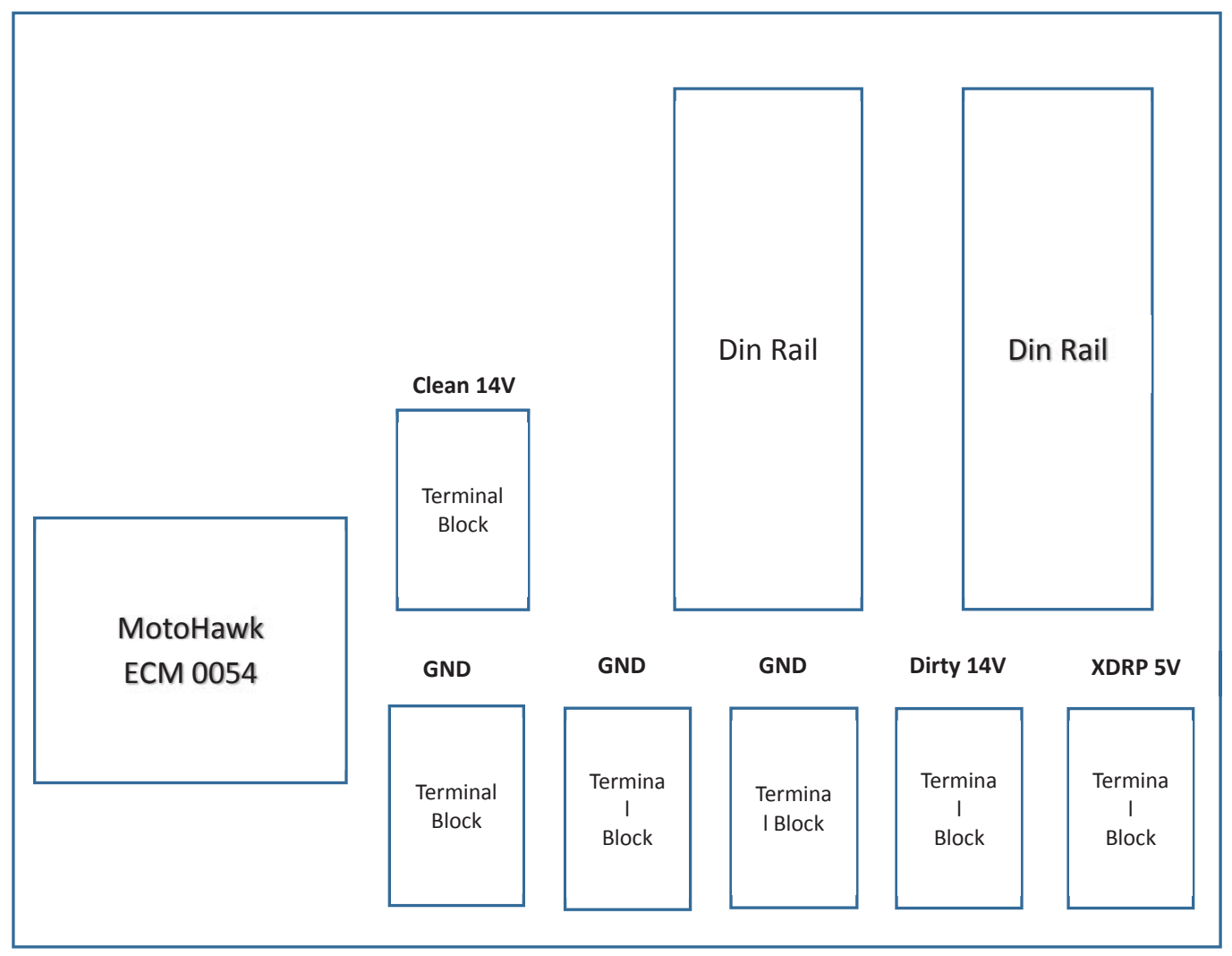

Figure 4-18: ECU Enclosure inside Components Block Diagram

Besides the din rails, six terminal blocks are also mounted on the panel of the enclosure. Their functions are similar to din rails, providing connections between the ECU, the optical engine and the interface panel connects. For a single block, all the terminals are actually connected with each other through a jumper panel. Half of the six blocks are used as power supplies for driving sensor including clean $14 \mathrm{~V}$, dirty $14 \mathrm{~V}$ and XDRP 5V. "XDRP" is a $5 \mathrm{~V}$ sensor power source provided by the ECU. The other three blocks are ground (GND) connectors. The dirty and clean $14 \mathrm{~V}$ are from the data acquisition system. All these GND blocks connect to the test cell ground through the interface panel ground connectors (Joy Cooper Interconnect E1018-1704). The detail connections of these terminal blocks are in Table 4-6. The main components of the ECU instrumentation are attached in APPENDIX 7. 


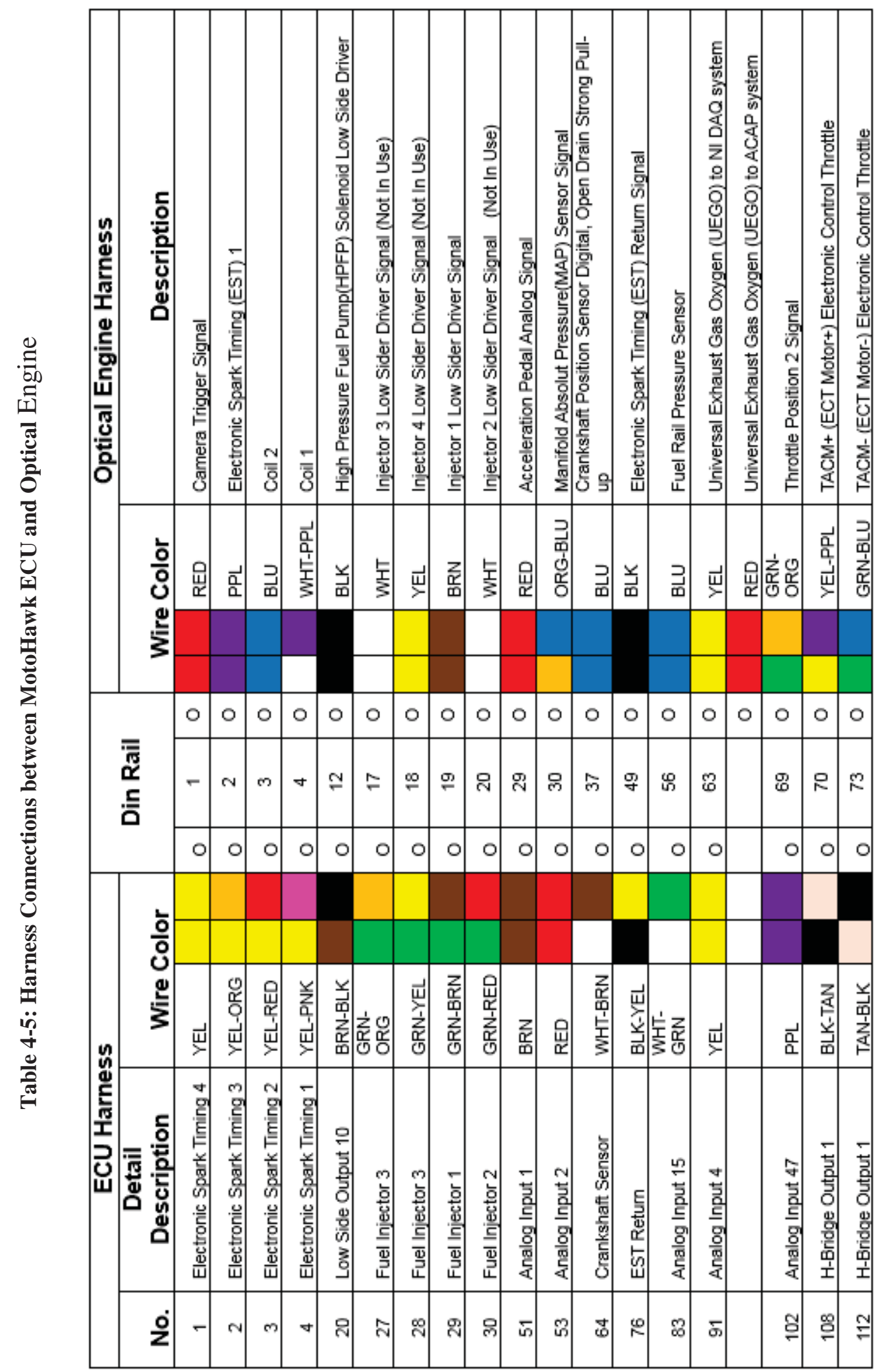




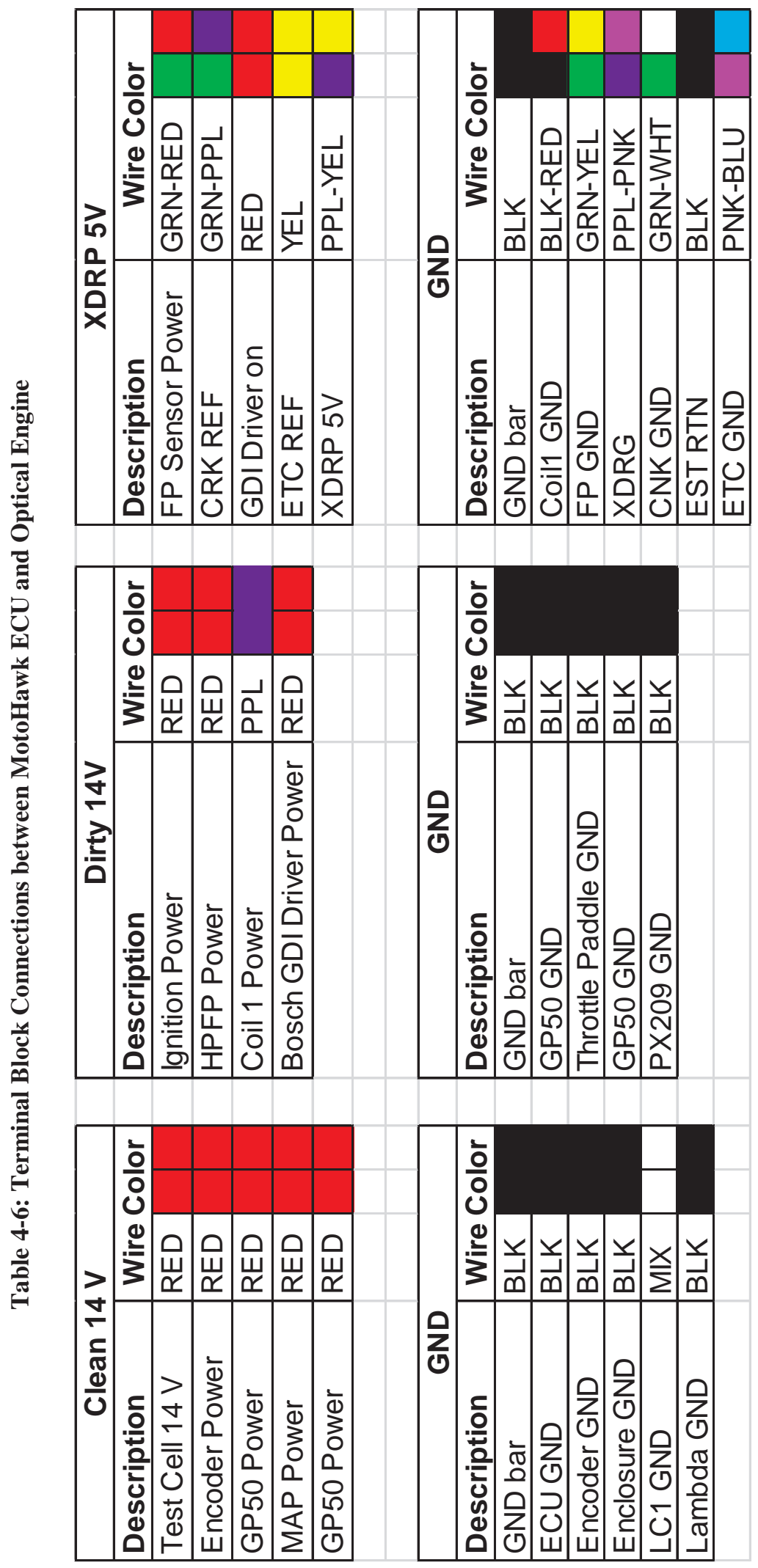




\section{CHAPTER 5Experiment}

\subsection{Experiment: Motoring and Firing Cycle}

After all the setup from previous chapters, the basic experiment on the optical engine has been performed. To obtain clean optics results from the optical engine, the engine is designed not to have any oil lubrication for the piston and rings. Instead of regular piston rings, the optical engine uses Torlon® PAI (polyamide-imide) piston rings because of their wear resistance and high strength for the thermal load. Even with these special piston rings, the engine could only operate under low load and run with a skip fire strategy due to the life cycle of the optical engine. Compared with a regular production engine continual fire strategy, the optical engine is controlled to fire at serval cycles and then motor for several cycles. One of the test results is used as an example here. The test condition is listed in Table 5-1. The manifold absolute pressure (MAP) is set as $33.5 \mathrm{kPa}$, which is a light load condition compared with the MAP under full open throttle condition. SA is the spark angle, and SOI is the start of injection, which is controlled by the ECU. FP is fuel pressure measured at the high-pressure fuel pump. In this test, the skip fire ratio is set as 10:15, which has 10 firing cycles and 15 motoring cycles. With the motoring cycle, the heat could dissipate out of the firing cycle to reduce the thermal load on the piston. The skip fire ratio could be adjusted through ECU.

With the gross indicated mean effective pressure (IMEPg) versus number of cycles in Figure 5-1, the skip fire strategy could be well observed. When the engine is firing, the IMEPg is around $150 \mathrm{kPa}$. Otherwise, the IMEPg is approximately stable at $-25 \mathrm{kPa}$ when the engine is motoring. Each dot on Figure 5-1 represents one cycle of the engine, during which the crankshaft rotates 720 degree. For this test, there are 4 firing groups, total 100 cycles. The last five combustion cycles of each group are recorded for later parameter calculations as shown in Figure 5-1 dash lines area. The purpose of recording the last five cycles is to reduce the motoring cycle effect on the combustion cycle.

Table 5-1: Test Condition for the Optical Engine

\begin{tabular}{|l|r|}
\hline Test Date & 2015-03-09 \\
\hline MAP (kPa) & 33.5 \\
\hline Speed (rpm) & 1000 \\
\hline Spark Angle (SA) (dBTDC) & 29 \\
\hline Dwell Time (ms) & 1.5 \\
\hline Start of Injection (SOI) (dBTDC) & 330 \\
\hline Fuel Pressure (FP) (MPa) & 9.5 \\
\hline Skip Fire Ratio & $10: 15$ \\
\hline Lambda & 1.07 \\
\hline
\end{tabular}




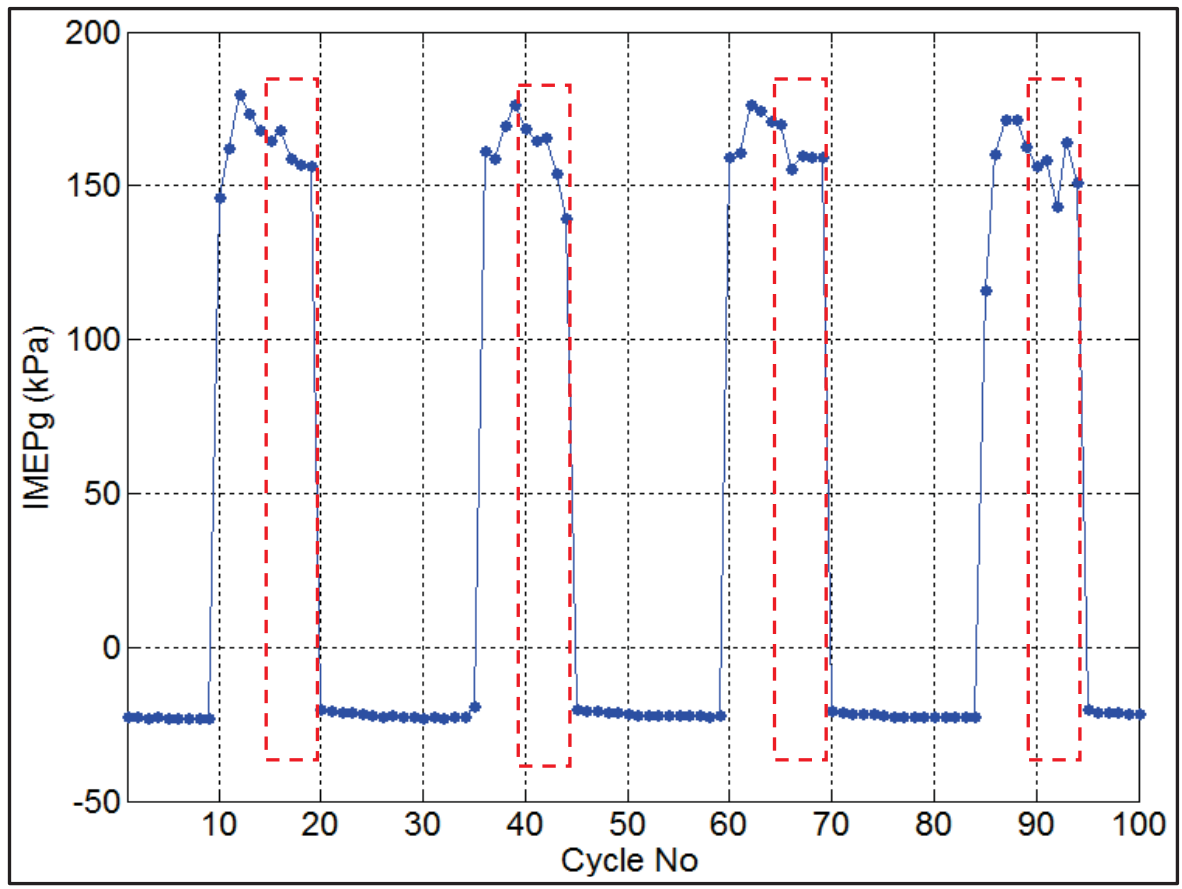

Figure 5-1: Optical Engine Skip Firing

During the test, the pressure trace of the optical engine could be monitored through the ACAP real time combustion analysis system. One motoring cycle and one firing cycle data from Figure 5-1 are used as an example. The pressure traces of these two cycles are displayed in Figure 5-2 and Figure 5-3. The engine reaches its peak pressure when the piston reaches its top dead center where crank angle is zero degree during the motoring cycle as shown in Figure 5-2.

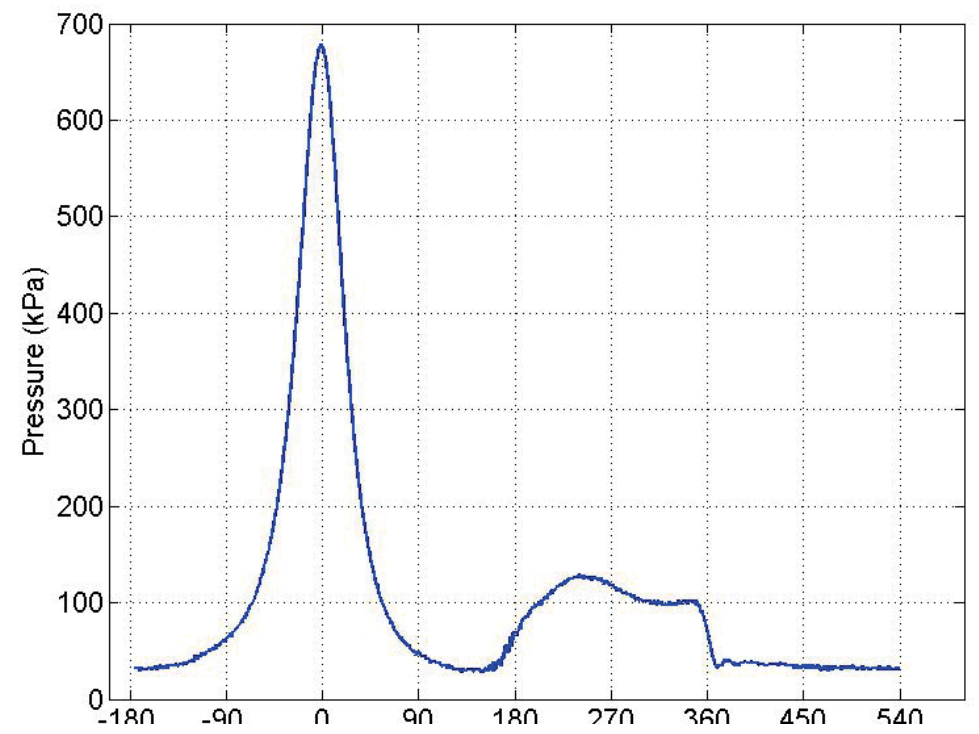

Figure 5-2: Optical Engine Pressure Trace for Motoring Cycle 


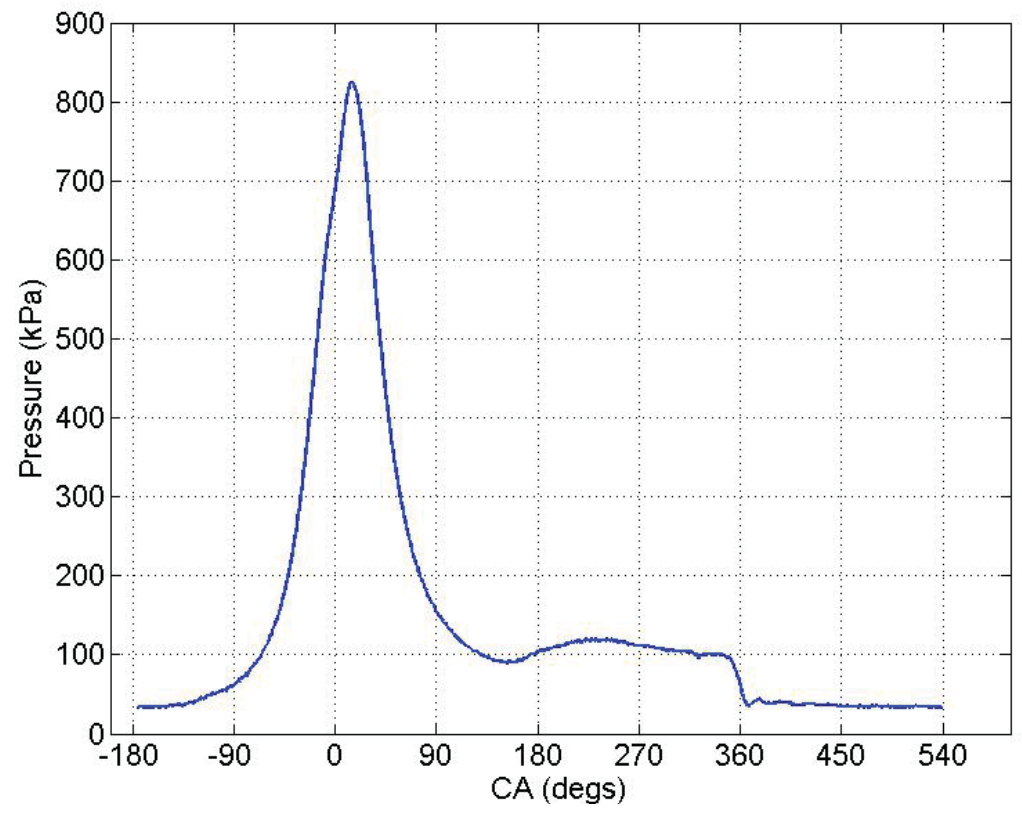

Figure 5-4: Optical Engine Pressure Trace for Firing Cycle

For the firing cycle, the spark timing is controlled, and the peak pressure is offset from the top dead center as shown in Figure 5-4. Through the data collected by the ACAP system, the Log P versus Log V diagram can be plotted as shown in Figure 5-3, which is used to check the quality of the cylinder pressure data. $\mathrm{P}$ is the in-cylinder pressure and $\mathrm{V}$ is the cylinder volume at any crank position.

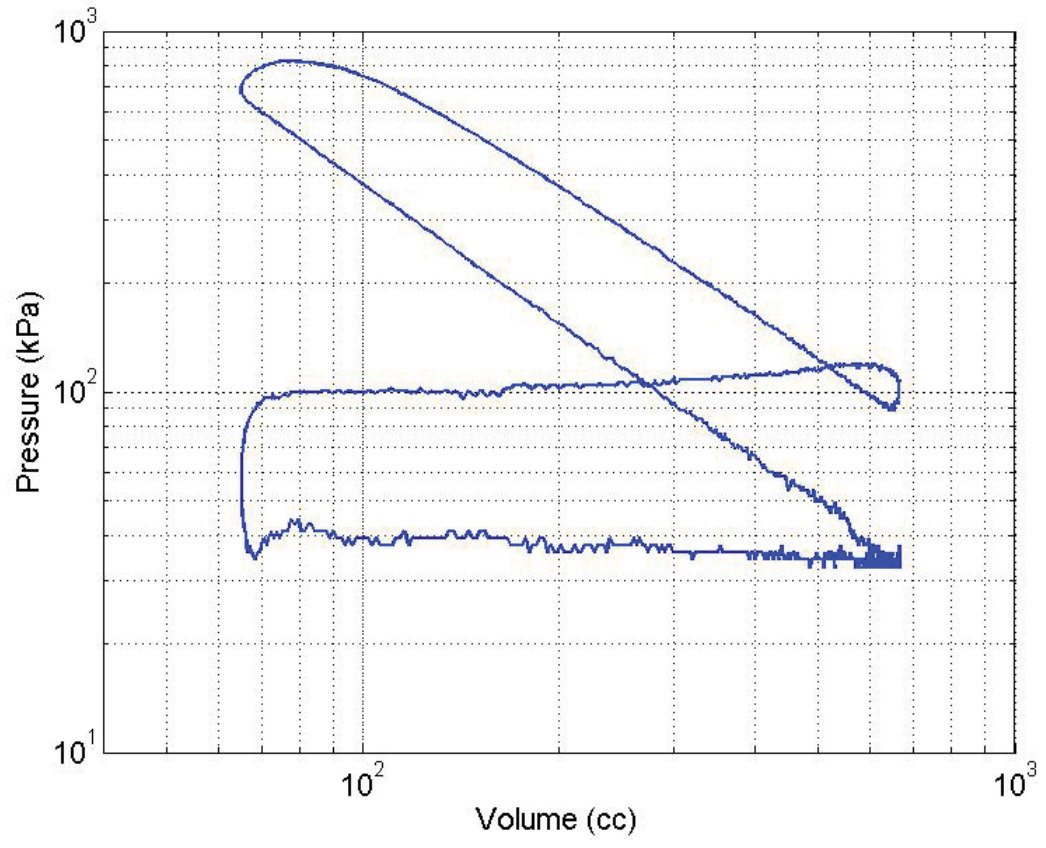

Figure 5-3: Optical Engine Log P-log V at Firing Cycle 


\subsection{Optical Instrumentation}

The advantage of the optical engine is the visualization of the combustion chamber through the optical window. The current research under sponsorship by Ford Motor Company is to study the gasoline engine ignition system. The optical instrument setup is displayed in Figure 5-5. A LaVision Ultra Speed Star 16 high-speed camera is used for the test in Figure 5-5. The camera for the ignition research has not been decided yet. Different cameras will be examined by engine tests to achieve better images. The camera bridge shown in Figure 5-5 is supported by 2 tripods located outside the test cell bed to avoid vibration effect. A metal plate with holes to mount the high speed camera is clamped on the surface of the camera bridge. A Nikon 200mm lens is used in this test. With manual focus and aperture $\mathrm{f} 4$, the camera could focus on the area around the spark plug. The aperture f4 could be reduced for wider depth of field. The test condition is shown in Table 5-2.

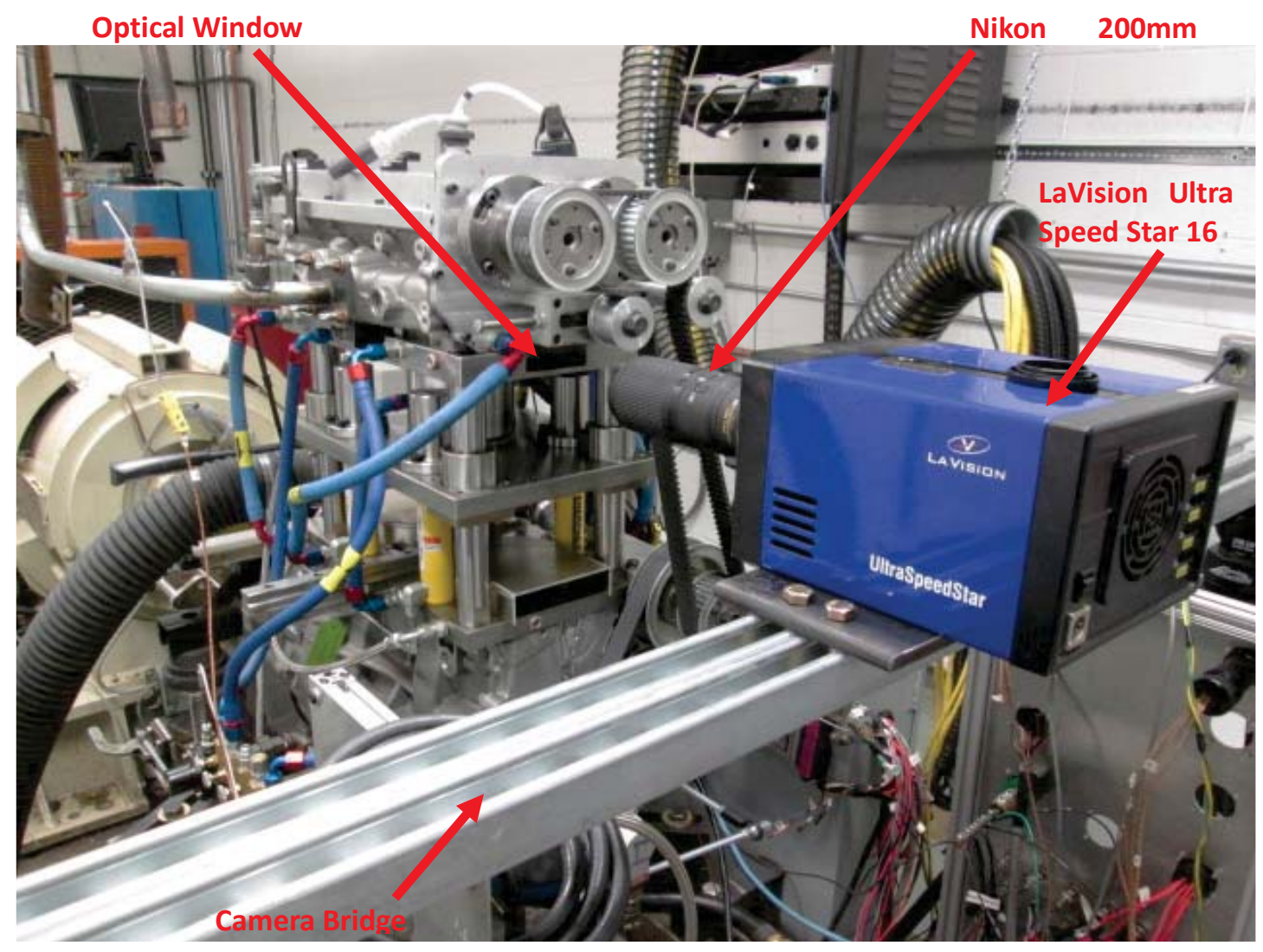

Figure 5-5: Optical Engine and Camera Setup 
Table 5-2: Test Condition for the Optical Engine

\begin{tabular}{|l|r|}
\hline Test Date & 2015-02-19 \\
\hline MAP (kPa) & 33 \\
\hline Speed (rpm) & 1000 \\
\hline SA (dBTDC) & 22 \\
\hline Dwell Time (ms) & 1.5 \\
\hline Skip Fire Ratio & $10: 15$ \\
\hline
\end{tabular}

With MATLAB post processing, the post processed images captured by the LaVision Ultra Speed Star 16 is shown in Figure 5-6, which is just one engine cycle out of 20 combustion cycles. The frame rate and exposure time can be adjusted through the Ultra Speed Star software. Since the light sensitivity of this camera is low, the result is dark in Figure 5-6. The spark plug is visualized on the second row of the figure. The lens used in this test is a Nikon 200mm f4.0 D lens. The camera is set to capture an image every 1000 us, which is approximate to 6 crank angle degree with engine operating at1000rpm (167 us per crank angle). The exposure time is set by default through the software, which must be less than the time between two frames. Limited by the camera and lens, shortening the time between two frames to capture an image every crank angle leads to a darker image.

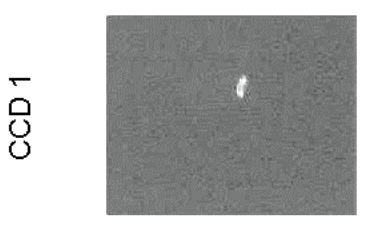

22 BTDC

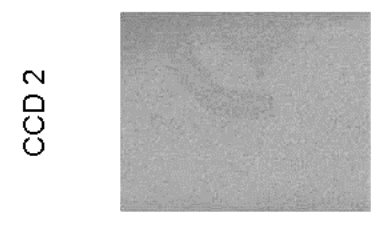

10 ATDC

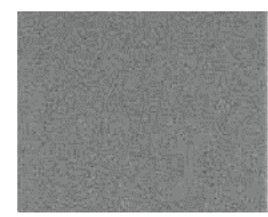

42 ATDC

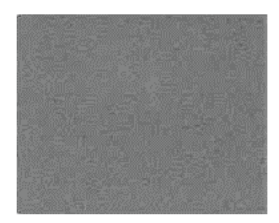

14 BTDC

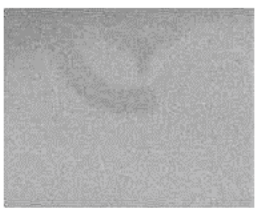

18 ATDC

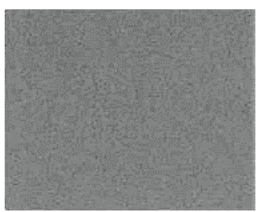

50 ATDC

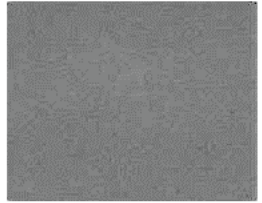

6 BTDC

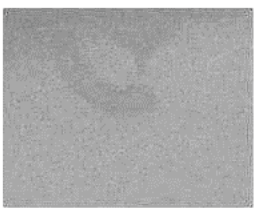

26 ATDC

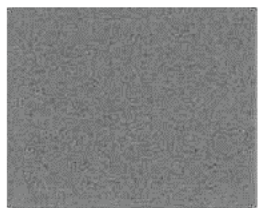

58 ATDC

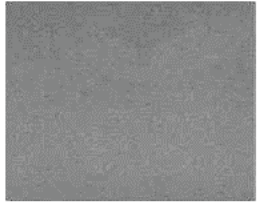

2 ATDC

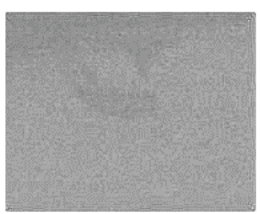

34 ATDC

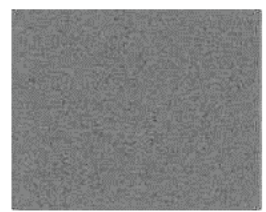

66 ATDC

Figure 5-6: Optical Engine USS 16 Imaging Result with Nikon 200 Lens, 6 CA (1000 us) per Frame, F/4, Exp 975 us, Distance $2.75 \mathrm{ft}$ 
Besides the Ultra Speed Star 16 camera, a Canon 60D and Photron SA 1.1 high speed camera have been tried out to capture images for the optical engine under simila operation condition as shown in Figure 5-7. The images capture by Canon 60D covers almost one cycle, which could see the spark overlays with flame in Figure 5-7a because of the long exposure. The results recorded by Photron SA 1.1 is the best among these cameras since its ability to capture images for every crank angel degree. The white area in Figure 5-7b is the flame developed after ignition. The camera used for the optical engine research has not been decided yet. Different cameras will be used and compared to achieve best imaging results in the future.
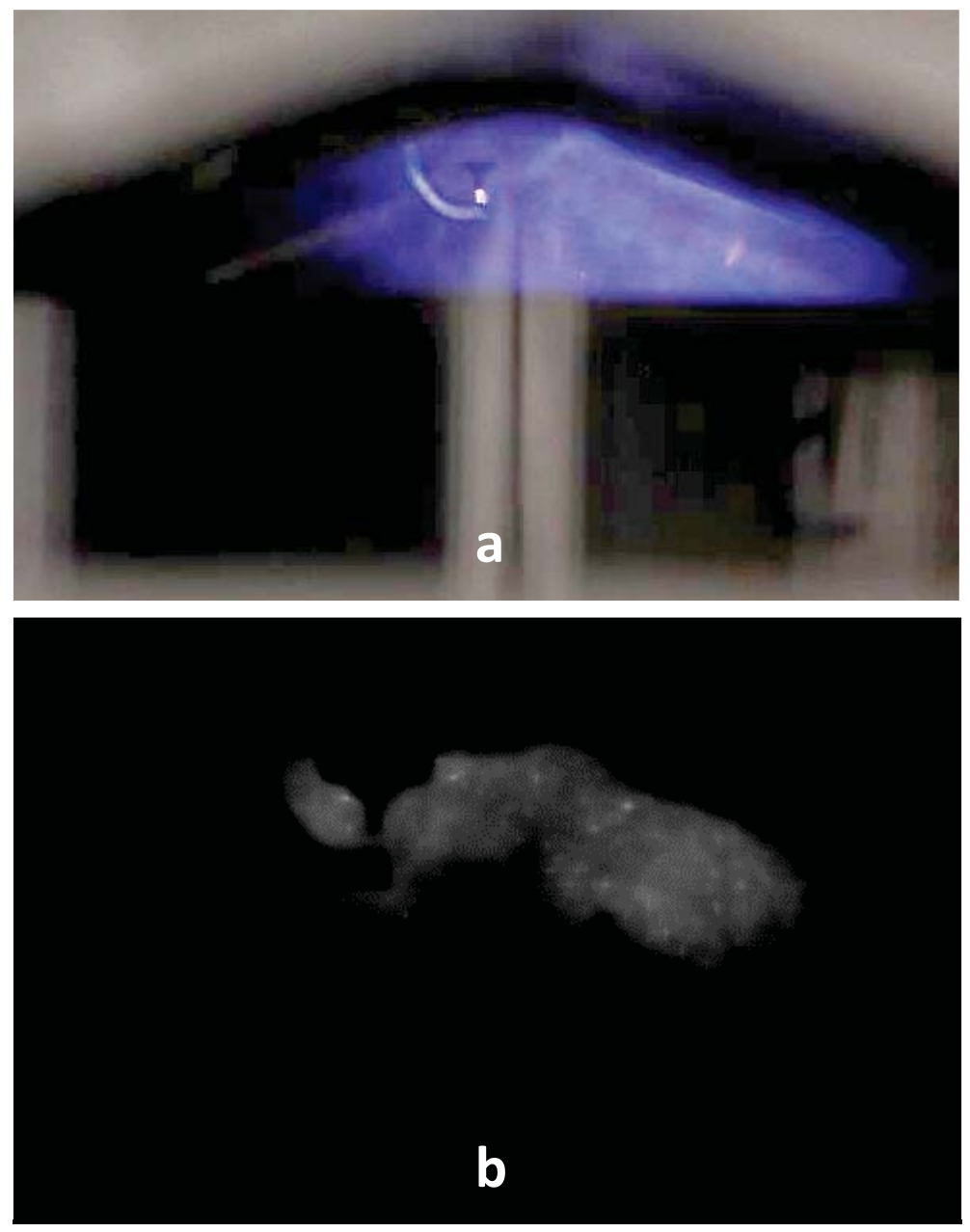

Figure 5-7: Optical Engine Image Results:

(a) Image Captured by Canon 60D DSLR f5.6, Exposure time 50000 us (300 CA), ISO 640, 33kPa MAP, 2ms Dwell Time;

(b) Image Captured by Photron SA 1.1, Nikon 85mm lens, f1.8, 12mm Extension Tube, Exposure time 100 us (1 CA), $33.5 \mathrm{kPa}$ MAP, $1.5 \mathrm{~ms}$ Dwell Time 


\section{CHAPTER 6 Conclusion and Future Work}

Above all, the optical access engine instrumentation is recorded in detail covering the test cell setup and optical engine setup, which serves as reference material for instrumentation update and experiment. Moreover, the experiment performed in CHAPTER 4 validates that the current optical engine setup operates normally and is prepared for optical instrument integration and engine research.

Future work on the optical engine is integrating the optical access engine with the diagnostic and optical measurement techniques and cooperating with Ford Motor Company in ignition research through the optical access engine. The future work is listed as follows.

1. A high-speed camera will be chosen to have the ability to capture sharp images per crank angle degree while the optical engine operating under skip firing strategy.

2. Ignition research including spark plasma stretching and spark energy study on different spark plugs and ignition coils through optical access engine will be performed utilizing the diagnostic and optical measurement techniques

3. Particle image velocimetry (PIV) system will be instrumented to study flow condition inside the combustion chamber. 


\section{Reference}

1. Lucchini, T., Fiocco, M., Onorati, A., Montanaro, A. et al., "Full-Cycle CFD Modeling of Air/Fuel Mixing Process in an Optically Accessible GDI Engine," SAE Int. J. Engines 6(3):1610-1625, 2013, doi:10.4271/2013-24-0024.

2. Gill, K. and Zhao, H., "In-cylinder Studies of Fuel Injection and Combustion from a Narrow Cone Fuel Injector in a High Speed Single Cylinder Optical Engine," SAE Technical Paper 2008-01-1789, 2008, doi:10.4271/2008-01-1789.

3. REDLINE ACAP, User Manual Version 4.0, DSP Technology Inc.

4. www. Ni. Com

5. 2013 Escape Workshop Manual Section 303-01B Engine-2.0L GTDI Specifications

6. MAHLE Powertrain 01735 DOE Optical Engine Specifications

7. Woodward Datasheet 36350, MotoHawk Control Solution ECM-5554-112-0904-C/F 


\section{APPENDIX}

\section{ADEK MS-98A9 Ivy Bridge Industrial ATX motherboard}

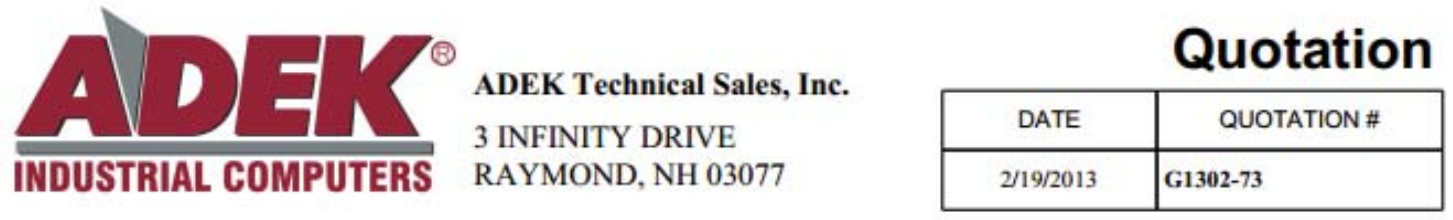

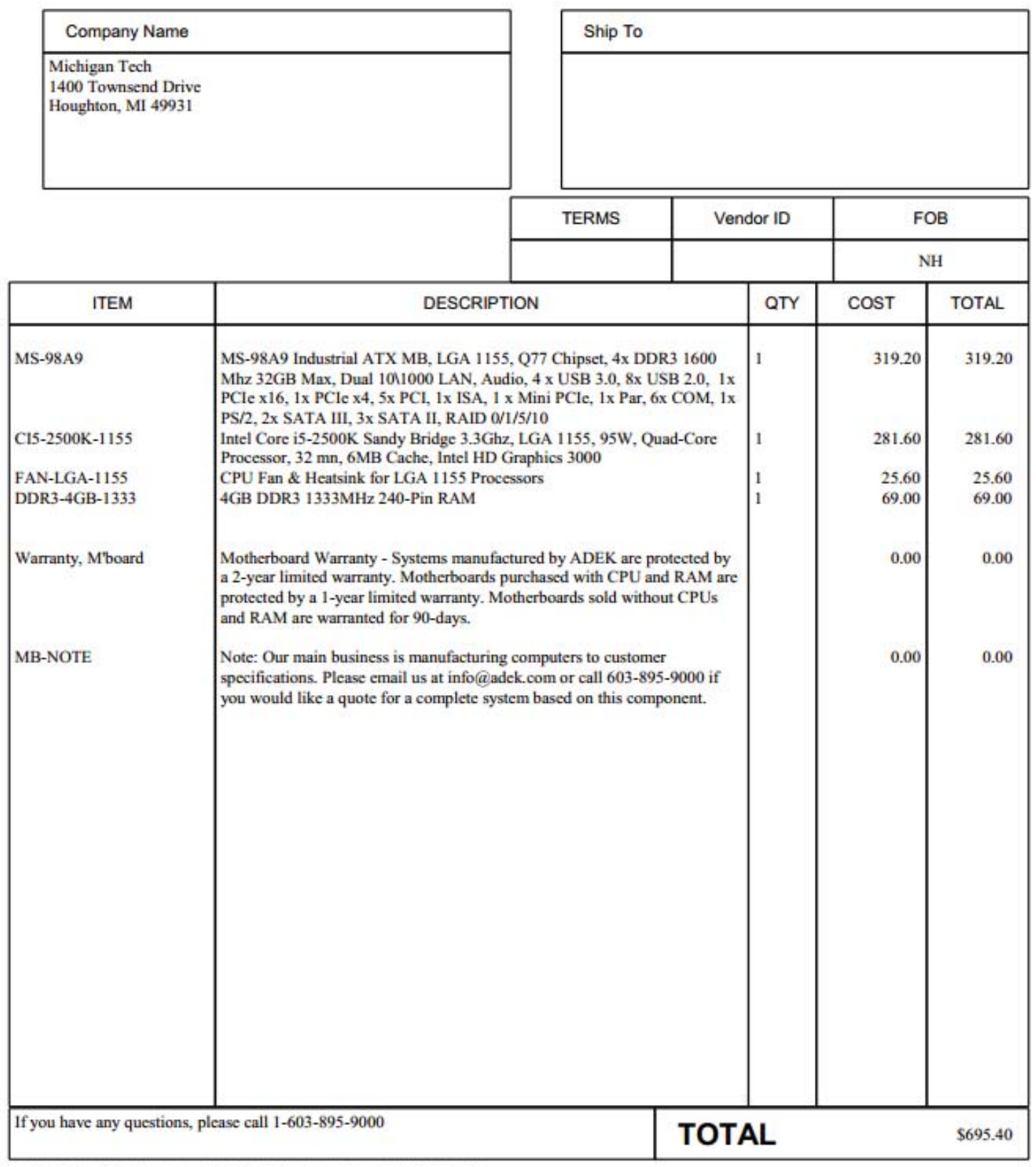

Adek Technical Sales, Inc. Tel (603) 895-9000 Fax (603) 895-9001 
2. Engine Mount Components Drawing - Screw Jack Adapter

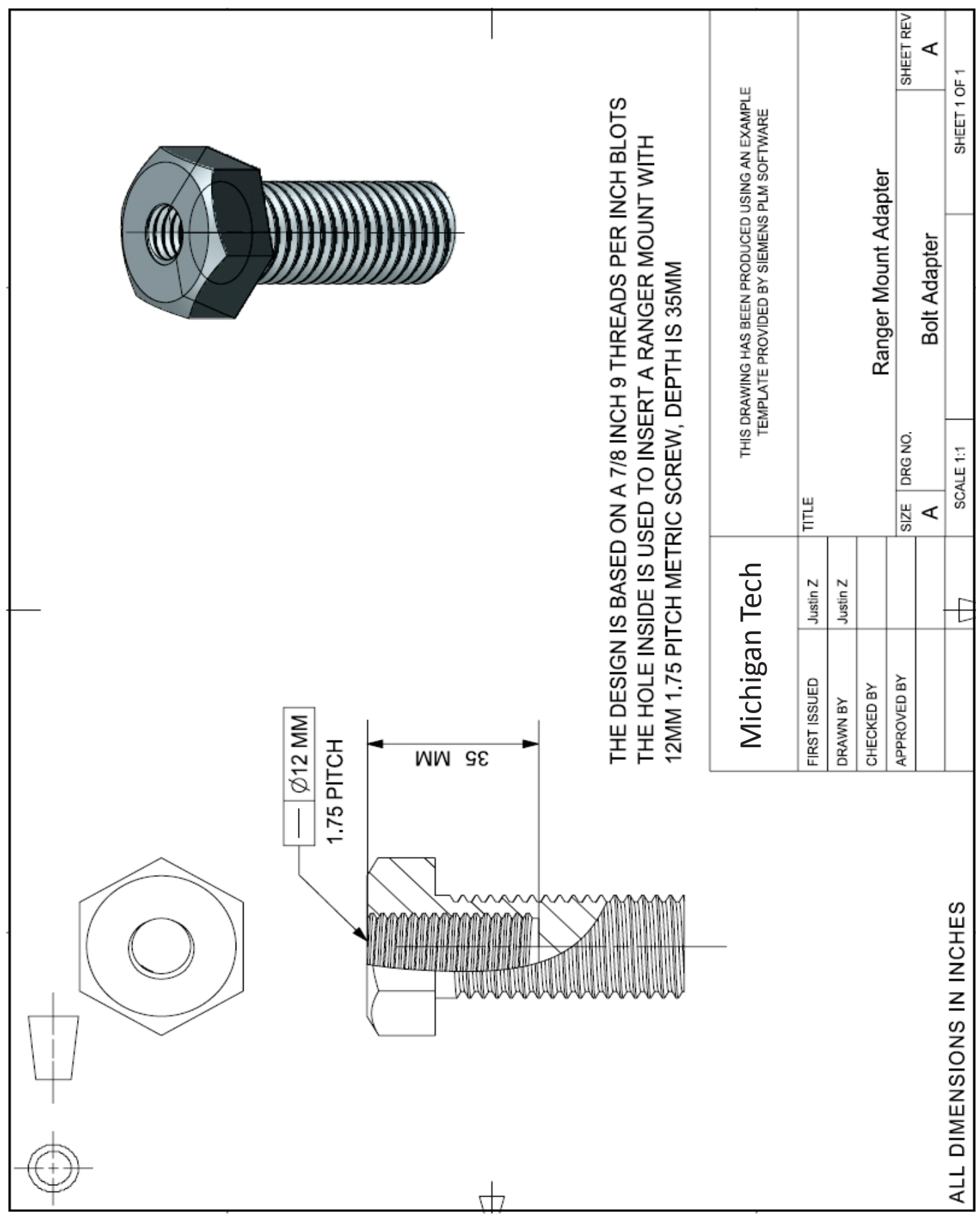




\section{Coolant and Fuel Panel}

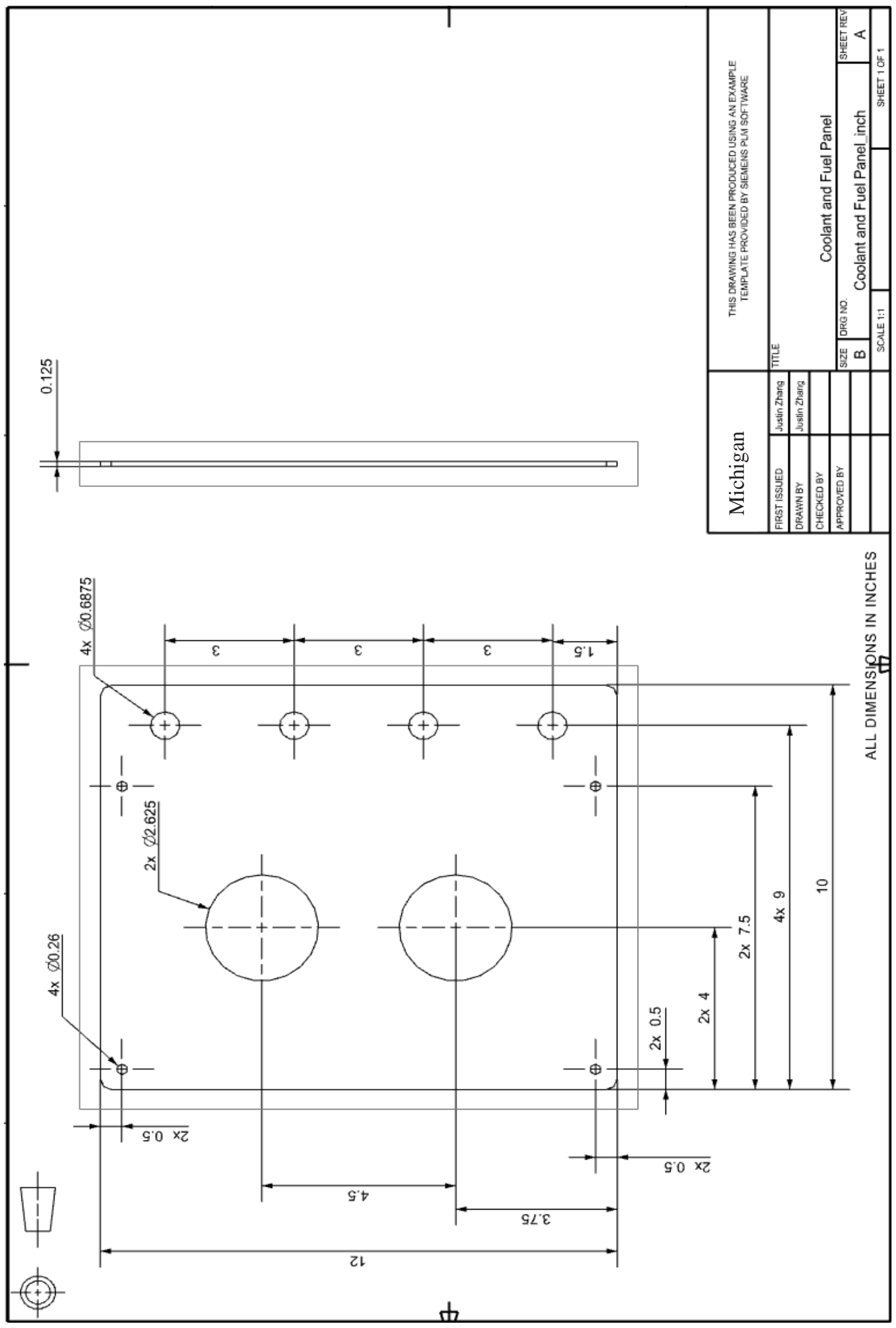




\section{Connector Panel}
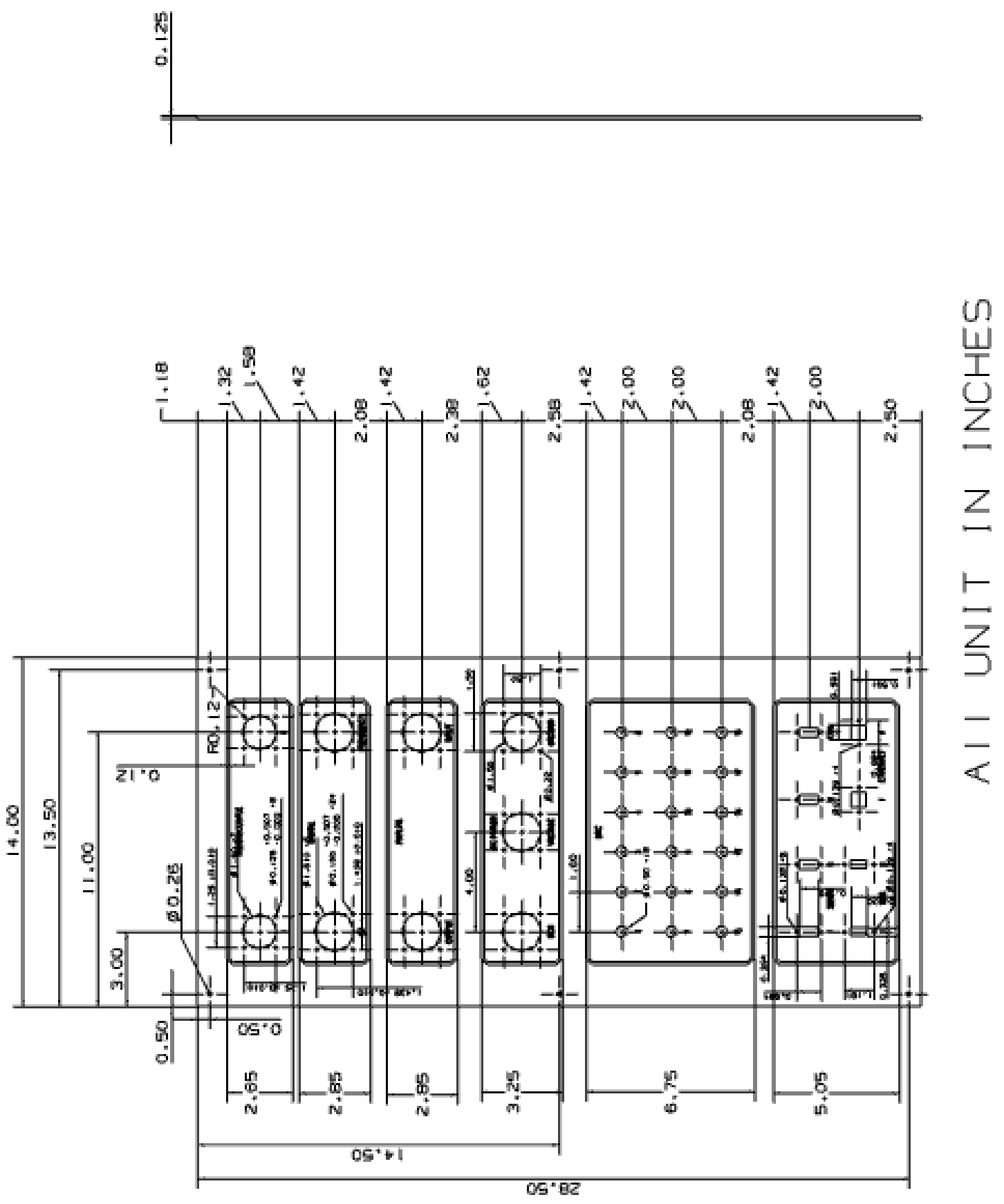
5. Cart Interface Components.

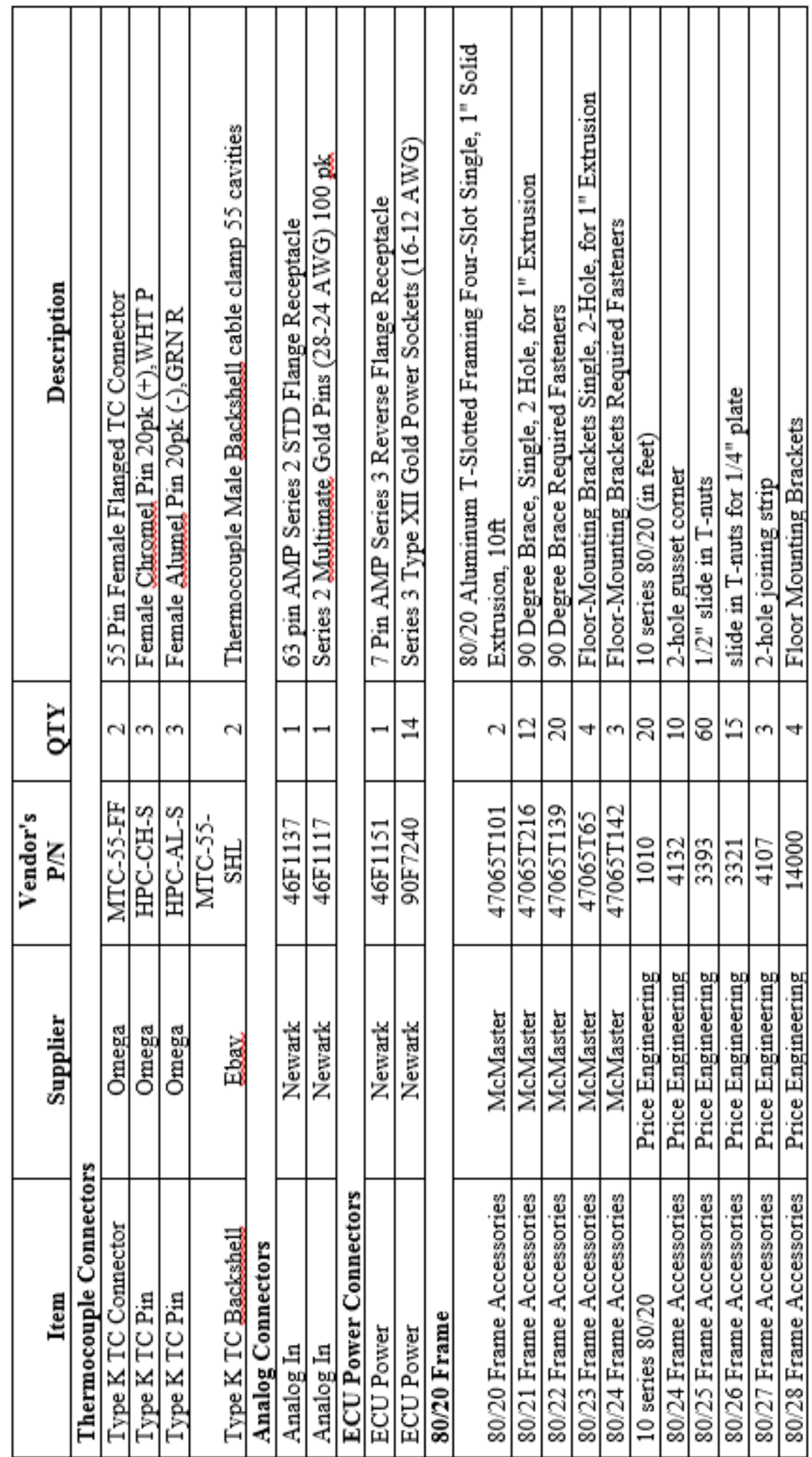




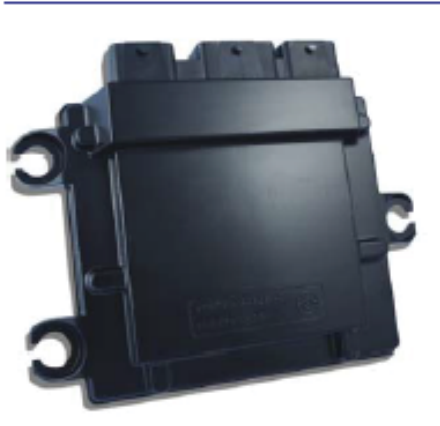

\section{MotoHawk Control Solutions \\ ECM-0554-112-0904-C/F Engine Control Modules Calibratible / Flash}

(0904-C: 1751-6455) (0904-F: 1751-6454)

\section{Description}

Presenting the ECM-5554-112-0904-C/F engine control modules from Woodward's MotoHawk Control Solutions product line. These rugged controllers are capable of operating in harsh automotive, marine, and off-highway applications. The module and its connector system are environmentally sealed and suitable for engine mounting in many applications.

This unit provides 112 connector pins with inputs, outputs, and communications interfaces that support a wide variety of applications.

The ECM-5554-112-0904 is part of the ControlCore ${ }^{\oplus}$ family of embedded control systems. The ControlCore operating system, MotoHawk ${ }^{\circ}$ code generation product, and MotoHawk's suite of development tools enable rapid development of complex control systems.

Each controller is available in ' $\mathrm{F}$ ' (Flash) or ' $\mathrm{C}$ ' (Calibratible) versions. Flash modules are typically used for production purposes. Calibratible modules are typically for prototyping/development only; they can be calibrated in real time using MotoTune

\section{Physical Dimensions}

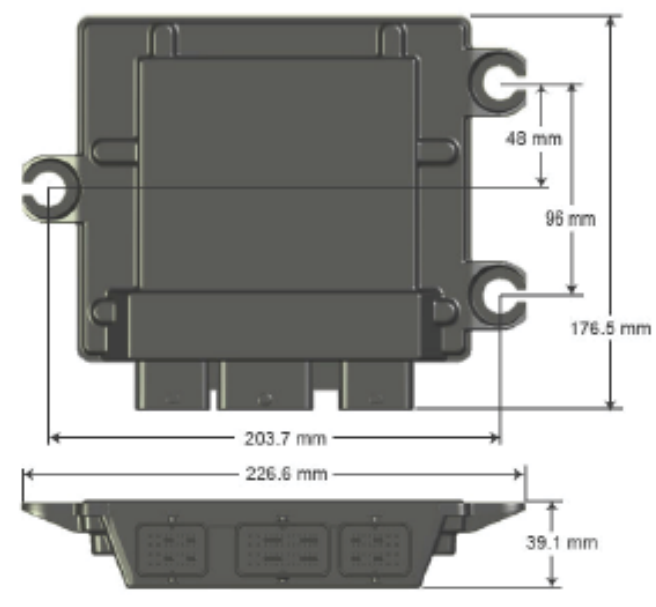

- 112-pin platform

- Microprocessor: Freescale MPC5554, $80 \mathrm{MHz}$

- Memory: 2MB Flash, 64K RAM, + 32K Cache, 32K EEPROM

- Calibratible Memory: $512 \mathrm{~K}(256 \mathrm{~K} \times 2)$ RAM

- Operating Voltage: 9-16 Vdc, $24 \mathrm{~V}$ (jump start), $4.5 \mathrm{~V}$ (crank)

- Operating Temperature: -40 to $+105^{\circ} \mathrm{C}$

- Inputs:

VR and Digital Engine Position Sensor (crank and cam) Inputs

33 Analog

4 Oxygen Sensor

3 Speed (digital)

2 Knock Sensor

1 Emergency Stop

- Outputs:

8 Injector (high impedance)

8 Electronic Spark Trigger (5 V)

1 Tachometer or Link Interface

14 Low Side Driver Outputs

1 Digital Output 1 Main Power Relay Driver Output 2 H-Bridge Outputs

- Communications: 3 CAN 2.0B Channels 1 RS-485 Channel 


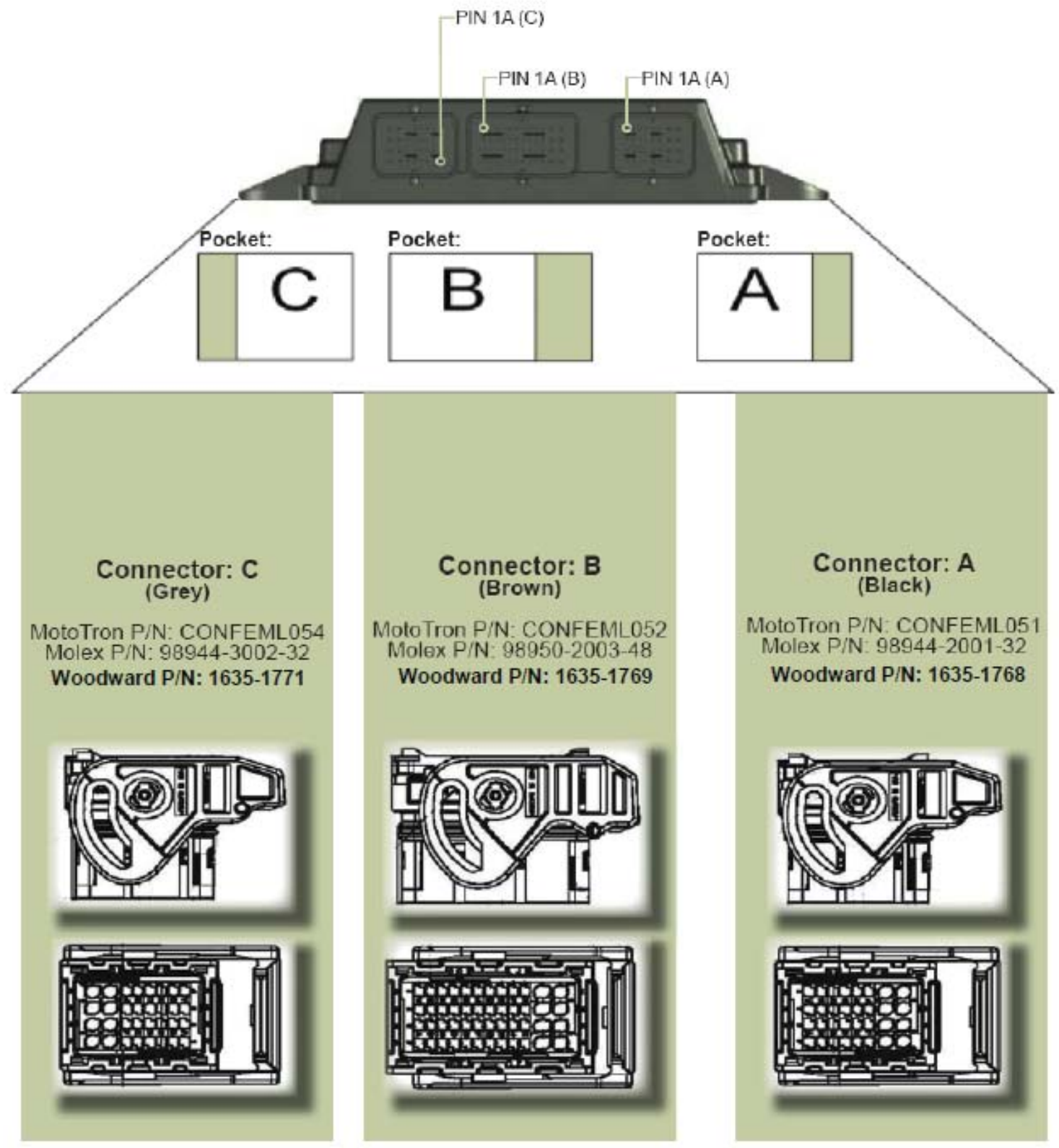




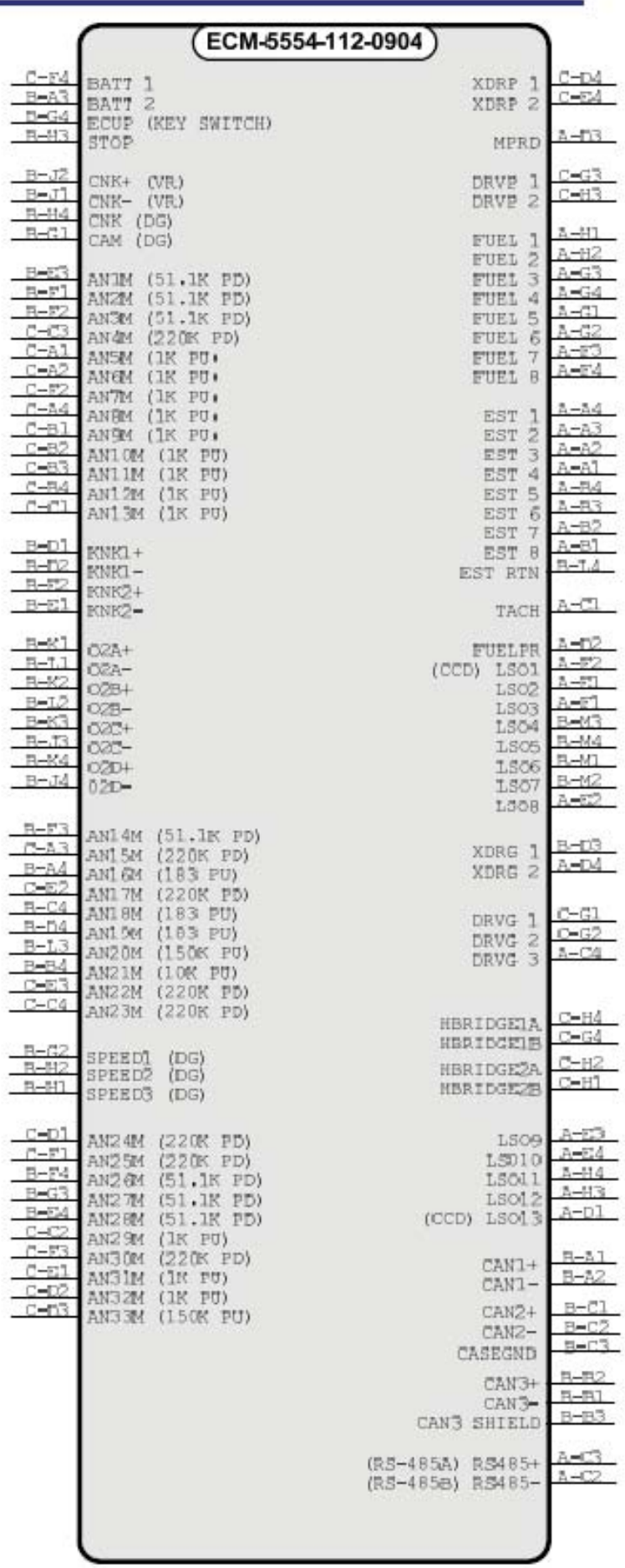


7. BOSCH ES-HDEV1 Fuel Injector Driver Information

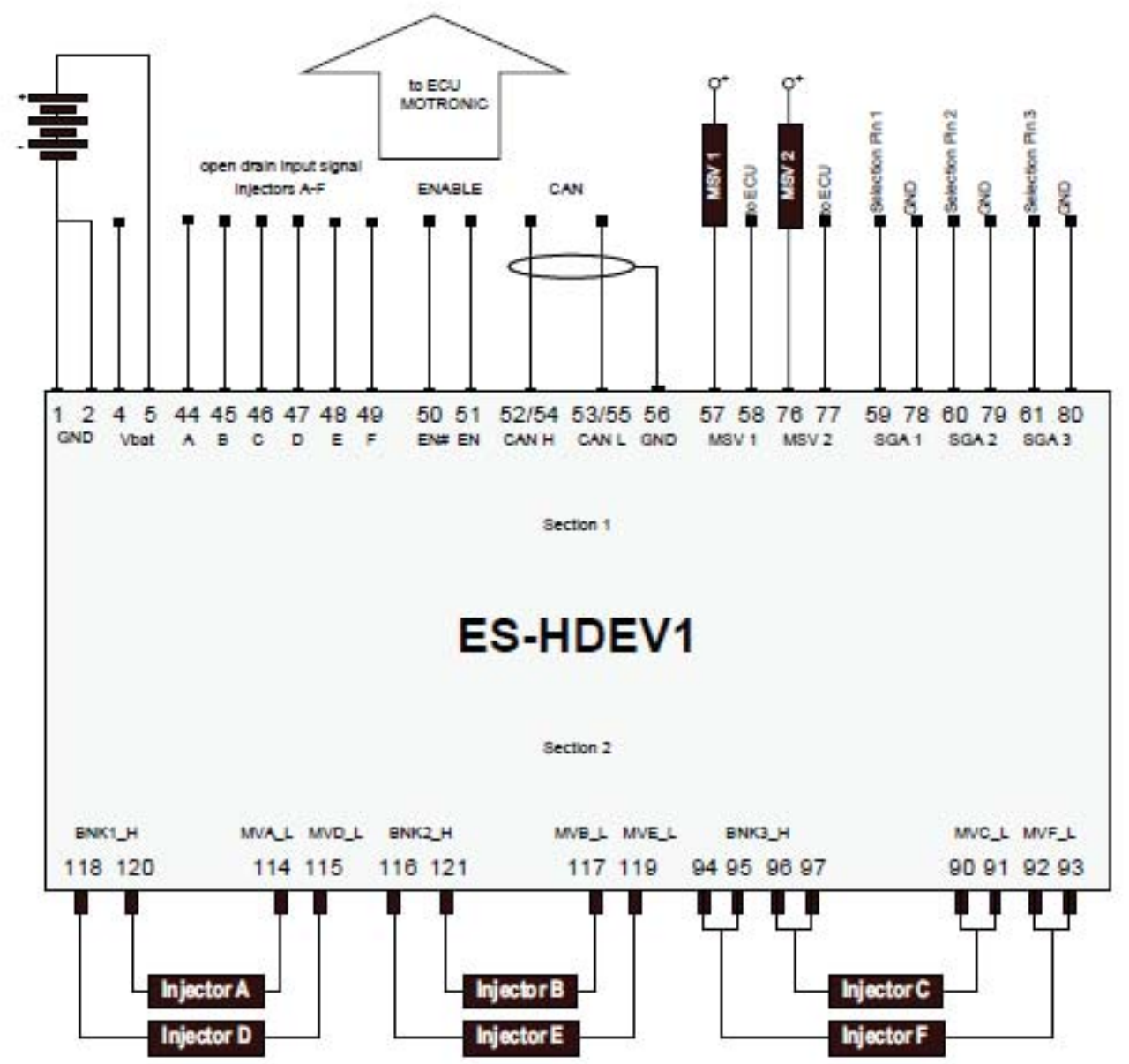




\begin{tabular}{|c|c|c|c|}
\hline \multirow{3}{*}{ BOSCH } & $\begin{array}{c}\text { Operating Manual } \\
\text { Injector Power Stage }\end{array}$ & $\begin{array}{c}\text { Version/Number } \\
\text { Y 280 U61 829 }\end{array}$ & $\begin{array}{c}\text { Date } \\
04 / 10 / 1999\end{array}$ \\
\cline { 2 - 5 } & ES-HDEV1 & Version: 2.1 & 19 \\
\hline
\end{tabular}

\section{PINNING}

Type of connector: BOSCH K3-MK 121 pol.

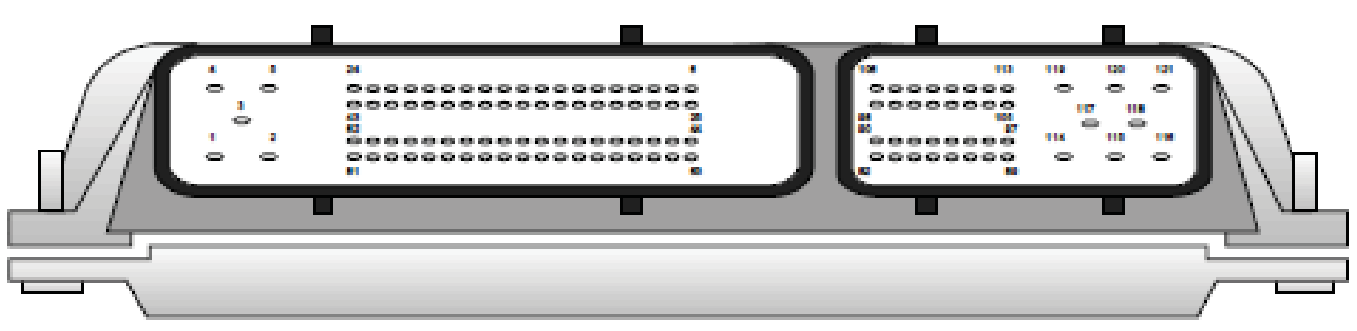

Figure 7: View to edge connector

\begin{tabular}{|c|c|c|c|}
\hline Section 1 & Signal & Description & Remark \\
\hline $1 / 2$ & GND & BAT- connection & \\
\hline 4 & $V_{B A T} 1$ & BAT+ connection & C) oedtonas \\
\hline 5 & $V_{\text {BAT }} 2$ & BAT+ connection & \\
\hline 44 & MV_A & input signal injector $\mathrm{A}$ & low-active \\
\hline 45 & MV_B & input signal injector $\mathrm{B}$ & low-active \\
\hline 46 & MV_C & input signal injector $\mathrm{C}$ & low-active \\
\hline 47 & MV_D & input signal injector D & low-active \\
\hline 48 & MV_E & input signal injector $\mathrm{E}$ & low-active \\
\hline 49 & MV_F & input signal injector $\mathrm{F}$ & low-active \\
\hline 50 & ENABLE\# & enable not powerstage & low-active \\
\hline 51 & ENABLE & enable powerstage & high-active \\
\hline $52 / 54$ & $\mathrm{CAN}-\mathrm{H}$ & CAN High & \\
\hline $53 / 55$ & CAN-L & CAN LoW & \\
\hline 56 & GND shield & CAN Ground & \\
\hline 57 & MSV OUT 1 & $\begin{array}{l}\text { output decay diode } \\
\text { for quantity control valve } 1\end{array}$ & \\
\hline 58 & MSV IN 1 & $\begin{array}{c}\text { input decay diode } \\
\text { for quantity control valve } 1\end{array}$ & \\
\hline 59 & SGA 1 & ECU selection pin 1 & \\
\hline 60 & SGA 2 & ECU selection pin 2 & \\
\hline 61 & SGA 3 & ECU selection pin 3 & \\
\hline
\end{tabular}




\begin{tabular}{|c|c|c|c|}
\hline \multirow{2}{*}{ BOSCH (6) } & $\begin{array}{c}\text { Operating Manual } \\
\text { Injector Power Stage }\end{array}$ & $\begin{array}{c}\text { Version/Number } \\
\text { Y } 280 \text { U61 } 829\end{array}$ & $\begin{array}{c}\text { Date } \\
04 / 10 / 1999\end{array}$ \\
\cline { 2 - 4 } & ES-HDEV1 & Version: 2.1 & 20 \\
\hline
\end{tabular}

\begin{tabular}{|c|c|c|l|}
\hline 76 & MSV OUT 2 & $\begin{array}{c}\text { output decay diode } \\
\text { for quantity control valve 2 }\end{array}$ & \\
\hline 77 & MSV IN 2 & $\begin{array}{c}\text { input decay diode } \\
\text { for quantity control valve 2 }\end{array}$ & \\
\hline 78 & GND SGA 1 & ECU selection ground 1 & \\
\hline 79 & GND SGA 2 & ECU selection ground 2 & \\
\hline 80 & GND SGA 3 & ECU selection ground 3 & \\
\hline
\end{tabular}

\begin{tabular}{|c|c|c|c|}
\hline Section 2 & Signal & Description & Remark \\
\hline $\begin{array}{l}94 / 95 \\
96 / 97\end{array}$ & BNK3_H & $\begin{array}{l}\text { Common connection Highside } \\
\text { injector C, F }\end{array}$ & \\
\hline $90 / 91$ & MVC_L & Output Lowside injector $\mathrm{C}$ & HDEV 31 \\
\hline $92 / 93$ & MVF_L & Output Lowside injector $F$ & HDEV 32 \\
\hline $118 / 120$ & BNK1_H & $\begin{array}{l}\text { Common connection Highside } \\
\text { injector A, D }\end{array}$ & \\
\hline 114 & MVA_L & Connection Lowside injector A & HDEV11 \\
\hline 115 & MVD_L & Connection Lowside injector D & HDEV12 \\
\hline $116 / 121$ & BNK2_H & $\begin{array}{l}\text { Common connection Highside } \\
\text { injector B, E }\end{array}$ & \\
\hline 117 & MVB_L & connection Lowside injector B & HDEV 21 \\
\hline 119 & MVE_L & connection Lowside injector $\mathrm{E}$ & HDEV 22 \\
\hline
\end{tabular}


8. ECU Instrumentation Components

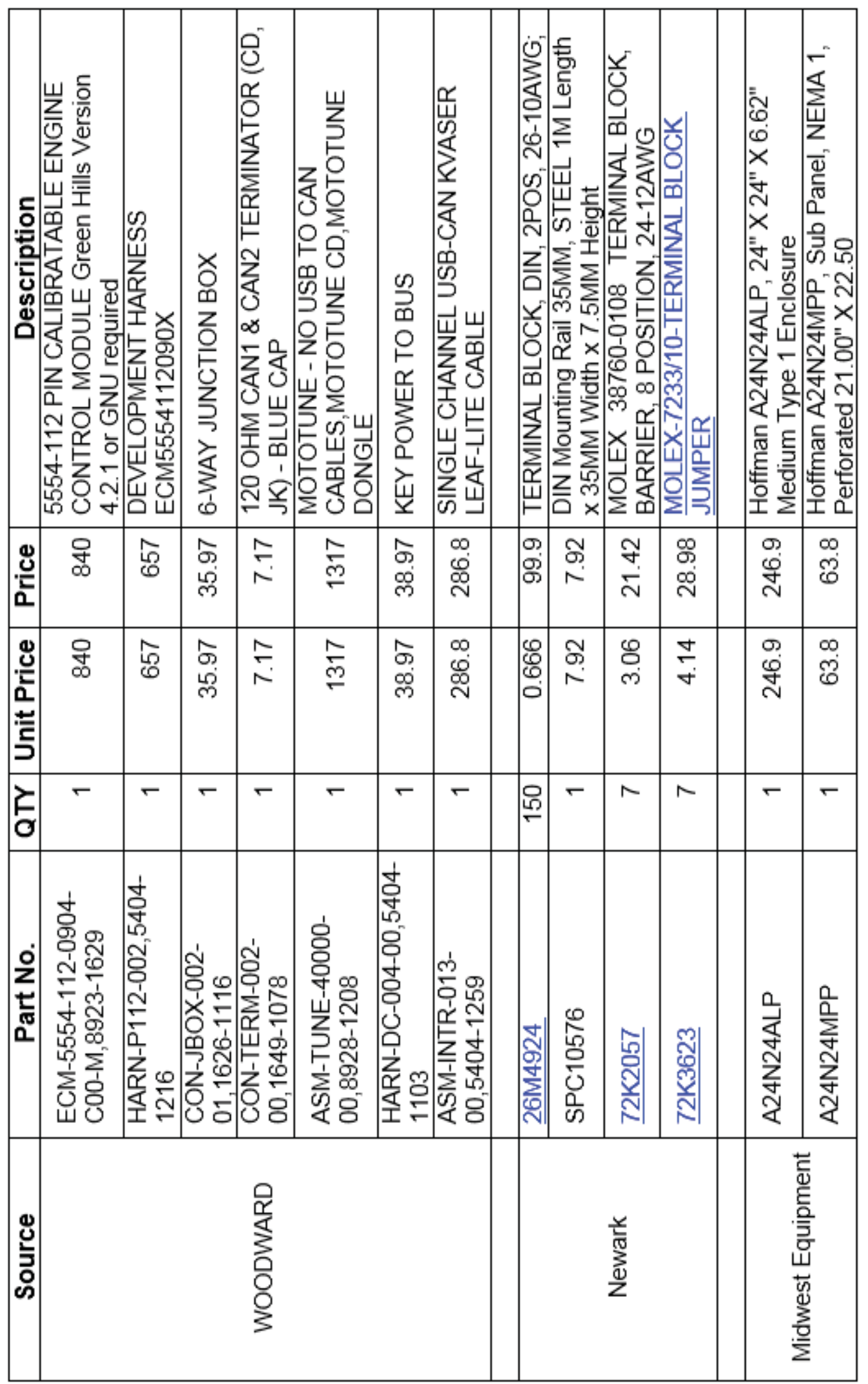

